Keywords: DWPF, mercury, SRAT, chemical process cell

Retention: Permanent

\title{
Behavior of Mercury During DWPF Chemical Process Cell Processing
}

J. R. Zamecnik

D. C. Koopman

January 2012

Savannah River National Laboratory Savannah River Nuclear Solutions, LLC Aiken, SC 29808

Prepared for the U.S. Department of Energy under

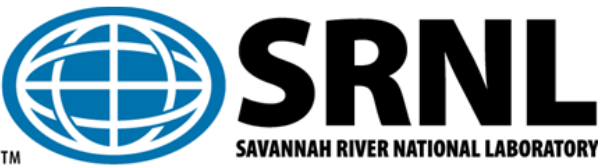
contract number DE-AC09-08SR22470. 
SRNL-STI-2012-00051

Revision 0

DISCLAIMER

This work was prepared under an agreement with and funded by the U.S. Government. Neither the U.S. Government or its employees, nor any of its contractors, subcontractors or their employees, makes any express or implied:

1. warranty or assumes any legal liability for the accuracy, completeness, or for the use or results of such use of any information, product, or process disclosed; or

2. representation that such use or results of such use would not infringe privately owned rights; or

3. endorsement or recommendation of any specifically identified commercial product, process, or service.

Any views and opinions of authors expressed in this work do not necessarily state or reflect those of the United States Government, or its contractors, or subcontractors.

\section{Printed in the United States of America}

Prepared for

U.S. Department of Energy 


\section{REVIEWS AND APPROVALS}

\section{AUTHORS:}

J. R. Zamecnik, Process Technology Programs Date

D. C. Koopman, Process Technology Programs Date

TECHNICAL REVIEW:

M. E. Stone, Process Technology Programs Date

APPROVALS:

C. C. Herman, Manager Date

Process Technology Programs

S. L. Marra, Manager

Date

Environmental \& Chemical Process Technology Research Programs

J. E. Occhipinti, Manager Date

SRR Waste Solidification Engineering 


\section{EXECUTIVE SUMMARY}

The Defense Waste Processing Facility has experienced significant issues with the stripping and recovery of mercury in the Chemical Processing Cell (CPC). The stripping rate has been inconsistent, often resulting in extended processing times to remove mercury to the required endpoint concentration. The recovery of mercury in the Mercury Water Wash Tank has never been high, and has decreased significantly since the Mercury Water Wash Tank was replaced after the seventh batch of Sludge Batch 5 . Since this time, essentially no recovery of mercury has been seen.

Pertinent literature was reviewed, previous lab-scale data on mercury stripping and recovery was examined, and new lab-scale CPC Sludge Receipt and Adjustment Tank (SRAT) runs were conducted. For previous lab-scale data, many of the runs with sufficient mercury recovery data were examined to determine what factors affect the stripping and recovery of mercury and to improve closure of the mercury material balance. Ten new lab-scale SRAT runs (HG runs) were performed to examine the effects of acid stoichiometry, sludge solids concentration, antifoam concentration, form of mercury added to simulant, presence of a SRAT heel, operation of the SRAT condenser at higher than prototypic temperature, varying noble metals from none to very high concentrations, and higher agitation rate.

Data from simulant runs from SB6, SB7a, glycolic/formic, and the HG tests showed that a significant amount of $\mathrm{Hg}$ metal was found on the vessel bottom at the end of tests. Material balance closure improved from $12-71 \%$ to $48-93 \%$ when this segregated $\mathrm{Hg}$ was considered. The amount of $\mathrm{Hg}$ segregated as elemental $\mathrm{Hg}$ on the vessel bottom was $4-77 \%$ of the amount added.

The highest recovery of mercury in the offgas system generally correlated with the highest retention of $\mathrm{Hg}$ in the slurry. Low retention in the slurry (high segregation on the vessel bottom) resulted in low recovery in the offgas system. High agitation rates appear to result in lower retention of mercury in the slurry. Both recovery of mercury in the offgas system and removal (segregation + recovery) from the slurry correlate with slurry consistency. Higher slurry consistency results in better retention of $\mathrm{Hg}$ in the slurry (less segregation) and better recovery in the offgas system, but the relationships of recovery and retention with consistency are sludge dependent. Some correlation with slurry yield stress and acid stoichiometry was also found.

Better retention of mercury in the slurry results in better recovery in the offgas system because the mercury in the slurry is stripped more easily than the segregated mercury at the bottom of the vessel. Although better retention gives better recovery, the time to reach a particular slurry mercury content (wt\%) is longer than if the retention is poorer because the segregation is faster. The segregation of mercury is generally a faster process than stripping.

The stripping factor (mass of water evaporated per mass of mercury stripped) of mercury at the start of boiling were found to be less than 1000 compared to the assumed design basis value of 750 (the theoretical factor is 250). However, within two hours, this value increased to at least $2000 \mathrm{lb}$ water per lb Hg. For runs with higher mercury recovery in the offgas system, the stripping factor remained around 2000, but runs with low recovery had stripping factors of 4000 to 40,000. DWPF data shows similar trends with the stripping factor value increasing during boiling. These high values correspond to high segregation and low retention of mercury in the sludge. The stripping factor for a pure $\mathrm{Hg}$ metal bead in water was found to be about $10,000 \mathrm{lb} / \mathrm{lb}$.

About $10-36 \%$ of the total $\mathrm{Hg}$ evaporated in a SRAT cycle was refluxed back to the SRAT during formic acid addition and boiling. Mercury is dissolved as a result of nitric acid formation from 
absorption of $\mathrm{NO}_{\mathrm{x}}$. The actual solubility of dissolved mercury in the acidic condensate is about 100 times higher than the actual concentrations measured. Mercury metal present in the MWWT from previous batches could be dissolved by this acidic condensate.

The test of the effect of higher SRAT condenser temperature on recovery of mercury in the MWWT and offgas system was inconclusive. The recovery at higher temperature was lower than several low temperature runs, but about the same as other runs. Factors other than temperature appear to affect the mercury recovery.

The presence of chloride and iodide in simulants resulted in the formation of mercurous chloride and mercurous iodide, respectively, in the offgas system. Actual waste data shows that the chloride content is much less than the simulant concentrations. Future simulant tests should minimize the addition of chloride. Similarly, iodine addition should be eliminated unless actual waste analyses show it to be present; currently, total iodine is not measured on actual waste samples.

Excess antifoam addition resulted in poor coalescence of elemental $\mathrm{Hg}$ in the offgas system and resulted in finely divided beads on the SRAT condenser tubes. Nominal antifoam amounts gave significantly less finely divided $\mathrm{Hg}$ and did not result in as many condenser deposits. Accumulation of antifoam and antifoam degradation products on the offgas lines was also found to hinder the settling and coalescence of elemental mercury.

None of these results show why there has been no measurable recovery of mercury in the DWPT MWWT in recent sludge batches. Several factors affecting this recovery have been found in this work, but how to apply this information to DWPF operation is not apparent. Some characteristics of the DWPF process such as equipment cleanliness and deposits, physical configuration of equipment, flow velocities, etc. could not be studied in the laboratory.

Mercury deposits segregated on the bottom of the SRAT vessel ranged from very large beads to finely divided granular beads. Some mercury deposits were found to be amalgamated with Ag, $\mathrm{Cu}, \mathrm{Pd}$, and Rh, but very little Ru. In some samples, greater than $50 \%$ of the total amount of one of the metals $\mathrm{Ag}, \mathrm{Cu}$, or Pd added in the batch was found in the amalgam. Some of these deposits were extremely viscous and would be difficult to pump with the DWPF mercury pump. 


\section{TABLE OF CONTENTS}

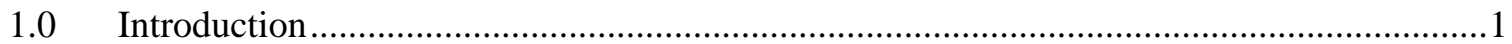

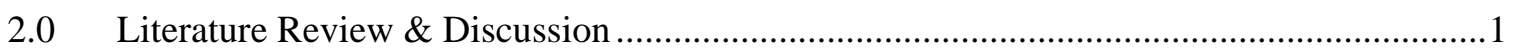

3.0 Experimental and Analytical Methods and Non-Mercury Results ....................................5

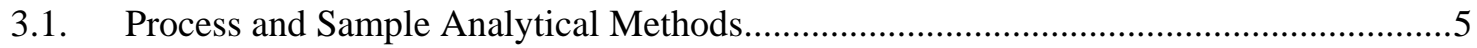

3.1.1. Ten Lab-Scale SRAT 'HG’ Runs ..........................................................................

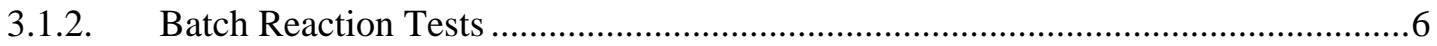

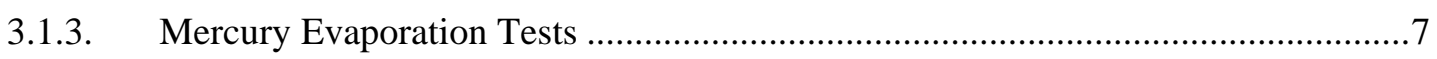

3.1.4. Recovery of Mercury from SRAT and SME Products ...........................................

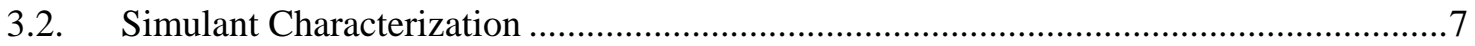

3.3. Chemical Process Cell SRAT Run Details ..................................................................

3.3.1. Equipment and Chemical Additions......................................................................

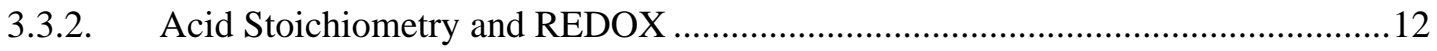

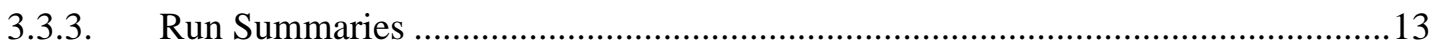

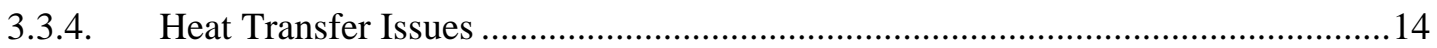

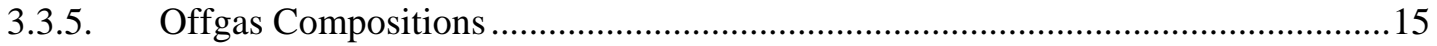

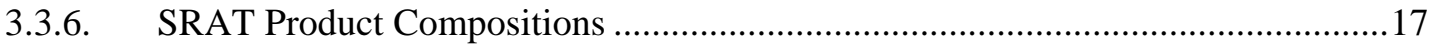

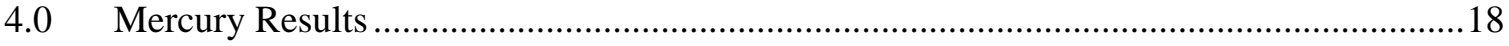

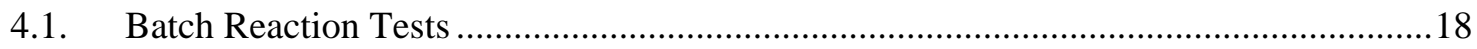

4.2. Lab-Scale SRAT HG Runs \& Mercury Balances ......................................................22

4.2.1. Mercury Recovery and Material Balance ..............................................................22

4.2.2. Effect of Rheology and Acid Stoichiometry on Mercury Removal ........................35

4.2.3. Soluble Mercury in Sludge and Condensates .........................................................

4.2.4. Form of Mercury in the Offgas System..............................................................43

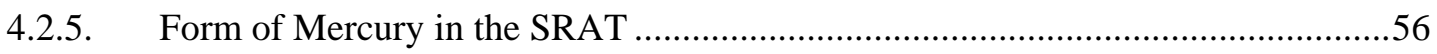

5.0 Process Modeling of Mercury Reactions in the Offgas and Condensate...........................61

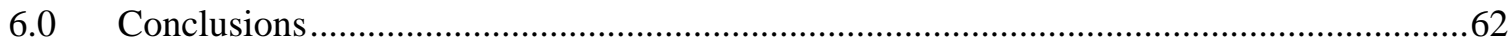

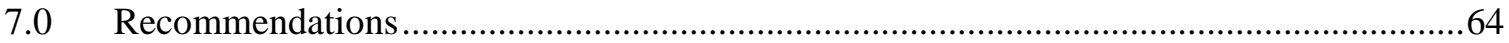

7.1. $\quad$ Improved Retention and Stripping of Mercury ….....................................................64

7.2. Improved Removal of Mercury in the SRAT Condenser and MWWT.........................64

7.3. Removal of Mercury from the SRAT Bottom in DWPF.............................................65

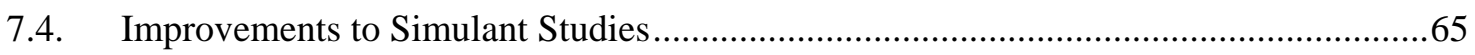

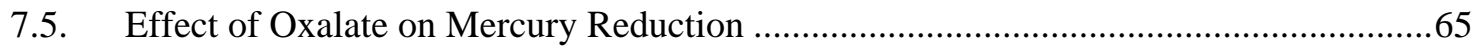

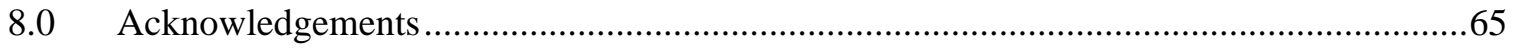

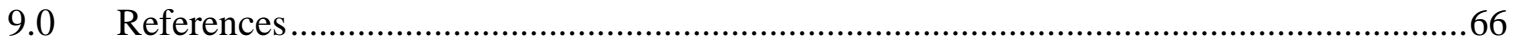

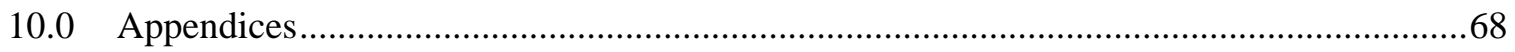




\section{TABLE OF CONTENTS}

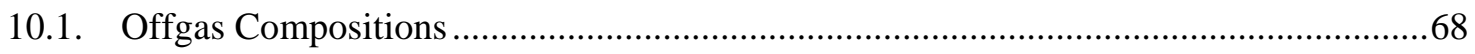

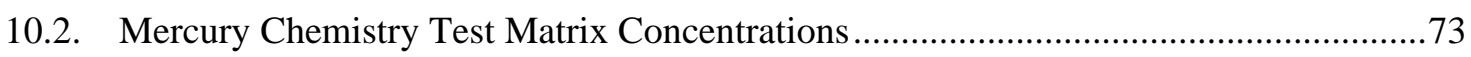




\section{LIST OF TABLES}

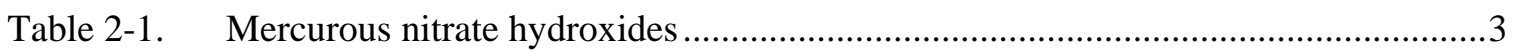

Table 2-2. Possible reactions to form mercurous nitrate hydroxides .........................................4

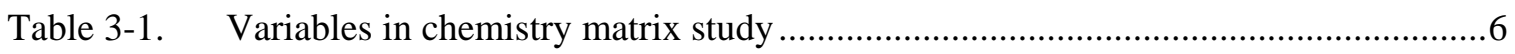

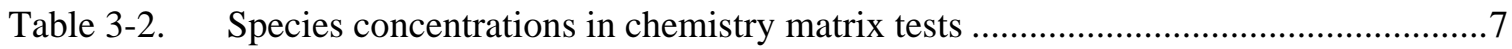

Table 3-3. ABC simulant composition - calcine elements (wt\%) ..........................................

Table 3-4. ABC simulant Total Inorganic Carbon and Base Equivalents .................................8

Table 3-5. ABC simulant composition - physical properties and anions ..................................

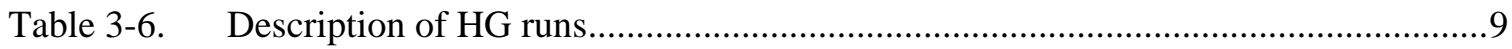

Table 3-7. HG runs mercury and noble metals target concentrations.....................................11

Table 3-8. HG run descriptions, redox, and acid stoichiometry ..........................................12

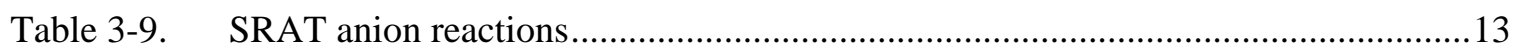

Table 3-10. SRAT product compositions - calcine elements (wt\%) and properties ..................17

Table 3-11. SRAT product anion compositions (mg/kg supernate)..........................................18

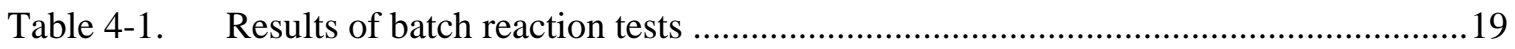

Table 4-2. Distribution of mercury in SRAT or SME products for HG, SB6, and SB7a

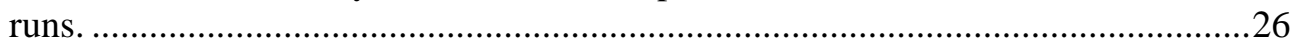

Table 4-3. Comparison of extrapolated and un-extrapolated distribution of mercury in

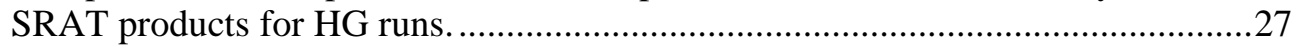

Table 4-4. HG runs final concentration of mercury in SRAT products ....................................29

Table 4-5. Distribution of mercury in the offgas system .....................................................41

Table 4-6. Comparison of predicted and measured distribution of mercury in offgas

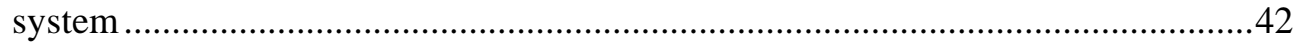

Table 4-7. Chloride and iodide content of simulants and radioactive sludge batches ..............43

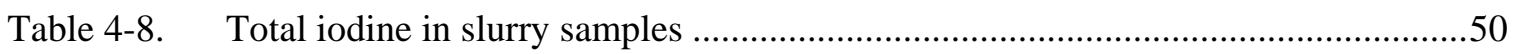

Table 4-9. Composition of MWWT sample from run SB7b-10 …........................................56

Table 4-10. Metals found in mercury recovered from SRAT and SME ..................................61 


\section{LIST OF FIGURES}

Figure 2-1. Deposits in the MTH, SMECT Hg pump, and MPC ..............................................

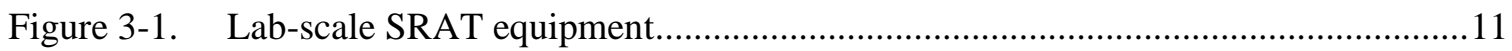

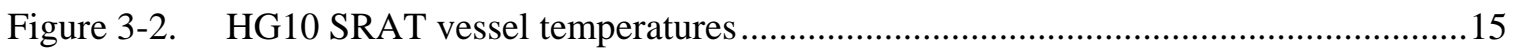

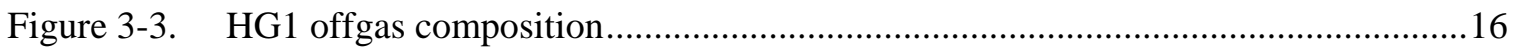

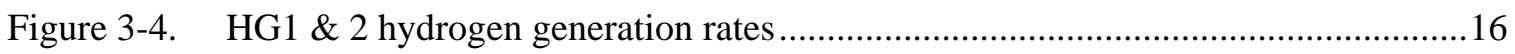

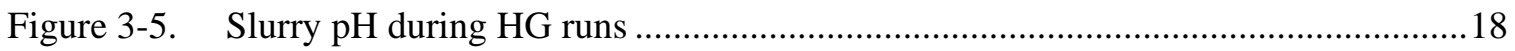

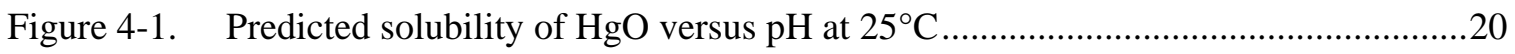

Figure 4-2. Predicted solubility of $\mathrm{HgO}$ versus temperature...............................................20

Figure 4-3. Measured mercury concentration in water versus $\mathrm{pH}$ for batch reaction tests ........21

Figure 4-4. Measured mercury concentration in supernate simulant versus $\mathrm{pH}$ for batch reaction tests

Figure 4-5. Measured dissolved mercury concentration at $\mathrm{pH} 13$ versus presence of solids

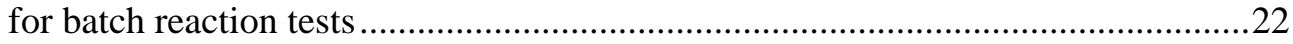

Figure 4-6. Measured dissolved mercury concentration at pH 13 versus presence of sodium oxalate for batch reaction tests.....................................................................22

Figure 4-7. Terminology for distribution of mercury in the CPC ............................................23

Figure 4-8. Percent recovery of mercury in the MWWT + SRAT condenser............................24

Figure 4-9. Extrapolated percent recovery of mercury in the MWWT + SRAT condenser ......25

Figure 4-10. HG Runs mercury retained in sludge versus time ................................................28

Figure 4-11. HG Runs total mercury material balance versus time ...........................................29

Figure 4-12. MWWT and SRAT Slurry mercury distributions ...............................................30

Figure 4-13. Mercury in MWWT correlation with mercury remaining in slurry and

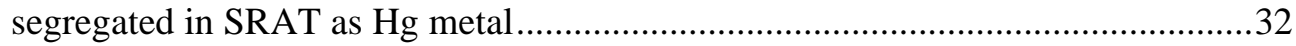

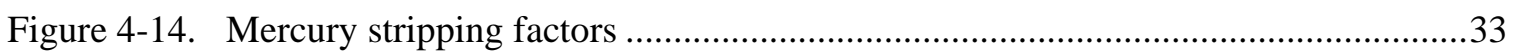

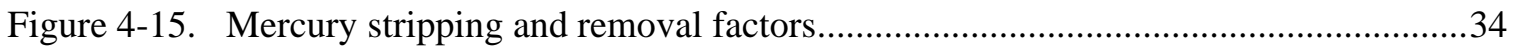

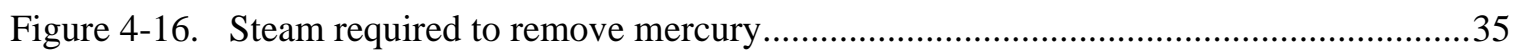

Figure 4-17. Elemental mercury found in MWWT and mercury removed from slurry versus

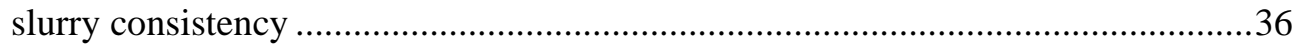

Figure 4-18. Elemental mercury found in MWWT and mercury removed from slurry versus

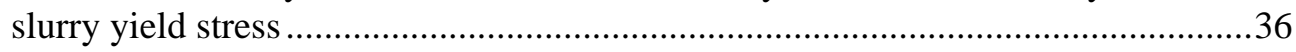

Figure 4-19. Elemental mercury found in MWWT and mercury removed from slurry versus

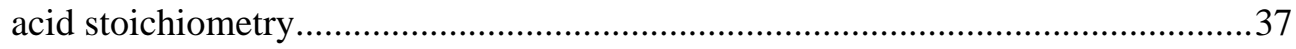

Figure 4-20. Measured and predicted solubility of mercury in initial SRAT slurry ....................38

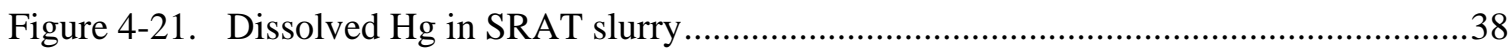

Figure 4-22. Dissolved mercury and nitrate concentrations in condensate ................................39

Figure 4-23. Rates of mercury accumulation and reflux in the MWWT ...................................40

Figure 4-24. Dissolved mercury in condensate versus nitrate ..................................................41

Figure 4-25. Runs HG2 to HG6 MWWT Hg photos ................................................................45

Figure 4-26. Mercury deposits in offgas system in Run HG6.................................................46

Figure 4-27. Black mercury deposits from run HG7 .......................................................48 


\section{LIST OF FIGURES}

Figure 4-28. XRD and XRF analyses of Run HG7 offgas deposits ..........................................49

Figure 4-29. HG8 mercury deposits in MWWT before and during cleaning with 8M nitric

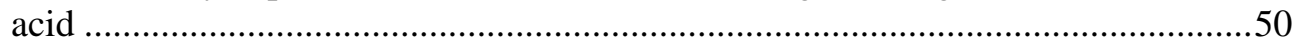

Figure 4-30. Mercury deposits in SRAT condenser downcomer for various runs .......................52

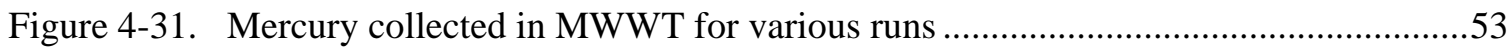

Figure 4-32. Organics buildup on SRAT condenser to MWWT line during NGS back-to-

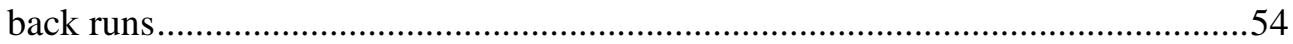

Figure 4-33. Microscope photos of mercury from MWWT in glycolic/formic runs ...................54

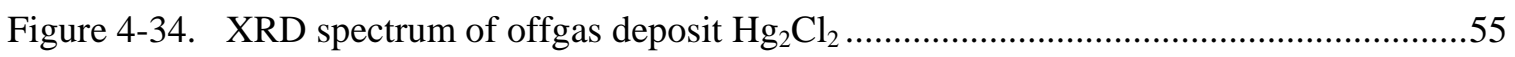

Figure 4-35. Mercury collected from MWWT in run SB7b-10 .............................................56

Figure 4-36. Mercury recovered from SRAT bottom for run HG8............................................57

Figure 4-37. Mercury recovered from SRAT bottom for run HG8 - dried sample .....................58

Figure 4-38. Extremely granular mercury from SRAT bottom from run HG6 ...........................59

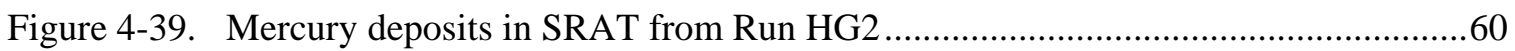

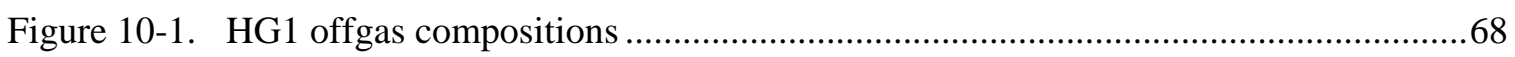

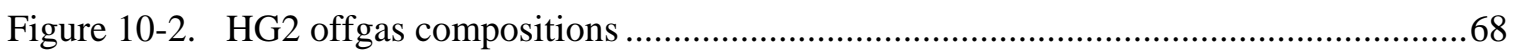

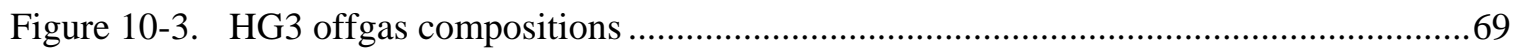

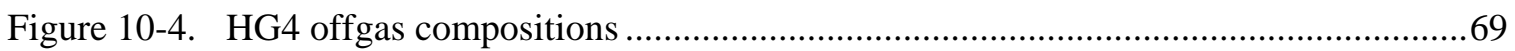

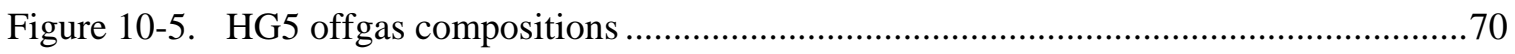

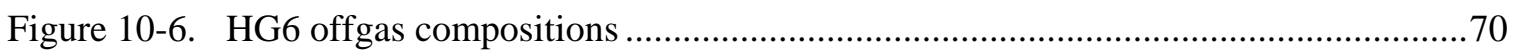

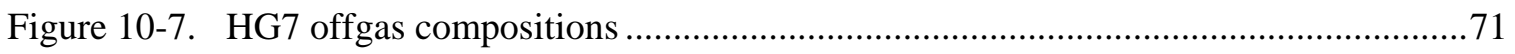

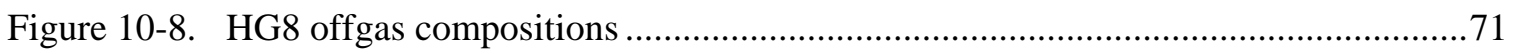

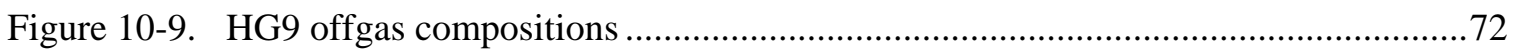

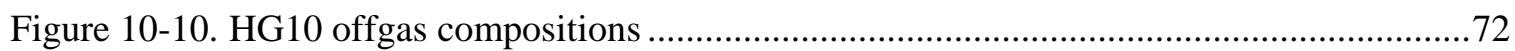




\section{LIST OF ACRONYMS \& DEFINITIONS}

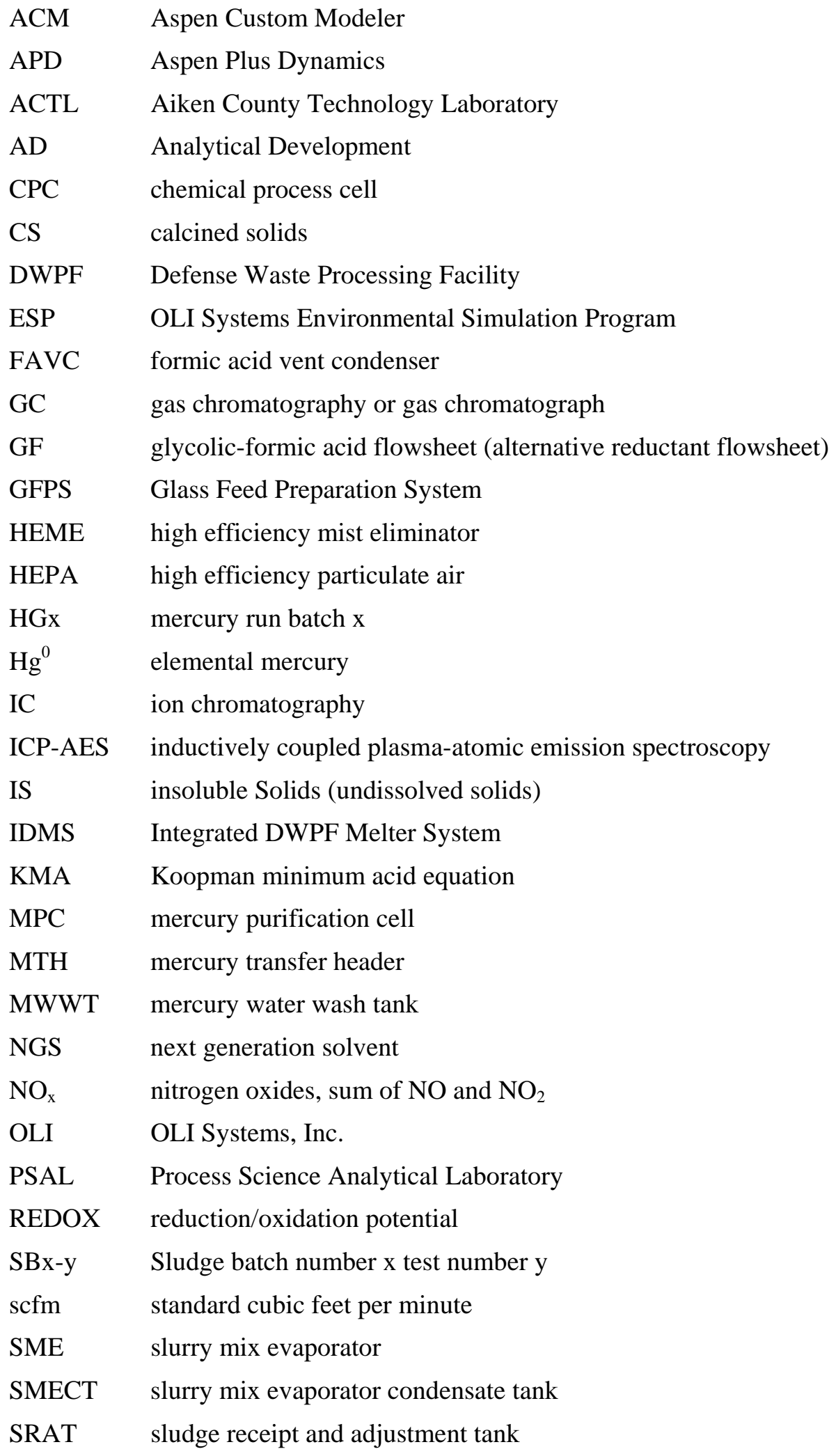




\section{LIST OF ACRONYMS \& DEFINITIONS}

\begin{tabular}{|c|c|}
\hline SRNL & Savannah River National Laboratory \\
\hline SS & soluble solids (supernate solids) \\
\hline $\begin{array}{l}\text { stripping } \\
\text { factor }\end{array}$ & mass of water evaporated per mass of mercury stripped \\
\hline SVOA & semi-volatile organic analysis \\
\hline TIC & total inorganic carbon \\
\hline TS & total solids \\
\hline TT\&QAP & Technical Task and Quality Assurance Plan \\
\hline TTR & Technical Task Request \\
\hline UDS & undissolved solids (insoluble solids) \\
\hline VOA & volatile organic analysis \\
\hline WAPS & Waste Acceptance Product Specification \\
\hline
\end{tabular}




\subsection{Introduction}

The Defense Waste Processing Facility (DWPF) has experienced significant issues with the stripping and recovery of mercury in the Chemical Processing Cell (CPC). The stripping rate has been inconsistent, often resulting in extended processing times to remove mercury to the required endpoint concentration. The recovery of mercury in the Mercury Water Wash Tank (MWWT) has never been high, and has decreased significantly since the Mercury Water Wash Tank was replaced after the seventh batch of Sludge Batch (SB) 5. Only about 15\% of the expected mercury was collected in the first MWWT and essentially no recovery of mercury has been seen since SB5 batch $8 .^{1}$

This task consisted of several approaches to develop a better understanding of the behavior of mercury in the CPC. The approach used was multi-pronged and included a review of literature, examination of previous lab-scale data on mercury stripping and recovery, conducting new lab-scale CPC Sludge Receipt and Adjustment Tank (SRAT) runs, and other experiments to study mercury evaporation and chemical reactions in solution. For previous lab-scale data, many of the runs with sufficient mercury recovery data were examined to determine what factors affect the stripping and recovery of mercury and to improve closure of the mercury material balance. Ten new lab-scale SRAT runs were performed to examine the effects of acid stoichiometry, sludge solids concentration, antifoam concentration, form of mercury added to simulant, presence of a SRAT heel, operation of the SRAT condenser at higher than prototypic temperature, varying noble metals from none to very high concentrations, and higher agitation rate. In these runs dedicated to studying mercury, many more than the usual number of samples were taken of the sludge and condensate during processing to better understand the chemistry of mercury in both the sludge and offgas and condensate. Preliminary work on developing a computational model for mercury in the offgas system was also done.

To examine the material balance for mercury, data from sludge batch $\mathrm{SB}^{2-4}, \mathrm{SB}^{2} \mathrm{a}^{5}$, and glycolic-formic ${ }^{6}$ (GF) alternative reductant lab-scale tests were examined in addition to the new data from the ten mercury (HG1-HG10) runs. In one of the SB7a runs, the four GF, and all of the HG runs, the distribution of mercury in the process at the end of testing was more thoroughly examined. Measurements of mercury in the SRAT or Slurry Mix Evaporator (SME) residual vessel sludge, on the agitator, and throughout the offgas system were done at the end of these runs. These measurements included quantifying the amount of mercury deposits in the SRAT condenser and MWWT.

Several tests of pure mercury evaporation from deionized water were conducted to determine the stripping factor of large beads of mercury. A matrix of batch reaction tests was performed to study the effects of $\mathrm{pH}$, nitrite, oxalate, and formate on the solubility of mercuric oxide (HgO), the conversion to elemental mercury, and whether HgO was converted to other forms.

Testing was performed at the Savannah River National Laboratory Aiken County Technology Laboratory (SRNL-ACTL) facility. This work was performed under the Task Technical and Quality Assurance Plan SRNL-RP-2011-00266 Rev. $0^{7}$ for the behavior of mercury in the CPC written in response to HLWDWPF-TTR-2011-0007 Rev. 0. ${ }^{8}$

\subsection{Literature Review \& Discussion}

A literature review was previously completed as part of a study of the reactions of mercury in the DWPF melter offgas system. ${ }^{9,10}$ Many of the gas-phase and most of the liquid-phase reactions reviewed are applicable to the chemical process cell operations. Review of past lab-scale tests has been included in the discussions in this report and the references are not tabulated here. Previous SRNL work with the pilotscale Integrated DWPF Melter System (IDMS) and Glass Feed Preparation System (GFPS) was reviewed. No pertinent information was found for the GFPS. For both the IDMS and GFPS, elemental 
mercury was reported to be found throughout the offgas and condensate systems. No quantitative information useful for material balances was available for either system. The IDMS mercury operations report $^{11}$ states that the amount of elemental mercury in the MWWT and condensate line from the SRAT condenser to the MWWT was measured after each of three runs, but this information was not reported. Only the amount of mercury remaining in the sludge was reported. For the IDMS, there was information available on the performance of the Formic Acid Vent Condenser (FAVC) in removing elemental mercury. ${ }^{12,13}$ The mercury concentration leaving the FAVC was found to be up to 12.7 times saturation with no High Efficiency Mist Eliminator (HEME) present, while with the HEME present, the mercury concentration was less than 0.4 times saturation.

Several journal articles were found pertaining to the reaction of mercury or mercuric oxide with nitric acid or nitrogen dioxide $\mathrm{NO}_{2}$. The reaction between elemental $\mathrm{Hg}^{0}$ with $\mathrm{NO}_{2}$ gas was studied at room temperature with no water present. ${ }^{14}$ Mixtures of mercurous (mercury(I)) nitrate and nitrite were reported to be formed. The authors suggested the overall reaction:

$$
4 \mathrm{Hg}^{0}+6 \mathrm{NO}_{2}=\mathrm{Hg}_{2}\left(\mathrm{NO}_{3}\right)_{2}+\mathrm{Hg}_{2}\left(\mathrm{NO}_{2}\right)_{2}+2 \mathrm{NO}
$$

The oxidation and dissolution of $\mathrm{Hg}$ metal by nitric acid solutions was studied at several nitric acid concentrations and a temperature of $90^{\circ} \mathrm{C}^{15}$ The nitric acid concentrations were $2.0,4.0$, and $5.5 \mathrm{M}$ which are all higher than the concentrations seen in the SRAT or SMECT. (SRAT condenser condensate nitric acid concentrations up to $1.8 \mathrm{M}$ were found in the HG run tests described in Section 4.2.3.) Their products contained primarily $\mathrm{Hg}^{2+}$ (mercury(II)) but also some $\mathrm{Hg}_{2}^{2+}$ (mercury(I)). The following stoichiometry was proposed for the formation of both $\mathrm{Hg}^{2+}$ and $\mathrm{Hg}_{2}^{2+}$ :

$$
5 \mathrm{Hg}^{0}+8 \mathrm{H}^{+}+2 \mathrm{NO}_{3}^{-}=\mathrm{Hg}^{2+}+2 \mathrm{Hg}_{2}^{2+}+2 \mathrm{NO}+4 \mathrm{H}_{2} \mathrm{O}
$$

The disproportionation reaction $\mathrm{Hg}_{2}^{2+}=\mathrm{Hg}^{0}+\mathrm{Hg}^{2+}$ can be combined with Eq. (2.2) to give a range of overall stoichiometries such as:

$$
11 \mathrm{Hg}^{0}+24 \mathrm{H}^{+}+6 \mathrm{NO}_{3}^{-}=7 \mathrm{Hg}^{2+}+2 \mathrm{Hg}_{2}^{2+}+6 \mathrm{NO}+12 \mathrm{H}_{2} \mathrm{O}
$$

which gives more $\mathrm{Hg}^{2+}$ than $\mathrm{Hg}_{2}^{2+}$ as was actually found during these authors' tests.

Mercurous nitrate is a crystalline compound similar to the deposits that were found in the DWPF GC filter assembly HEME and High Efficiency Particulate Air (HEPA) filters in 2009. ${ }^{16}$ The compounds found in the filter assemblies were identified to be the mercurous nitrate hydroxides $\operatorname{Hg}_{4}(\mathrm{OH})\left(\mathrm{NO}_{3}\right)_{3}$ and $\mathrm{Hg}_{10}(\mathrm{OH})_{4}\left(\mathrm{NO}_{3}\right)_{6}$. The compound $\mathrm{Hg}_{4}(\mathrm{OH})\left(\mathrm{NO}_{3}\right)_{3}$ can be alternately represented as $\mathrm{Hg}_{8}(\mathrm{OH})_{2}\left(\mathrm{NO}_{3}\right)_{6}$, or expressing the $\mathrm{Hg}$ as mercurous $\mathrm{Hg}_{2}^{2+}$ to give $3 \mathrm{Hg}_{2}\left(\mathrm{NO}_{3}\right)_{2} \bullet \mathrm{Hg}_{2}(\mathrm{OH})_{2}$, which empirically is 3 mercurous nitrates plus 2 mercurous hydroxides. Similarly, $\mathrm{Hg}_{10}(\mathrm{OH})_{4}\left(\mathrm{NO}_{3}\right)_{6}$ can be written as $3 \mathrm{Hg}_{2}\left(\mathrm{NO}_{3}\right)_{2} \cdot 2 \mathrm{Hg}_{2}(\mathrm{OH})_{2}$.

In a study of Raman spectra of mercurous compounds, four different mercury nitrate hydroxides were described, including methods to create them. ${ }^{17}$ The compounds that were created are given in Table 2-1. 
Table 2-1. Mercurous nitrate hydroxides

\begin{tabular}{|c|c|c|c|}
\hline & Compound & Alternate Formulation & Conditions to Produce \\
\hline 1 & $\mathrm{Hg}_{2}\left(\mathrm{NO}_{3}\right)_{2} \cdot 2 \mathrm{H}_{2} \mathrm{O}$ & 'mercurous nitrate dihydrate' & $2 \mathrm{M} \mathrm{HNO}_{3}$ \\
\hline 2 & $3 \mathrm{Hg}_{2}\left(\mathrm{NO}_{3}\right)_{2} \cdot \mathrm{Hg}_{2}(\mathrm{OH})_{2}$ & $\mathrm{Hg}_{8}(\mathrm{OH})_{2}\left(\mathrm{NO}_{3}\right)_{6}$ & $0.5 \mathrm{M} \mathrm{HNO}_{3}$ \\
\hline 3 & $3 \mathrm{Hg}_{2}\left(\mathrm{NO}_{3}\right)_{2} \cdot 2 \mathrm{Hg}_{2}(\mathrm{OH})_{2} \cdot \mathrm{H}_{2} \mathrm{O}$ & $\mathrm{Hg}_{10}(\mathrm{OH})_{4}\left(\mathrm{NO}_{3}\right)_{6} \cdot \mathrm{H}_{2} \mathrm{O}$ (hydrate $)$ & $0.1 \mathrm{M} \mathrm{HNO} \mathrm{HN}_{3}$ or $0.1 \mathrm{M} \mathrm{NaOH}$ \\
\hline 4 & $\mathrm{Hg}_{2}\left(\mathrm{NO}_{3}\right)_{2} \cdot \mathrm{Hg}_{2}(\mathrm{OH})_{2}$ & $\mathrm{Hg}_{4}(\mathrm{OH})_{2}\left(\mathrm{NO}_{3}\right)_{2}$ & hot water \\
\hline
\end{tabular}

None of the compounds identified in DWPF or given in Table 2-1 are nitrites, so mercurous nitrite formation as shown in Eq. (2.1) does not appear to occur in these systems, or it occurs but the nitrite is then decomposed. A similar reaction to form only mercurous nitrate would be:

$$
2 \mathrm{Hg}^{0}+4 \mathrm{NO}_{2}=\mathrm{Hg}_{2}\left(\mathrm{NO}_{3}\right)_{2}+2 \mathrm{NO}
$$

Note that compounds (2) and (3) are the compounds identified in the GC filter deposits. Compound (1) is the same as commercially available mercurous nitrate and was made by recrystallizing it from a $2 \mathrm{M}$ nitric acid solution. Compound 2 was made from a solution of (1) in $0.5 \mathrm{M}$ nitric acid that was evaporated at room temperature until crystals formed. Compound (3) was created by crystallization of (1) from either $0.1 \mathrm{M}$ nitric acid or $0.1 \mathrm{M}$ sodium hydroxide. Compound 4 was formed from (1) by successive treatments with hot water; this compound was yellow and in solution appeared greenish-yellow. Additional washing of (1) with hot water eventually yielded blackish solids indicative of the disproportionation of $\mathrm{Hg}_{2}^{2+}$ to give $\mathrm{Hg}^{0}+\mathrm{Hg}^{2+}$.

Crystalline material visibly similar to the GC filter deposits has been seen in DWPF in the SMECT vent to the Mercury Transfer Header (MTH), the SMECT mercury pump deposits, and the crystalline material in the Mercury Purification Cell (MPC) (Figure 2-1; photos provided by DWPF Engineering). None of these deposits has been experimentally identified as mercurous nitrate hydroxides compounds, but their similarity to the GC filter deposits suggests they likely are.

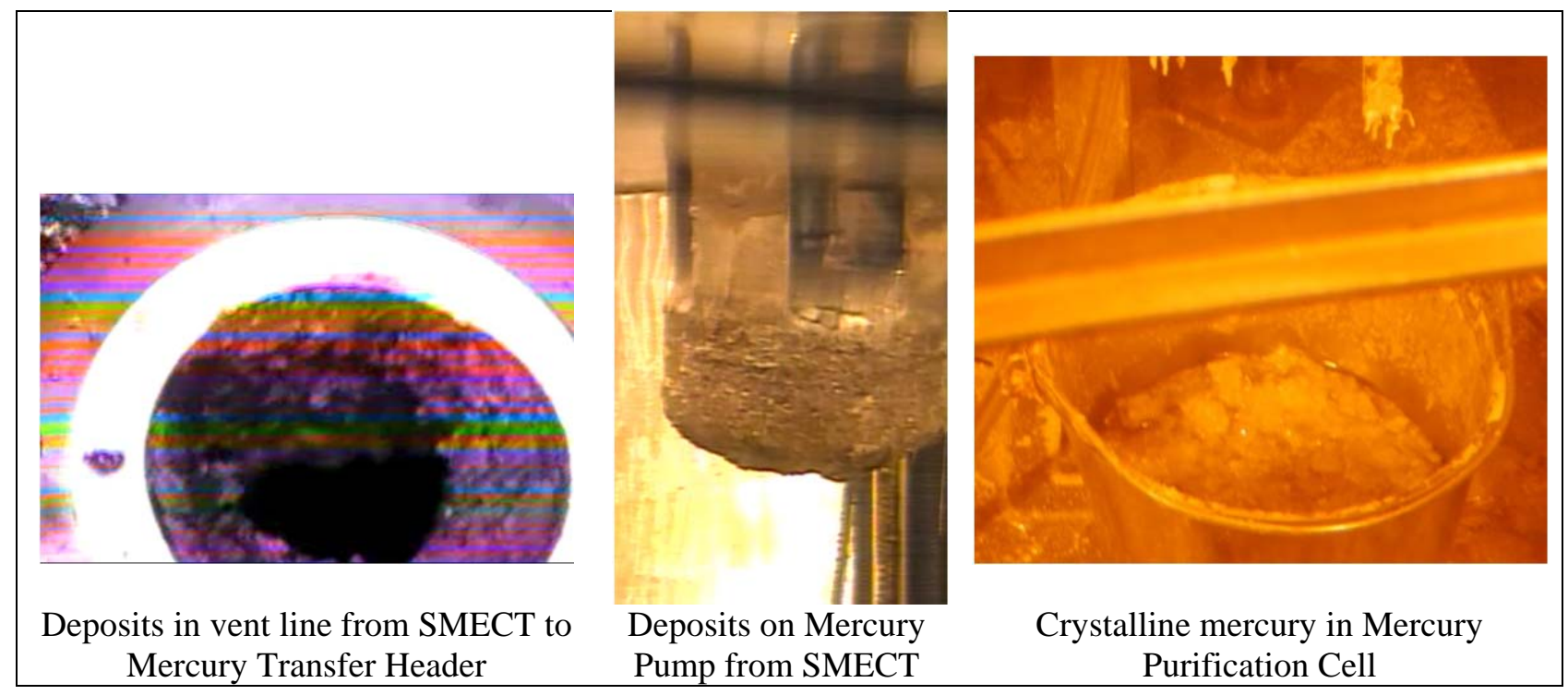

Figure 2-1. Deposits in the MTH, SMECT Hg pump, and MPC 
The conditions for the oxidation of $\mathrm{Hg}^{0}$ metal described above could occur in the SMECT, CPC offgas system, and the MPC. To form crystalline mercurous nitrate hydroxides in the offgas system, elemental $\mathrm{Hg}^{0}$ must be oxidized. The following possible sequence of reactions in Table 2-2 would lead to mercurous nitrate hydroxides.

Table 2-2. Possible reactions to form mercurous nitrate hydroxides

\begin{tabular}{|r|l|}
\hline & Reaction \\
\hline Oxidation by $\mathrm{NO}_{2}:$ & $2 \mathrm{Hg}^{0}+4 \mathrm{NO}_{2}=\mathrm{Hg}_{2}\left(\mathrm{NO}_{3}\right)_{2}+2 \mathrm{NO}$ \\
\hline Oxidation by $\mathrm{HNO}_{3}:$ & $6 \mathrm{Hg}^{0}+8 \mathrm{H}^{+}+2 \mathrm{NO}_{3}^{-}=3 \mathrm{Hg}_{2}^{2+}+2 \mathrm{NO}+4 \mathrm{H}_{2} \mathrm{O}$ \\
\hline Mercurous hydroxide: & $\mathrm{Hg}_{2}^{2+}+2 \mathrm{H}_{2} \mathrm{O}=\mathrm{Hg}_{2}(\mathrm{OH})_{2}+2 \mathrm{H}^{+}$ \\
\hline Mercurous nitrate: & $\mathrm{Hg}_{2}^{2+}+2 \mathrm{NO}_{3}^{-}=\mathrm{Hg}_{2}\left(\mathrm{NO}_{3}\right)_{2}$ \\
\hline Mercurous nitrate hydroxide: & $\mathrm{a} \mathrm{Hg}\left(\mathrm{NO}_{3}\right)_{2}+\mathrm{b} \mathrm{Hg} \mathrm{Hg}_{2}(\mathrm{OH})_{2}=\mathrm{Hg}_{(2 \mathrm{a}+2 \mathrm{~b})}\left(\mathrm{NO}_{3}\right)_{2 \mathrm{a}}(\mathrm{OH})_{2 \mathrm{~b}}$ \\
\hline
\end{tabular}

Reaction (2.4) could form mercurous nitrate by a gas phase reaction between $\mathrm{Hg}^{0}$ vapor and $\mathrm{NO}_{2}$, or a gas-solid reaction between liquid $\mathrm{Hg}^{0}$ and $\mathrm{NO}_{2}$. Such reactions could occur anywhere in the offgas system where $\mathrm{Hg}^{0}$ and $\mathrm{NO}_{2}$ are present. $\mathrm{NO}_{2}$ is generated during nitrite destruction and is present in the SRAT condenser, ammonia scrubber, and FAVC. Any $\mathrm{Hg}^{0}$ deposited, such as on process lines or the GC filters, could react with $\mathrm{NO}_{2}$ generated during nitrite destruction to form mercurous nitrate. Moisture present in the gas streams could convert some nitrate to hydroxide by reaction (2.4). $\mathrm{NO}_{2}$ can also be generated from the reaction of $\mathrm{NO}$ with $\mathrm{O}_{2}$; this reaction is favored by lower temperature such as those in the ammonia scrubber and FAVC. The $\mathrm{NO}_{2}$ would also dissolve in any condensed water on the HEME or HEPA filter to form nitric acid. This mechanism of deposition of $\mathrm{Hg}^{0}$ on the filter media, followed by oxidation by $\mathrm{NO}_{2}$ or $\mathrm{HNO}_{3}$ and formation of mercurous nitrate hydroxides, would account for how these solid compounds have formed primarily on the HEPA that is downstream of the HEME. In other words, the deposits were formed in situ rather than being transported to the filters. This type of deposition is similar to the ammonium nitrate deposition in the Integrated DWPF Melter System; the ammonium nitrate deposits were found in the gas sampling system downstream of several HEPA-efficiency filters, so must have formed by reactions ammonia with $\mathrm{HNO}_{3}$ vapor or $\mathrm{NO}_{2}$ plus water vapor.

Oxidation by nitric acid as in reaction (2.4) could occur anywhere condensate is present. Mercury present in the SRAT condenser, condensate lines, and MWWT could be oxidized by $\mathrm{HNO}_{3}$ which can be present during nitrite destruction up to $1.8 \mathrm{M}$. These conditions are similar to those that generate compounds 1-3 in Table 2-1.

The SMECT and ammonia scrubber $\mathrm{pH}$ is maintained at approximately 2-3, which is a nitric acid concentration of 0.001 to $0.01 \mathrm{M}$. This concentration range is more dilute than the conditions to generate compound 3 in Table 2-1, but much slower formation of this compound could still occur. These reactions in the condensate could form the mercurous nitrate hydroxides that may be what was seen on the SMECT mercury pump.

The SMECT is air-sparged to mix the tank. Based on the amount of elemental mercury that has been found in the Mercury Transfer Header (SMECT vent), a significant amount of elemental $\mathrm{Hg}^{0}$ must be evaporated or entrained into the vent. The crystalline material shown in Figure 2-1 could be formed by reaction of the $\mathrm{Hg}^{0}$ with entrained condensate containing nitric acid. 
The Mercury Purification Cell (MPC) treats the collected $\mathrm{Hg}^{0}$ first with $2 \mathrm{M}$ nitric acid, then with process water. If some of the $\mathrm{Hg}^{0}$ is oxidized by the nitric acid, the formation of mercurous nitrate is likely. The mercurous nitrate dihydrate in Table 2-1 was formed from dissolved mercurous nitrate in 2M nitric acid, which is what is used in the MPC. The subsequent water wash could create conditions that would favor formation of compounds 2 and 3 in Table 2-1.

\subsection{Experimental and Analytical Methods and Non-Mercury Results}

\section{1. $\quad$ Process and Sample Analytical Methods}

\subsubsection{Ten Lab-Scale SRAT 'HG' Runs}

The automated data acquisition system developed for the 4-L SRAT rigs was used to collect electronic data on computers. Collected data included SRAT slurry temperature, SRAT condenser condensate and exit gas temperatures, Formic Acid Vent Condenser (FAVC) exit temperature, SRAT condenser and FAVC cooling water temperatures, slurry $\mathrm{pH}$, SRAT mixer speed, and air and helium purge flows (helium is used as an internal standard and is set to about $0.5 \%$ of the nominal SRAT air purge flow). Raw GC chromatographic data were acquired on a separate computer interfaced to the data acquisition computer.

Agilent 3000A micro GC's were used for all runs. The GC's were baked out before and between runs. Column-A can collect data related to $\mathrm{He}, \mathrm{H}_{2}, \mathrm{O}_{2}, \mathrm{~N}_{2}$, NO, and $\mathrm{CO}$, while column-B can collect data related to $\mathrm{CO}_{2}, \mathrm{~N}_{2} \mathrm{O}$, and water. GC's were calibrated with a standard calibration gas containing 0.510 vol\% $\mathrm{He}, 1.000$ vol\% $\mathrm{H}_{2}, 20.10$ vol\% $\mathrm{O}_{2}, 50.77$ vol\% $\mathrm{N}_{2}, 25.1$ vol\% $\mathrm{CO}_{2}$ and 2.52 vol\% $\mathrm{N}_{2} \mathrm{O}$. The GCs were not calibrated for NO, CO, or water. The calibration was verified prior to starting and after the SRAT cycle. Room air was used to give a two point calibration for $\mathrm{N}_{2}$. The chilled off-gas leaving the FAVC was passed through a Nafion dryer in counter-current flow with a dried air stream to reduce the moisture content at the GC inlet. The dried, chilled off-gas stream was sampled by a GC from the start of the SRAT cycle through most of the cool down following the SRAT cycle.

Process samples were analyzed by various methods. Slurry elemental compositions were determined by inductively coupled plasma-atomic emission spectroscopy (ICP-AES) after lithium metaborate and sodium peroxide fusions at the Process Science Analytical Laboratory (PSAL). Slurry samples were first calcined at $1100^{\circ} \mathrm{C}$. The main advantage of this approach is to permit easier comparisons between SRAT product elements and sludge elements. Some supernate samples were also analyzed by ICP-AES, with no sample preparation required. Noble metals and mercury are trimmed uniquely for each SRAT run, and their concentrations are known more accurately from material balance considerations than they could be from ICP-AES analyses.

Mercury in sludge and supernate samples was analyzed by ICP-AES after dissolution in aqua regia. Offgas condensate samples were either analyzed directly by ICP-AES or were first acidified before analysis. Offgas system deposits were recovered by dissolution in 8-M nitric acid and analyzed directly by ICP-AES.

Water soluble slurry anions were determined by ion chromatography (IC) on 100-fold weighted dilutions of slurry with water followed by filtration to remove the remaining insoluble solids. Offgas condensate samples were analyzed directly by IC after appropriate dilution.

Slurries and condensate samples were analyzed by PSAL for slurry and supernate density using the Anton-Parr instrument or by weighing a known volume of sample on an analytical balance. Total (TS), 
supernate (soluble; SS) solids, and undissolved solids (UDS; or insoluble solids IS) were measured using a halogen lamp solids analyzer.

The base equivalents and TIC/carbonate values were not measured. The previous characterization values were used. ${ }^{18}$ Ammonium concentrations in the ammonia scrubber vessel or the sludge were not measured.

For the run with high antifoam addition, some special samples were taken for analysis by volatile organic analysis (VOA) and semi-volatile organic analysis (SVOA). The final MWWT condensate and a hexane extraction/rinse of the SRAT condenser and MWWT were analyzed by SRNL Analytical Development (AD).

\subsection{2. $\quad$ Batch Reaction Tests}

A matrix of batch reaction tests were conducted using mercuric oxide (HgO) and a simplified set of sludge components. In these tests, $150 \mathrm{~mL}$ of either deionized water or supernate simulant was added to a $250 \mathrm{~mL}$ glass vessel. Sodium nitrite, sodium oxalate, or SRAT heel solids, or a combination of these was then added. The species that were varied are shown in Table 3-1. A plus sign denotes that the supernate was initially a supernate simulant, while a zero denotes that the untrimmed supernate was DI water. A plus sign denotes that the species was added in the case of oxalate, nitrite, and solids, while a zero denotes that the species was not added. The matrix used was a factorial design except that levels with water and solids were not done. Each set of 11 conditions were performed at the approximate pH's of 13, 10, and 6.

\section{Table 3-1. Variables in chemistry matrix study}

Each set of 11 conditions done at $\sim \mathrm{pH} 13,6,10$. Value $=0$ for supernate simulant is water only.

\begin{tabular}{|c|c|c|c|c|}
\hline $\begin{array}{c}\text { "Case } \\
\text { Number" }\end{array}$ & $\begin{array}{c}\text { Supernate } \\
\text { Simulant }\end{array}$ & Oxalate & Nitrite & Solids \\
\hline 0 & 0 & 0 & 0 & 0 \\
\hline 3 & 0 & + & 0 & 0 \\
\hline 6 & 0 & 0 & + & 0 \\
\hline 7 & 0 & + & + & 0 \\
\hline 1 & + & 0 & 0 & 0 \\
\hline 4 & + & + & 0 & 0 \\
\hline 8 & + & 0 & + & 0 \\
\hline 9 & + & + & + & 0 \\
\hline 2 & + & 0 & 0 & + \\
\hline 5 & + & + & 0 & + \\
\hline 10 & + & 0 & + & + \\
\hline 11 & + & + & + & + \\
\hline
\end{tabular}

The SRAT product supernate simulant consisted of sodium nitrate and sodium formate in water. The nitrate and formate concentrations were 20,350 and $50,870 \mathrm{mg} / \mathrm{kg}$, respectively. These values are fairly typical concentrations for SRAT products. The SRAT heel solids used were from SRAT runs performed without any antifoam to produce SRAT product for antifoam testing. SRAT product slurry was centrifuged and then washed and centrifuged ten times with an equal volume of water to remove most of the supernate species. The solids collected were then dried at room temperature; the final solids remained slightly damp. 
The average concentrations or ranges of each species for each test are shown in Table 3-2. These concentrations are the average of the calculated values for the tests containing each species (i.e., zero values where the species wasn't added were not averaged in). The target addition of $\mathrm{Hg}$ as $\mathrm{HgO}$ was 0.31 $\mathrm{g}$ for some tests and $0.61 \mathrm{~g}$ for other tests. The additional nitrate in the $\mathrm{pH} 6$ tests is due to the addition of $\mathrm{HNO}_{3}$ to adjust the $\mathrm{pH}$. The nitrate, formate, nitrite, and oxalate were all at least an order of magnitude in molar excess relative to the $\mathrm{HgO}$ added. The oxalate, added as sodium oxalate was added in excess of its solubility.

Table 3-2. Species concentrations in chemistry matrix tests

\begin{tabular}{|c|c|c|c|c|c|c|c|c|}
\hline \multirow{2}{*}{$\begin{array}{c}\text { Target } \\
\text { pH }\end{array}$} & \multicolumn{4}{|c|}{ mg/kg slurry } & \multicolumn{2}{c|}{ wt\% } \\
\cline { 2 - 9 } & Actual pH & Nitrate & Formate & Oxalate & Nitrite & Na & solids & Hg \\
\hline 13 & $12.7-12.9$ & 19600 & 48900 & 21500 & 10800 & $2900-47800$ & 0.394 & $0.17-0.37$ \\
\hline $10^{(1)}$ & $\begin{array}{c}7.8-8.2 \\
9.7-10.2\end{array}$ & 19500 & 48600 & 21400 & 10800 & $5500-48000$ & 0.390 & $0.17-0.37$ \\
\hline $6^{(2)}$ & $\begin{array}{c}\text { avg. }=6.2 \\
3.0-8.1\end{array}$ & $7350-27900$ & 48500 & 21300 & 10700 & $5500-47400$ & 0.390 & $0.17-0.37$ \\
\hline
\end{tabular}

1) In some tests, the $\mathrm{pH}$ was misadjusted to about 8 instead of 10

2) The final $\mathrm{pH}$ in some tests was in the 7-8 range

In the first tests, the $\mathrm{pH}$ of the water or supernate simulant was first adjusted to 13 using $50 \mathrm{wt} \%$ sodium hydroxide. The $\mathrm{HgO}$ and additional species were then added and the solutions heated to $90-95^{\circ} \mathrm{C}$ for four hours. The upper section of each glass vessel was cooled to minimize water vapor loss. For all tests at $\mathrm{pH}$ 13, there was no significant change in appearance of the solutions. Aqueous samples were taken for determination of soluble $\mathrm{Hg}$. Each of the solutions was then adjusted to approximately $\mathrm{pH} 6$ using concentrated nitric acid, and again heated to $90-95^{\circ} \mathrm{C}$ for four hours. The $\mathrm{pH} 10$ tests were done similarly to the $\mathrm{pH} 13$ tests. The $\mathrm{pH}$ adjustment was done with dilute $\mathrm{NaOH}$ rather than $50 \mathrm{wt} \% \mathrm{NaOH}$.

\subsection{3. $\quad$ Mercury Evaporation Tests}

The evaporation of pure mercury $\mathrm{Hg}^{0}$ in deionized water was studied using a small SRAT rig that had a vessel that held about $400 \mathrm{~g}$ of water. In these tests, the evaporation rate of mercury was measured over time by periodically weighing the mercury that was collected in the drain leg of the MWWT. Three tests were performed with $5.0 \mathrm{~g}$ of elemental $\mathrm{Hg}$ in $400 \mathrm{~g}$ of water. To determine if mercury dispersed into small beads would have a lower stripping factor, further tests with $5 \mathrm{~g}$ of mercury dispersed into many small droplets were planned, but due to equipment problems, dispersed mercury could not be made.

\subsubsection{Recovery of Mercury from SRAT and SME Products}

Careful recovery of elemental $\mathrm{Hg}$ was performed from the SRAT or SME products from six of ten SB7a runs and four glycolic-formic (GF, alternate reductant) runs was performed. The products were dried after sampling the slurry for $\mathrm{Hg}$ to recover as much mercury as possible. The dried products were then examined and segregated elemental mercury was collected and weighed to determine the amount of $\mathrm{Hg}$ not dispersed throughout the slurry. Similar sampling was done for the HG runs, except the segregated elemental mercury was removed from the slurry liquid heels in the vessels.

\subsection{Simulant Characterization}

The simulant used in these runs was the "ABC" simulant previously prepared for the hydrogen and rheology modifier programs. ${ }^{18,19}$ The simulant composition used was not intended to match any particular DWPF sludge batch. In general, this simulant is rheologically thin because only iron, nickel, and manganese were co-precipitated during its manufacture. The other insoluble species were added as 
reagent chemicals. The elemental analyses of calcined ABC simulant are shown in Table 3-3. Shown here are the compositions from the original report and the compositions measured from samples taken during the HG runs. The HG3 sample was measured after addition of $\mathrm{HgO}$ and noble metals. Table 3-4 gives the total inorganic carbon (TIC) and hydroxide values, which were measured only for the ABC report.

Table 3-3. ABC simulant composition - calcine elements (wt\%)

\begin{tabular}{|c|c|c|c|c|c|c|}
\hline Element & $\begin{array}{c}\text { ABC } \\
\text { Report }\end{array}$ & $\begin{array}{c}\text { Bottle 18- } \\
\text { SP-15L }\end{array}$ & $\begin{array}{c}\text { Bottle 20- } \\
\text { SP-15L }\end{array}$ & Run HG3 & AVERAGE & $\begin{array}{c} \pm 95 \% \\
\text { Confidence }\end{array}$ \\
\hline $\mathrm{Al}$ & 16.1 & 14.1 & 13.8 & 15.6 & 14.9 & 1.80 \\
\hline $\mathrm{Ba}$ & 0.221 & 0.185 & 0.209 & 0.217 & 0.208 & 0.026 \\
\hline $\mathrm{Ca}$ & 2.55 & 2.05 & 2.19 & 2.50 & 2.32 & 0.39 \\
\hline $\mathrm{Cr}$ & 0.163 & 0.146 & 0.253 & 0.178 & 0.185 & 0.075 \\
\hline $\mathrm{Cu}$ & 0.143 & 0.068 & 0.112 & 0.0870 & 0.102 & 0.052 \\
\hline $\mathrm{Fe}$ & 21.8 & 20.3 & 20.0 & 22.6 & 21.2 & 1.93 \\
\hline $\mathrm{K}$ & 0.275 & 0.215 & 0.213 & $\mathrm{NM}$ & 0.234 & 0.088 \\
\hline $\mathrm{Mg}$ & 1.76 & 1.51 & 1.51 & 1.77 & 1.63 & 0.23 \\
\hline $\mathrm{Mn}$ & 4.05 & 3.48 & 3.47 & 4.04 & 3.76 & 0.52 \\
\hline $\mathrm{Na}$ & 12.2 & 11.0 & 10.8 & 11.6 & 11.4 & 1.02 \\
\hline $\mathrm{Ni}$ & 0.998 & 0.748 & 0.723 & 1.01 & 0.869 & 0.245 \\
\hline $\mathrm{P}$ & 0.0229 & 0.0261 & 0.0262 & $<0.100$ & 0.0250 & 0.005 \\
\hline $\mathrm{Pb}$ & 0.0550 & $<0.010$ & $<0.010$ & $<0.010$ & $<0.01$ & $\mathrm{NA}$ \\
\hline $\mathrm{S}$ & 0.238 & 0.244 & 0.229 & 0.272 & 0.246 & 0.030 \\
\hline $\mathrm{Si}$ & 1.72 & 1.23 & 1.18 & 1.74 & 1.47 & 0.48 \\
\hline $\mathrm{Ti}$ & 0.018 & 0.017 & 0.017 & 0.021 & 0.018 & 0.003 \\
\hline $\mathrm{Zn}$ & 0.213 & 0.177 & 0.198 & 0.210 & 0.200 & 0.026 \\
\hline $\mathrm{Zr}$ & 0.628 & 0.404 & 0.418 & 0.459 & 0.477 & 0.164 \\
\hline
\end{tabular}

NM: not measured

Table 3-4. ABC simulant Total Inorganic Carbon and Base Equivalents

\begin{tabular}{|r|c|}
\hline Total Inorganic Carbon (mg/kg) & 1350 \\
\hline Base Equivalents (pH 5.5) (M) & 0.381 \\
\hline Base Equivalents (pH 7) (M) & 0.313 \\
\hline
\end{tabular}

Table 3-5 shows the densities, solids contents, and anions. Again, the HG run samples were measured after $\mathrm{HgO}$ and noble metal additions. 
Table 3-5. ABC simulant composition - physical properties and anions

\begin{tabular}{|c|c|c|c|c|c|c|c|c|c|c|c|c|}
\hline & \multirow{2}{*}{$\begin{array}{c}\text { Slurry } \\
\text { Density } \\
\text { (kg/L) }\end{array}$} & \multirow{2}{*}{$\begin{array}{l}\text { Supernate } \\
\text { Density } \\
\text { (kg/L) }\end{array}$} & \multirow{2}{*}{$\begin{array}{l}\text { Total } \\
\text { Solids } \\
\text { (wt\%) }\end{array}$} & \multirow{2}{*}{$\begin{array}{c}\text { Undissolved } \\
\text { Solids } \\
\text { (wt\%) }\end{array}$} & \multirow{2}{*}{\begin{tabular}{|c|}
$\begin{array}{c}\text { Supernate } \\
\text { Solids } \\
\text { (wt\%) }\end{array}$ \\
\end{tabular}} & \multirow{2}{*}{$\begin{array}{l}\text { Calcine } \\
\text { Solids } \\
\text { (wt \%) }\end{array}$} & \multicolumn{6}{|c|}{ Anions (mg/kg slurry) } \\
\hline & & & & & & & $\mathrm{Cl}^{-}$ & $\mathrm{NO}_{2}^{-}$ & $\mathrm{NO}_{3}^{-}$ & $\mathrm{SO}_{4}^{2-}$ & Oxalate & $\mathrm{PO}_{4}^{3-}$ \\
\hline ABC Report & 1.175 & 1.053 & $22.81 \%$ & $16.82 \%$ & $7.20 \%$ & $16.00 \%$ & 390 & 17950 & 13788 & 1625 & 1400 & 160 \\
\hline Bottle 18-SP-15L & 1.158 & 1.052 & $23.48 \%$ & $17.48 \%$ & $7.27 \%$ & $16.45 \%$ & 411 & 17550 & 12200 & 1800 & 1030 & $<100$ \\
\hline Bottle 20-SP-15L & 1.160 & 1.052 & $22.93 \%$ & $16.90 \%$ & $7.26 \%$ & $16.04 \%$ & 410 & 17800 & 12050 & 1740 & 1025 & $<100$ \\
\hline HG1 & & 1.074 & & & & & & & & & & \\
\hline HG2 & & 1.057 & & & & & & & & & & \\
\hline HG3 & 1.164 & 1.049 & $22.71 \%$ & $17.14 \%$ & $6.72 \%$ & $15.77 \%$ & 428 & 20850 & 11400 & 1550 & 922 & $<100$ \\
\hline HG4 & 1.169 & & $21.64 \%$ & $15.64 \%$ & $7.11 \%$ & & 427 & 16050 & 11500 & 1555 & 926 & $<100$ \\
\hline HG6 & 1.155 & & $21.83 \%$ & $15.74 \%$ & $7.23 \%$ & & 431 & 16350 & 11650 & 1570 & 930 & $<100$ \\
\hline HG7* & 1.152 & & $22.19 \%$ & $16.12 \%$ & $7.24 \%$ & & 358 & 16200 & 11500 & 1565 & 927 & $<100$ \\
\hline HG8* & 1.135 & & $22.29 \%$ & $16.24 \%$ & $7.22 \%$ & & 651 & 16250 & 11950 & 1560 & 935 & $<100$ \\
\hline HG9* & 1.144 & 1.050 & $23.54 \%$ & $17.24 \%$ & $7.61 \%$ & & 465 & 17000 & 12200 & 1660 & 982 & $<100$ \\
\hline AVERAGE & 1.157 & 1.055 & $22.60 \%$ & $16.59 \%$ & $7.21 \%$ & $16.07 \%$ & 441 & 17333 & 12026 & 1625 & 1008 & $<100$ \\
\hline $\pm 95 \%$ confidence & 0.009 & 0.008 & $0.52 \%$ & $0.52 \%$ & $0.17 \%$ & $0.45 \%$ & 64 & 1159 & 561 & 70 & 118 & NA \\
\hline
\end{tabular}

* From Bottle 18-SP-15L. Blank cells: not measured. HG samples after addition of HgO and noble metals

\section{3. $\quad$ Chemical Process Cell SRAT Run Details}

The ten HG runs are summarized in Table 3-6.

Table 3-6. Description of HG runs

\begin{tabular}{|c|c|c|}
\hline Run & Title & Description \\
\hline HG1 & Baseline, $135 \%$ acid & $\begin{array}{l}\text { Hg added as HgO } \\
\text { Acid stoichiometry 135\% Koopman }\end{array}$ \\
\hline HG2 & Dissolved Hg, 135\% acid & $\begin{array}{l}\mathrm{HgO} \text { dissolved in } \mathrm{HNO}_{3} \\
\text { Acid with } \mathrm{Hg} \text { accounts for some of } \mathrm{HNO}_{3} \text { requirement } \\
\text { Acid stoichiometry } 135 \% \text { Koopman }\end{array}$ \\
\hline \multicolumn{3}{|c|}{ For all below, Hg added as HgO, acid stoichiometry $110 \%$ Koopman } \\
\hline HG3 & Baseline, $110 \%$ acid & \\
\hline HG4 & Hot Condenser & $\begin{array}{l}\text { SRAT condenser vapor temperature about } 60^{\circ} \mathrm{C} \\
\mathrm{Hg} \text { added as } \mathrm{HgO}\end{array}$ \\
\hline HG5 & Effect of Heel (from HG3) & $\begin{array}{l}\text { Fresh sludge added includes additional water } \\
\text { Leaves Hg on bottom from HG3 }\end{array}$ \\
\hline HG6 & Excess Antifoam & Antifoam added at $10000 \mathrm{ppm}$ \\
\hline HG7 & No Noble Metals & \\
\hline HG8 & High Noble Metals & Similar to HM levels \\
\hline HG9 & High Agitation Rate & Agitation rate 950 rpm vs usual $380 \mathrm{rpm}$ \\
\hline HG10 & High Solids & $\begin{array}{l}\text { Perform dewatering before acid additions } \\
\text { Concentrate sludge from } \sim 23 \text { wt } \% \text { to } \sim 28 \mathrm{wt} \% \\
\text { Maintain HgO:solids ratio }\end{array}$ \\
\hline
\end{tabular}




\subsubsection{Equipment and Chemical Additions}

The new SRAT system consisting of a bottom draining SRAT vessel that is heated with two immersed electrically-heated rods was used. ${ }^{20}$ This equipment is shown in Figure 3-1. ${ }^{21}$ For each run, except HG5 and HG10 (as described below), about $2900 \mathrm{~g}$ of fresh sludge was charged into the SRAT vessel.

Scaled design basis DWPF SRAT processing conditions were generally used. The SRAT cycle, however, did not have a heel from a prior batch except for run HG5. R\&D directions were prepared for each run and used to supplement the standard SRNL procedure for non-radioactive CPC simulations. ${ }^{21}$

- The SRAT air purge scaled to $230 \mathrm{scfm}$ in DWPF.

- A 200 ppm antifoam addition was made prior to nitric acid addition. $†$

- A 100 ppm antifoam addition was made prior to formic acid addition. $\dagger$

- $\quad$ Nitric and formic acid additions were made at $93^{\circ} \mathrm{C}$.

- Acids were added at two gallons per minute scaled on the volume of sludge.

- A 500 ppm antifoam addition was made prior to going to boiling after acid addition. $\dagger$

- Boiling assumed a condensate production rate of 5,000 lb/hr at DWPF scale ( 4 mL/min).

- $\quad$ SRAT dewatering took 1-3.2 hours to produce a $25 \mathrm{wt}$. \% total solids slurry.

- Reflux followed dewatering. A total boiling period of about $18 \mathrm{~h}$ (dewater + reflux) defined the end of the SRAT cycle (theoretically this was sufficient to strip mercury to $0.8 \mathrm{wt} \%$ dry sludge basis). $\dagger$ (except for the high antifoam run)

The scaled air purge rate for each run was in the range 0.60-0.70 std. L/min, and was scaled on the volumetric ratio of the initial sludge $(\sim 6000$ gal $* 3.7854 \mathrm{~L} / \mathrm{gal}) /(\sim 2.85 \mathrm{~kg} / \sim 1.16 \mathrm{~kg} / \mathrm{L})=\sim 9244$. The formic and nitric acid addition rates were scaled using the same factor. 


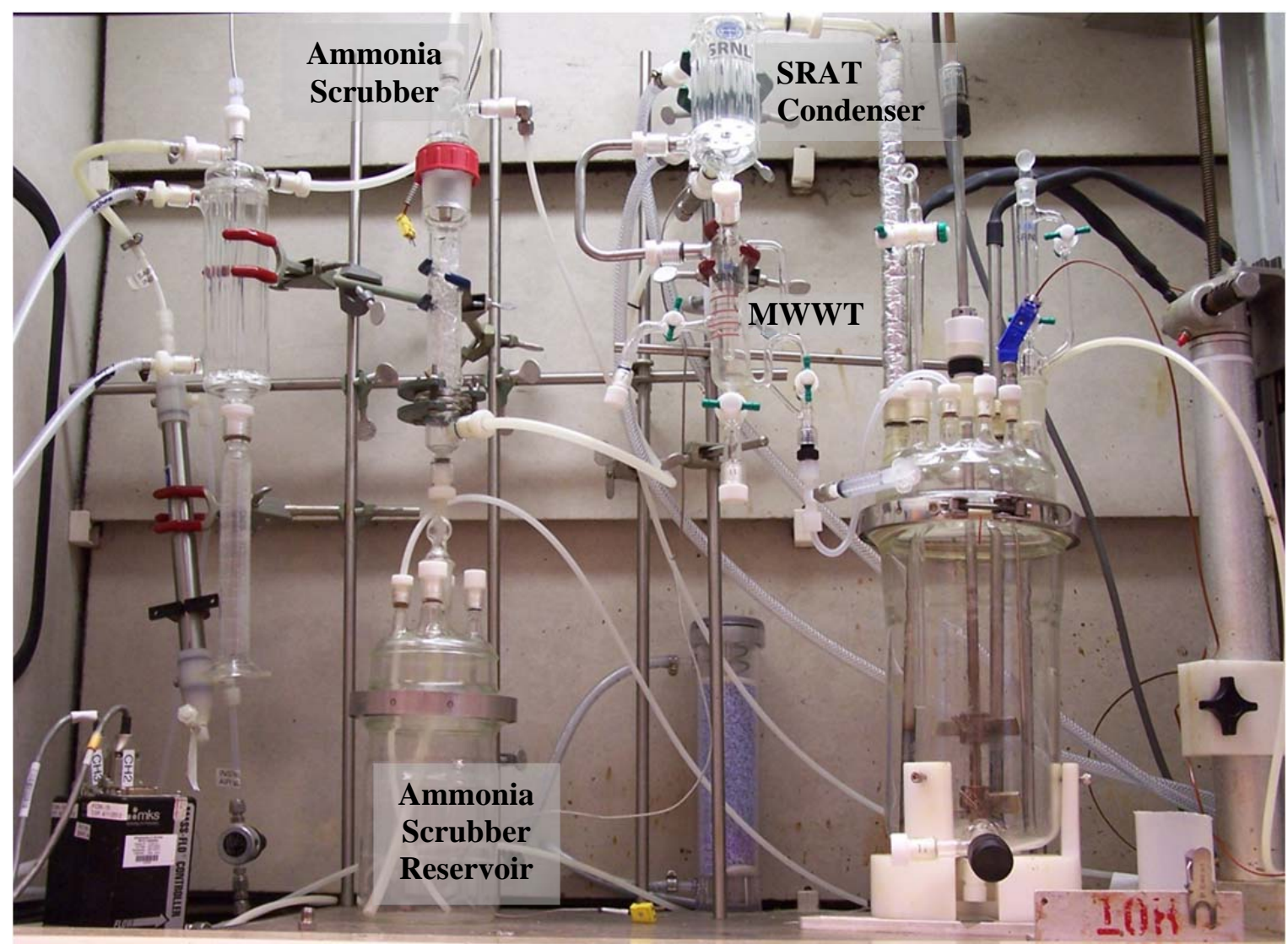

Figure 3-1. Lab-scale SRAT equipment

Mercury was added as reagent grade yellow HgO in all runs except HG2. In some cases, the HgO was added to the sludge the day before the run was performed, and in others it was added just before the run. For all runs, the initial sludge sample was taken after adding the $\mathrm{HgO}$ and agitating for at least 30 minutes. Noble metals were added prior to the $\mathrm{HgO}$. The noble metals were added as $\mathrm{AgNO} \mathrm{N}_{3}, \mathrm{Pd}_{\left(\mathrm{NO}_{3}\right)_{2}}$ solution, $\mathrm{Rh}\left(\mathrm{NO}_{3}\right)_{3}$ solution, and $\mathrm{RuCl}_{3}$. The target mercury and noble metals concentrations for the HG runs are summarized in Table 3-7. The mercury target for HG10 was slightly lower than the other runs because the same mass of $\mathrm{HgO}$ was added to a higher solids concentration.

Table 3-7. HG runs mercury and noble metals target concentrations

\begin{tabular}{|r|c|c|c|c|c|}
\multicolumn{7}{|c|}{ (wt\% dry basis) } \\
\hline Run & Hg & Ag & Rh & Ru & Pd \\
\hline HG1-HG6, HG9 & 1.74 & 0.0030 & 0.0078 & 0.0300 & 0.0010 \\
\hline HG7 & 1.74 & 0 & 0 & 0 & 0 \\
\hline HG8 & 1.74 & 0.0200 & 0.0260 & 0.1240 & 0.0100 \\
\hline HG10 & 1.56 & 0.0030 & 0.0078 & 0.0300 & 0.0010 \\
\hline
\end{tabular}

The Ammonia Scrubber Reservoir was charged with $1 \mathrm{~g} 50 \mathrm{wt} \%$ HNO3 and 999 g deionized water in all runs except in the hot condenser run HG3. In this run, because about $200 \mathrm{~g}$ of condensate was expected to be collected in the scrubber due to the higher temperature in the SRAT condenser, only $800 \mathrm{~g}$ of DI water was charged. Normally, with the SRAT condenser operating at $25^{\circ} \mathrm{C}$, there is only a small change in the scrubber reservoir liquid volume throughout a test. (The reservoir is not called the Slurry Mix Evaporator 
Condensate Tank, or SMECT, because condensates from the SRAT and SME are not drained into it.) The dilute acid reservoir solution was recirculated by a MasterFlex driven Micropump gear pump at about 300 $\mathrm{mL}$ per minute to a spray nozzle at the top of the scrubber packed section.

Acid additions were done using piston pumps that pumped specific amounts of acid from pre-weighed containers. Each acid addition was followed by a $20 \mathrm{~mL}$ water flush to completely remove the acid from the line. In this system, the first approximately $10 \mathrm{~mL}$ of acid fed each time was flush water from the previous pump use. Therefore, the actual acid addition time spans are from about 12 minutes after the start of the addition to 12 minutes after the acid has been completely fed into the line and the flush water has started (given an acid flowrate of $\sim 0.8 \mathrm{~mL} / \mathrm{min}$ ).

\subsubsection{Acid Stoichiometry and REDOX}

The estimated feed composition for each run was that given in the ABC simulant report. ${ }^{18}$ For all runs, the target REDOX was 0.200 . The description of each run, the acid stoichiometry (Koopman minimum acid, $\% \mathrm{KMA})^{22}$ target and actual values, and the REDOX $\left(\mathrm{Fe}^{2+} / \Sigma \mathrm{Fe}\right)$ predicted from the actual analytical data are shown in Table 3-8. The actual acid stoichiometry values are based on using the actual feed sample compositions rather than the estimated compositions and on the actual acid addition volumes. The actual acid stoichiometry values were close to the targeted values except for the no noble metals run HG7, where a formic acid batching error resulted in excess addition at about 167\% KMA. For eight runs, the predicted REDOX was between 0.19-0.24; for HG1, it was somewhat higher at 0.28, and for HG7 where too much formic acid was used, the predicted REDOX was 0.50. For all runs except HG9, the agitation rate was set at about 375 rpm, which is a typical value for the lab-scale SRAT runs.

Table 3-8. HG run descriptions, redox, and acid stoichiometry

\begin{tabular}{|c|c|c|c|c|}
\hline Run & Description & $\begin{array}{c}\text { \% } \\
\text { Stoichiometric } \\
\text { Acid Target* }\end{array}$ & $\begin{array}{c}\text { \% } \\
\text { Stoichiometric } \\
\text { Acid Actual }\end{array}$ & $\begin{array}{c}\text { Predicted } \\
\text { REDOX }\end{array}$ \\
\hline HG1 & Baseline, $135 \%$ acid & $135 \%$ & $140 \%$ & 0.28 \\
\hline HG2 & $135 \%$ acid, Hg added as Hg(NO $\left.{ }_{3}\right)_{2}$ & $135 \%$ & $140 \%$ & 0.21 \\
\hline HG3 & Baseline, $110 \%$ acid & $110 \%$ & $105 \%$ & 0.21 \\
\hline HG4 & Hot Condenser, $110 \%$ acid & $110 \%$ & $116 \%$ & 0.24 \\
\hline HG5 & SRAT Heel, $110 \%$ acid & $110 \%$ & NA & 0.24 \\
\hline HG6 & Excess Antifoam, $110 \%$ acid & $110 \%$ & $119 \%$ & 0.24 \\
\hline HG7 & No Noble Metals, $110 \%$ acid & $110 \%$ & $167 \%$ & 0.50 \\
\hline HG8 & High Noble Metals, $110 \%$ acid & $110 \%$ & $118 \%$ & 0.23 \\
\hline HG9 & High Agitation, $110 \%$ acid & $110 \%$ & $113 \%$ & 0.19 \\
\hline HG10 & High Total Solids, $110 \%$ acid & $110 \%$ & $108 \%$ & 0.21 \\
\hline
\end{tabular}

Total acid was partitioned between formic and nitric acids using the current REDOX equation. ${ }^{23}$ Assumptions of $20 \%$ formate loss and of $20-30 \%$ nitrite-to-nitrate conversions, and 50 or $5 \%$ oxalate destruction were also made to enable this calculation to be performed. These assumptions gave a target formic acid percentage of the total acid moles in the range of $94.4 \%$ for HG1-2 and $96.2 \%$ for HG3-10. The post-run calculated conversions are summarized in Table 3-9. The nitrite to nitrate conversions ranged from 3-37\% (average 21\%), formic acid destruction was 6-31\% (average 16\%), and oxalate 
destruction was 0-93\% (average 67\%) with eight values from 67-93. The nitrite destruction was 100\% ( $<100 \mathrm{mg} / \mathrm{kg}$ slurry) for seven runs and greater than $98 \%$ for three runs; in all cases, the target $<1000$ $\mathrm{mg} / \mathrm{kg}$ slurry was achieved.

Table 3-9. SRAT anion reactions

\begin{tabular}{|c|c|c|c|c|}
\hline Run & $\begin{array}{c}\text { Conversion } \\
\text { Nitrite to } \\
\text { Nitrate \% }\end{array}$ & $\begin{array}{c}\text { Destruction } \\
\text { of Formic } \\
\text { Acid \% }\end{array}$ & $\begin{array}{c}\text { Destruction } \\
\text { of Nitrite \% }\end{array}$ & $\begin{array}{c}\text { Destruction } \\
\text { of Oxalate \% }\end{array}$ \\
\hline Assumed & $20-30$ & 20 & 100 & 5,50 \\
\hline HG1 & 19 & 15 & 100 & 0 \\
\hline HG2 & 37 & 16 & 100 & 68 \\
\hline HG3 & 27 & 14 & 100 & 79 \\
\hline HG4 & 24 & 14 & 98.3 & 76 \\
\hline HG5 & 5 & 20 & 100 & 85 \\
\hline HG6 & 24 & 15 & 98.5 & 67 \\
\hline HG7 & 11 & 6 & 100 & 22 \\
\hline HG8 & 3 & 31 & 98.3 & 90 \\
\hline HG9 & 37 & 15 & 100 & 88 \\
\hline HG10 & 22 & 19 & 100 & 93 \\
\hline
\end{tabular}

\subsubsection{Run Summaries}

Run HG1 was a baseline run at 135\% KMA acid stoichiometry. Run HG2 repeated run HG1, except that the mercury was added as $\mathrm{HgO}$ dissolved in nitric acid. This solution was prepared by adding HgO to concentrated nitric acid and then diluting to a total volume of $100 \mathrm{~mL}$. The resulting solution contained $121,000 \mathrm{mg} / \mathrm{kg}(0.757 \mathrm{M})$ dissolved $\mathrm{Hg}\left(\mathrm{as} \mathrm{Hg}^{2+}\right), 103,000 \mathrm{mg} / \mathrm{L}$ nitrate $(2.02 \mathrm{M})$, and measured total acid of $1.29 \mathrm{M}$. The nitric acid addition for run HG2 was adjusted to account for the amount of nitric acid and nitrate added with this solution.

Because the amount of elemental mercury $\left(\mathrm{Hg}^{0}\right)$ collected in the MWWT was low in runs HG1 and HG2, run HG3 was performed at a lower acid stoichiometry since in past SRAT simulations, lower acid additions often resulted in higher $\mathrm{Hg}^{0}$ recovery. The target acid addition for the remaining runs was then set at $110 \%$ KMA. Run HG3 was the baseline run at this lower acid stoichiometry.

Run HG4 was conducted at the same conditions as HG3 except the SRAT condenser cooling water temperature was maintained at $65^{\circ} \mathrm{C}$ rather than the normally used $25^{\circ} \mathrm{C}$. The DWPF SRAT condenser operates at higher temperatures than the lab system, so the higher temperature was chosen to determine if it had any effect on mercury recovery in the MWWT. The value of $65^{\circ} \mathrm{C}$ is approximately the highest temperature that has occurred at DWPF; typical temperatures range from $50-65^{\circ} \mathrm{C}$ for the condensate and condenser exit gas. The scrubber reservoir liquid volume increased from the initial $800 \mathrm{~mL}$ to $930 \mathrm{~mL}$ during the run, so the amount of uncondensed offgas water was around $130 \mathrm{~mL}$ for the entire run. During the reflux period, two $100 \mathrm{~mL}$ additions of DI water were made to the SRAT vessel to adjust for the approximate loss of water. The addition of water to maintain level during reflux is consistent with DWPF practice where water loss is also noted.

In HG5, the vessel contained a 509 g heel of HG3 SRAT product. About $2393 \mathrm{~g}$ of fresh sludge was then added. To save time, the acid additions were based on only the fresh sludge. Analyses for anions, TIC, and free hydroxide would have delayed this run. The heel was assumed to have no effect on the SRAT 
chemistry even though because the heel is slightly acidic it will neutralize some of the base in the fresh sludge.

Run HG6 tested the effect of excessive antifoam addition. The amount of antifoam added was 10,000 ppm, with 1000 ppm added before nitric acid addition, 2000 ppm added before formic acid addition, 2000 ppm added before going to boiling, and then 2000, 2000, and $1000 \mathrm{ppm}$ additions at 1, 2, and 3 hours into boiling. The extra antifoam solution additions resulted in an increase in the dewater target of $224 \%$ (340 g to $760 \mathrm{~g}$ ). Therefore, the reflux time was decreased to maintain the total boiling time of approximately 18 hours.

As noted previously, the no noble metals run HG7 was intended to be done at $110 \%$ acid stoichiometry, but due to a formic acid batching error, the actual acid stoichiometry was about $167 \%$ and skewed towards higher redox (0.50) than intended (0.20).

The high noble metals additions to run HG8 were intended to approximate the maximum values for a hypothetical HM-only sludge. For run HG9, the only difference between it and the baseline HG3 run was that the agitator was operated at about 900 rpm throughout the run versus the normal 375 rpm.

In HG10, $3200 \mathrm{~g}$ of simulant at about $22.8 \mathrm{wt} \%$ total solids was concentrated by caustic boiling to remove $500 \mathrm{~g}$ of condensate. An additional $300 \mathrm{~g}$ of simulant was then added, and the slurry concentrated to about $28.3 \mathrm{wt} \%$ total solids by removing an additional $271 \mathrm{~g}$ of condensate. These dewatering steps resulted in there being no dewatering required after acid addition. After completion of caustic boiling, the HgO was added to the vessel and the acid additions were done. The noble metals and HgO additions were calculated based on the anticipated composition after the $3500 \mathrm{~g}$ of simulant was concentrated to $2900 \mathrm{~g}$ and $27.5 \mathrm{wt} \%$ total solids. The noble metals were added before caustic boiling.

\subsubsection{Heat Transfer Issues}

In HG10, problems with fouling of the heating rods occurred during caustic boiling. Such problems did not occur in any of the other runs. The SRAT and heating rod temperatures are shown in Figure 3-2. The target maximum heating rod temperature was $165^{\circ} \mathrm{C}$. Heating rod \#2, which was downstream of \#1 relative to the slurry flow, was the heater that always fouled first. This suggests that the obstruction from heating rod \#1 decreased the sludge velocity at heating rod \#2 sufficiently allowing buildup of sludge. The heating rods are approximately two inches apart and are centered on the same diameter.

Heating rod \#2 began to foul almost immediately at the beginning of caustic boiling. The total power input at the start of boiling was about 300W. Heating rod \#2 was then unplugged at $\mathbf{0}$ and the power input to heating rod \#1 was increased from $150 \mathrm{~W}$ to $185 \mathrm{~W}$, but this heat input was insufficient to maintain boiling. Heating rod \#2 was then cleaned and returned to the vessel; fouling again began almost immediately. At 2 , heating rod \#2 was rewired so that it could be operated independently at less power; the total power to both heating rods was still measured. After this change, heating progressed without fouling at total power from 240-280W. 


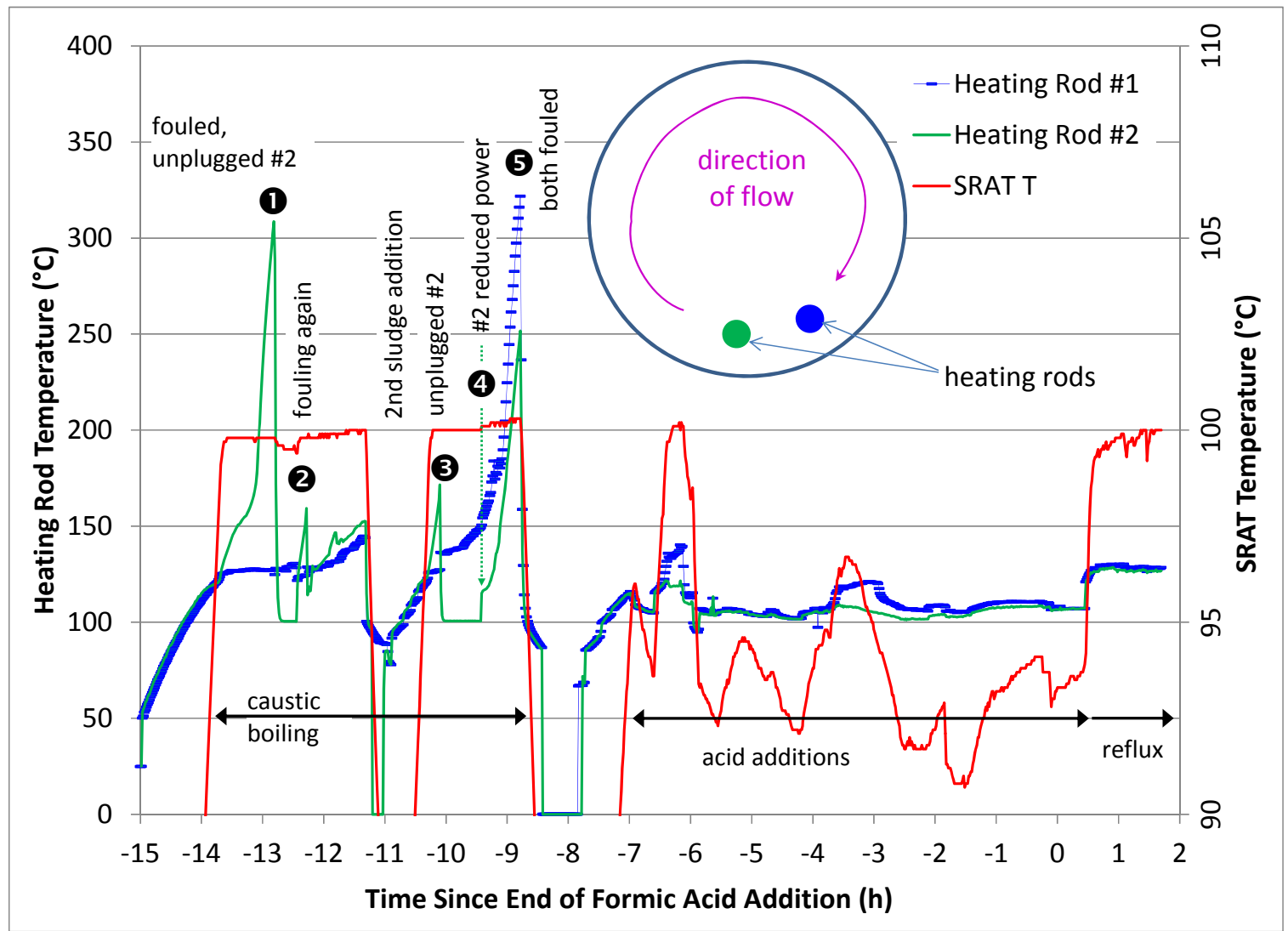

Figure 3-2. HG10 SRAT vessel temperatures

The second sludge addition was then made and heating restarted at $300 \mathrm{~W}$. Heating rod \#2 again began to foul almost immediately, and it was unplugged at 3. Heating then progressed at about 210W with only heating rod \#1, but then it also began to foul. Heating rod \#2 was then returned and operated at reduced power at $\mathbf{4}$; the total power was about 250W. Finally, at $\mathbf{5}$, both heating rods became fouled although boiling did not stop. The target solids concentration had been reached at $\mathbf{5}$, so caustic boiling was terminated. Both heating rods were then cleaned prior to acid additions. During and after acid addition, there were no further problems with heating rod fouling.

\subsubsection{Offgas Compositions}

Typical offgas compositions versus time are shown in Figure 3-3. The total $\mathrm{NO}_{\mathbf{x}}$ concentration was estimated from the measured concentrations and the oxygen depletion due to the reaction $\mathrm{NO}+\mathrm{O}_{2}=\mathrm{NO}_{2}$. The effect of absorption of $\mathrm{NO}_{2}$ into the condensate to form nitric acid was ignored in estimating the amount of $\mathrm{NO}_{\mathrm{x}}$. The offgas concentration profiles for all of the runs were very similar. These plots for runs HG2-HG10 are given in Appendix 10.1. 


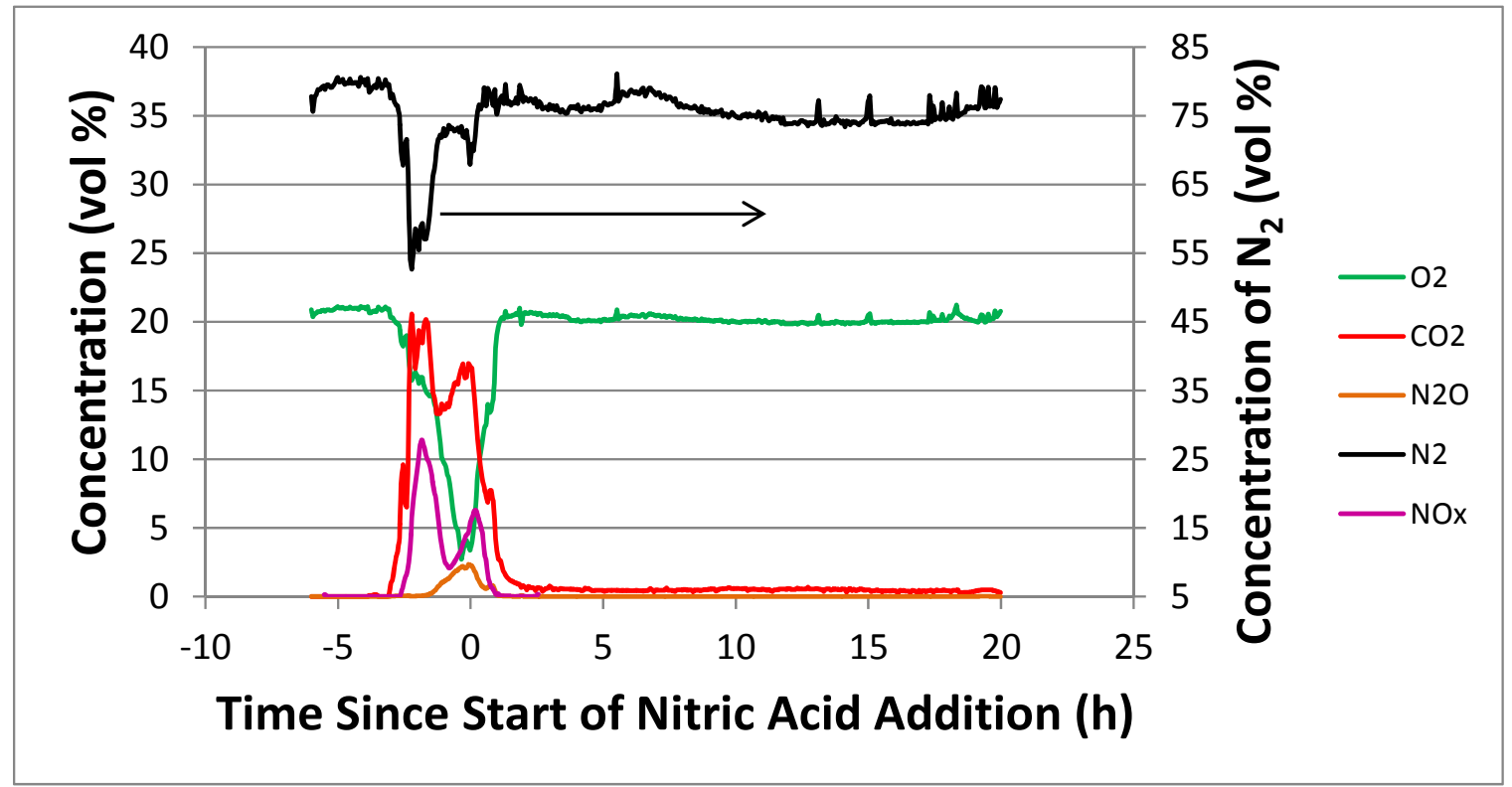

Figure 3-3. HG1 offgas composition

Hydrogen generation was detected only in runs HG1 and HG2 where the acid stoichiometry target was $135 \%$. Negligible hydrogen $(<0.005 \%)$ was detected in the other runs, conducted at $110 \%$ acid, including HG7 with high noble metals concentrations. The hydrogen generation rates for HG1 and HG2 are shown in Figure 3-4.

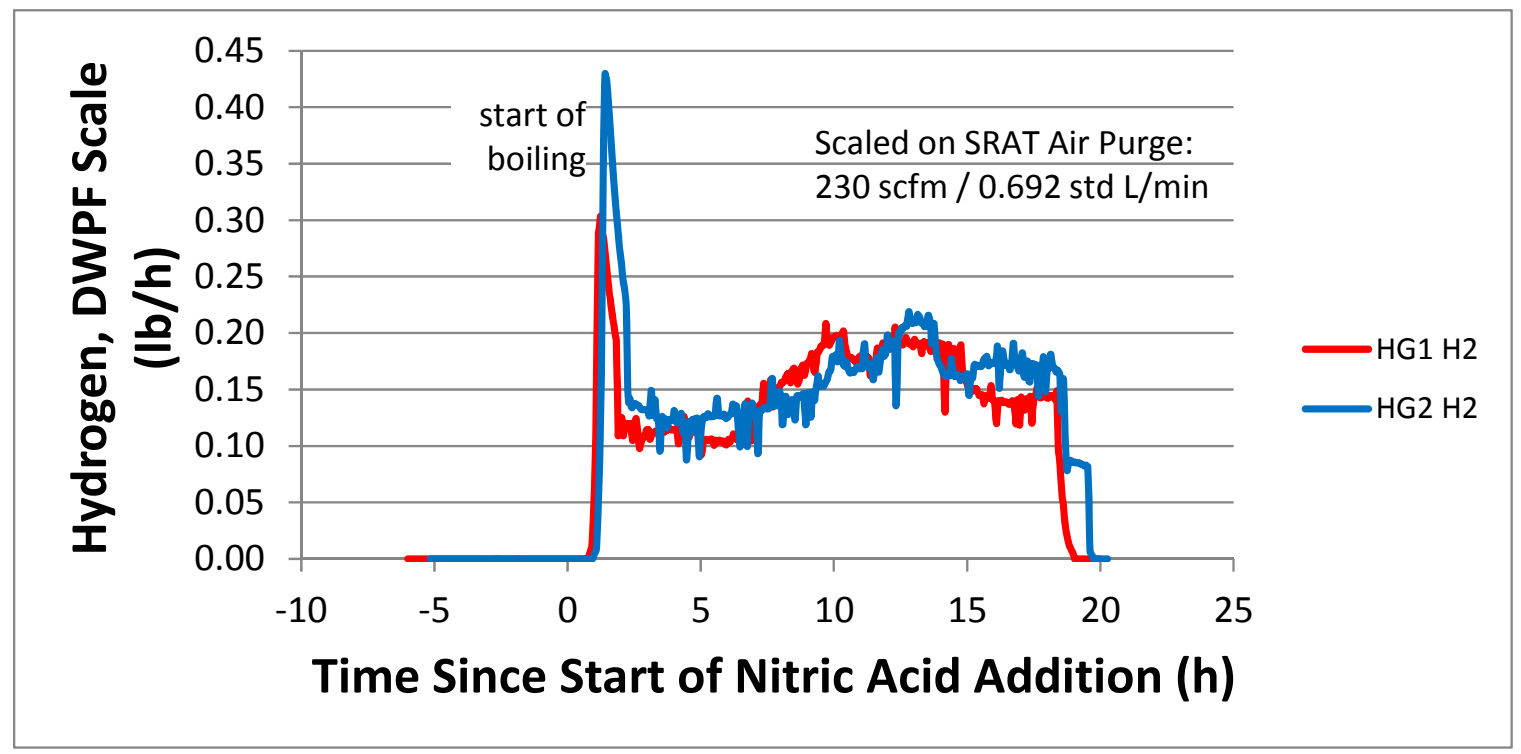

Figure 3-4. HG1 \& 2 hydrogen generation rates

Both of the ACTL GCs used are showing signs of aging. ${ }^{24}$ It was noted that calibration gas results obtained on column A (He, $\mathrm{H}_{2}, \mathrm{O}_{2}, \mathrm{~N}_{2}$ ) were sensitive to the calibration gas pressure (typically just 2-5 psig). After calibration, it was noted that oxygen in room air read in the 17-19 vol\% range, instead of approximately 20.9 vol\%. This observation implies that smaller sample volumes are being injected into column A at atmospheric pressure (experimental pressure) than at the calibration gas pressure. The result is that the absolute values for the $\mathrm{He}, \mathrm{H}_{2}$, and $\mathrm{O}_{2}$ concentrations could be low. Adjustments to the 
concentrations reported in Figure 3-3 and Appendix 10.1 were made. At the beginning and end of each run, where the gas sample is only (almost dry) air, the concentrations of $\mathrm{N}_{2}$ and $\mathrm{O}_{2}$ were adjusted by multiplicative factors so that $\mathrm{N}_{2}$ was about $77.8 \mathrm{vol} \%$ and $\mathrm{O}_{2}$ was about $20.87 \mathrm{vol} \%$ (with $\mathrm{Ar}=0.93$ vol\%). Between the beginning and end of the run, the multiplicative factors were linearly interpolated. The He concentrations were adjusted so that the flowrate calculated from the He purge at the beginning and end of the run equaled the air purge rate measured by the flowmeter. This adjustment was an increase of around $5-10 \%$ for each run, which is consistent with the previous hypothesis that the measured He concentration could be low. This correction could also be applied to the $\mathrm{H}_{2}$ results, so that the values reported in Figure 3-4 could be increased by 5-10\% (e.g., $0.20 \mathrm{lb} / \mathrm{h}$ would become $0.21-0.22 \mathrm{lb} / \mathrm{h}$ ).

\subsubsection{SRAT Product Compositions}

The average calcined (at $1100{ }^{\circ} \mathrm{C}$ ) elemental composition, solids, and densities of the SRAT products are shown in Table 3-10. The average composition for runs HG1-HG10 are given, with the HG10 solids and density results shown separately because HG10 had a higher total solids endpoint.

Table 3-10. SRAT product compositions - calcine elements (wt $\%)$ and properties

\begin{tabular}{|c|c|c|c|}
\hline $\begin{array}{l}\text { Element (wt\%) } \\
\text { or Property }\end{array}$ & Average & $\begin{array}{c} \pm 95 \% \\
\text { Confidence }\end{array}$ & $\begin{array}{l}\text { Run } \\
\text { HG10 }\end{array}$ \\
\hline $\mathrm{Al}$ & 15.3 & 0.32 & \\
\hline $\mathrm{Ba}$ & 0.207 & 0.006 & \\
\hline $\mathrm{Ca}$ & 2.28 & 0.06 & \\
\hline $\mathrm{Cr}$ & 0.179 & 0.011 & \\
\hline $\mathrm{Cu}$ & 0.091 & 0.017 & \\
\hline $\mathrm{Fe}$ & 21.2 & 0.37 & \\
\hline $\mathrm{K}$ & 0.255 & 0.014 & \\
\hline $\mathrm{Mg}$ & 1.67 & 0.04 & \\
\hline $\mathrm{Mn}$ & 3.76 & 0.10 & \\
\hline $\mathrm{Na}$ & 12.9 & 0.32 & \\
\hline $\mathrm{Ni}$ & 0.913 & 0.052 & \\
\hline $\mathrm{P}$ & 0.052 & 0.024 & \\
\hline$\overline{\mathrm{Pb}}$ & $<0.01$ & NA & \\
\hline $\mathrm{S}$ & 0.287 & 0.014 & \\
\hline $\mathrm{Si}$ & 1.62 & 0.08 & \\
\hline $\mathrm{Ti}$ & 0.020 & 0.002 & \\
\hline $\mathrm{Zn}$ & 0.200 & 0.004 & \\
\hline $\mathrm{Zr}$ & 0.446 & 0.028 & \\
\hline & \multicolumn{2}{|c|}{ HG1-HG9 Only } & \\
\hline Slurry Density $(\mathrm{kg} / \mathrm{L})$ & 1.156 & 0.025 & 1.171 \\
\hline Supernate Density $(\mathrm{kg} / \mathrm{L})$ & 1.082 & 0.004 & 1.096 \\
\hline Total Solids (wt\%) & $25.66 \%$ & $0.55 \%$ & $28.43 \%$ \\
\hline Undissolved Solids (wt\%) & $14.72 \%$ & $0.57 \%$ & $16.47 \%$ \\
\hline Supernate Solids (wt\%) & $12.82 \%$ & $0.51 \%$ & $14.32 \%$ \\
\hline Calcine Solids (wt\%) & $16.04 \%$ & $0.63 \%$ & $18.04 \%$ \\
\hline
\end{tabular}

Table 3-11 shows the product anion concentrations for each run. For all runs, the final nitrite concentration was below $300 \mathrm{mg} / \mathrm{kg}$ supernate, with seven runs below the quantification limit of 100 $\mathrm{mg} / \mathrm{kg}$. 
Table 3-11. SRAT product anion compositions ( $\mathrm{mg} / \mathrm{kg}$ supernate)

\begin{tabular}{|c|c|c|c|c|c|c|c|c|c|c|c|c|}
\hline Run $\rightarrow$ & HG1 & HG2 & HG3 & HG4 & HG5 & HG6 & HG7 & HG8 & HG9 & HG10 & Average & $\begin{array}{c} \pm 95 \% \\
\text { Confidence }\end{array}$ \\
\hline $\mathrm{Cl}^{-}$ & 414 & 416 & 466 & 470 & 445 & 444 & 310 & 586 & 438 & 478 & 447 & 49 \\
\hline $\mathrm{NO}_{2}^{-}$ & $<100$ & $<100$ & $<100$ & 288 & $<100$ & 246 & $<100$ & 286 & $<100$ & $<100$ & $<273$ & NA \\
\hline $\mathrm{NO}_{3}^{-}$ & 23950 & 24500 & 21650 & 20950 & 22300 & 20550 & 17382 & 16583 & 25156 & 28100 & 22112 & 2514 \\
\hline $\mathrm{SO}_{4}^{2-}$ & 1600 & 1420 & 1020 & 1145 & 956 & 1120 & 1678 & 793 & 925 & 1190 & 1185 & 210 \\
\hline Oxalate & 1165 & 330 & 179 & 250 & 210 & 320 & 750 & $<100$ & 126 & 102 & 381 & 270 \\
\hline Formate & 57000 & 55850 & 49100 & 48950 & 47700 & 46150 & 79036 & 38757 & 49509 & 54950 & 52700 & 7640 \\
\hline
\end{tabular}

All $\mathrm{PO}_{4}^{3-}$ values were $<100$.

The $\mathrm{pH}$ of the SRAT slurries for runs HG1-10 are shown in Figure 3-5. These pH values are the values measured at the process temperatures.

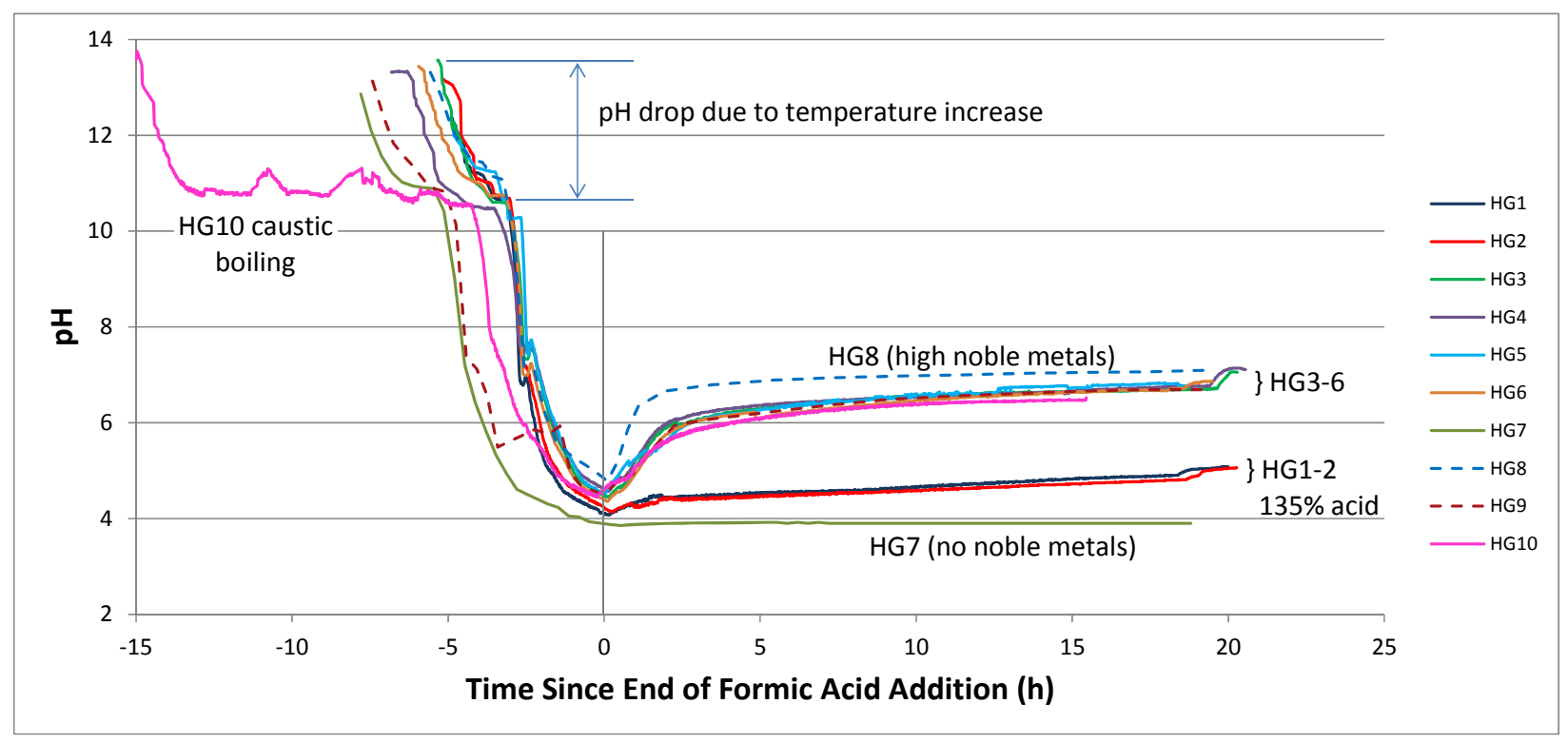

Figure 3-5. Slurry pH during HG runs

\subsection{Mercury Results}

\section{1. $\quad$ Batch Reaction Tests}

The calculated concentrations of the reactants for all 33 batch reaction tests are shown in Appendix 10.2. The measured $\mathrm{pH}$, dissolved mercury concentration, and the appearance of the solutions are given in Table 4- 1 versus the variables $\mathrm{pH}$, presence of nitrite, presence of oxalate, and presence of SRAT sludge solids. The target $\mathrm{pH}$ values of 10 and 6 were missed in some of the tests. These inconsistent $\mathrm{pH}$ values make interpreting the effects of the variables on the dissolved mercury concentration more difficult. 
Table 4-1. Results of batch reaction tests

\begin{tabular}{|c|c|c|c|c|c|c|c|c|c|c|c|c|c|}
\hline 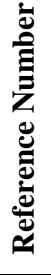 & 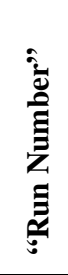 & 离 & 莺 & 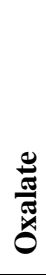 & : & in & 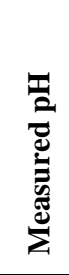 & 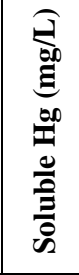 & 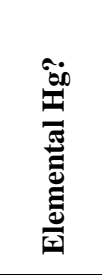 & 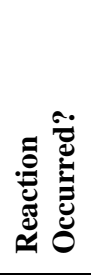 & $\begin{array}{l}\text { Solution } \\
\text { Color }\end{array}$ & Solids Color & Comments \\
\hline 1 & 0a & 13 & 0 & 0 & 0 & 0 & 12.8 & 81 & no & no & orange & orange & unreacted $\mathrm{HgO}$ \\
\hline 2 & $3 a$ & 13 & 0 & + & 0 & 0 & 12.9 & 275 & no & no & orange & orange & unreacted HgO \\
\hline 3 & $6 a$ & 13 & 0 & 0 & + & 0 & 12.8 & 222 & no & no & orange & orange & unreacted $\mathrm{HgO}$ \\
\hline 4 & $7 a$ & 13 & 0 & + & + & 0 & 12.8 & 314 & no & no & orange & orange & unreacted HgO \\
\hline 5 & 1a & 13 & + & 0 & 0 & 0 & 12.8 & 448 & no & no & orange & orange & unreacted $\mathrm{HgO}$ \\
\hline 6 & $4 a$ & 13 & + & + & 0 & 0 & 12.7 & 588 & no & no & orange & orange & unreacted $\mathrm{HgO}$ \\
\hline 7 & $8 a$ & 13 & + & 0 & + & 0 & 12.7 & 325 & no & no & orange & orange & unreacted $\mathrm{HgO}$ \\
\hline 8 & 9a & 13 & + & + & + & 0 & 12.8 & 535 & no & no & orange & orange & unreacted $\mathrm{HgO}$ \\
\hline 9 & $2 a$ & 13 & + & 0 & 0 & + & 12.8 & 100 & no & no & orange & orange & unreacted HgO \\
\hline 10 & $5 a$ & 13 & + & + & 0 & + & 12.8 & 132 & no & no & orange & orange & unreacted $\mathrm{HgO}$ \\
\hline 11 & $10 a$ & 13 & + & 0 & + & + & 12.7 & 113 & no & no & orange & orange & unreacted $\mathrm{HgO}$ \\
\hline 12 & $11 \mathrm{a}$ & 13 & + & + & + & + & 12.7 & 108 & no & no & orange & orange & unreacted $\mathrm{HgO}$ \\
\hline 13 & 0c & 10 & 0 & 0 & 0 & 0 & 10.2 & 78 & no & no & orange & orange & unreacted $\mathrm{HgO}$ \\
\hline 14 & $3 c$ & 10 & 0 & + & 0 & 0 & \begin{tabular}{|l|}
7.8 \\
\end{tabular} & 318 & no & no & orange & orange & unreacted $\mathrm{HgO}$ \\
\hline 15 & $6 c$ & 10 & 0 & 0 & + & 0 & 7.9 & 183 & no & no & orange & orange & unreacted $\mathrm{HgO}$ \\
\hline 16 & $7 \mathrm{c}$ & 10 & 0 & + & + & 0 & 9.7 & 336 & no & no & orange & orange & unreacted $\mathrm{HgO}$ \\
\hline 17 & 1c & 10 & + & 0 & 0 & 0 & 8.2 & 72 & yes & yes & clear & $\mathrm{Hg}^{0}$ & initially $\mathrm{Hg}^{0}$ \& some yellow $\mathrm{HgO}$, then all $\mathrm{Hg}^{0}$ \\
\hline 18 & 4c & 10 & + & + & 0 & 0 & 8.2 & 0 & maybe & yes & clear & gray & $\begin{array}{l}\text { gray film floating on top, solution turned blue } \\
\text { midway thru run, then clear }\end{array}$ \\
\hline 19 & 8c & 10 & + & 0 & + & 0 & 9.8 & 13 & yes & yes & clear & $\mathrm{Hg}^{0}$ & no other solids \\
\hline 20 & 9c & 10 & + & + & + & 0 & 9.8 & 9 & maybe & yes & clear & gray & $\begin{array}{l}\text { solids do not appear to be } \mathrm{Hg}^{0} \text { (maybe } \mathrm{Hg}^{0} \text { on } \\
\text { white solids) }\end{array}$ \\
\hline 21 & 2c & 10 & + & 0 & 0 & + & 10.0 & 205 & maybe & yes & clear & gray-green & powdery precipitate \\
\hline 22 & 5c & 10 & + & + & 0 & + & 10.0 & 183 & maybe & yes & clear & gray-brown & $\begin{array}{l}\text { gray solids look like small beads of } \mathrm{Hg}^{0} \text {, white \& } \\
\text { gray solids floating }\end{array}$ \\
\hline 23 & 10c & 10 & + & 0 & + & + & 10.0 & 2 & maybe & yes & yellow & gray, orange & mostly orange unreacted HgO, some gray solids \\
\hline 24 & 11c & 10 & + & + & + & + & 10.0 & 0 & yes & yes & clear & white, gray & $\begin{array}{l}\text { gray solids look like small beads of } \mathrm{Hg}^{0} \text {, white \& } \\
\text { gray solids floating, may be } \mathrm{Hg}^{0} \text { on sludge }\end{array}$ \\
\hline 25 & Ob & 6 & 0 & 0 & 0 & 0 & 3.0 & 524 & no & no & orange & orange & unreacted $\mathrm{HgO}$ \\
\hline 26 & $3 \mathrm{~b}$ & 6 & 0 & + & 0 & 0 & 7.1 & 232 & no & no & orange & orange & unreacted $\mathrm{HgO}$ \\
\hline 27 & $6 \mathrm{~b}$ & 6 & 0 & 0 & + & 0 & 8.1 & 1025 & no & no & orange & orange & unreacted $\mathrm{HgO}$ \\
\hline 28 & $7 \mathrm{~b}$ & 6 & 0 & + & + & 0 & 7.3 & 1405 & no & no & orange & orange & unreacted HgO \\
\hline 29 & $1 \mathrm{~b}$ & 6 & + & 0 & 0 & 0 & 5.2 & 16 & yes & yes & clear & $\mathrm{Hg}^{0}$ & $\begin{array}{l}\text { immediately went clear } \& \mathrm{Hg}^{0} \text {, then bluish, then } \\
\text { clear again }\end{array}$ \\
\hline 30 & $4 \mathrm{~b}$ & 6 & + & + & 0 & 0 & 5.4 & 0 & no & yes & clear & white & $\begin{array}{l}\text { immediately went clear \& some } \mathrm{Hg}^{0} \text {, then floating } \\
\mathrm{Hg}^{0} \text {, then white solids above } 75^{\circ} \mathrm{C} \text {, no apparent } \\
\mathrm{Hg}^{0}\end{array}$ \\
\hline 31 & $8 b$ & 6 & + & 0 & + & 0 & 6.2 & 0 & yes & yes & clear & gray & $\begin{array}{l}\text { immediately went clear } \& \mathrm{Hg}^{0} \text {, then bluish, then } \\
\text { clear again, gray solids }\end{array}$ \\
\hline 32 & $9 b$ & 6 & + & + & + & 0 & 6.4 & 0 & maybe & yes & clear & gray & $\begin{array}{l}\text { whitish solids first, then gray (maybe } \mathrm{Hg}^{0} \text { on white } \\
\text { solids) }\end{array}$ \\
\hline 33 & $2 b$ & 6 & + & 0 & 0 & + & 5.8 & 0 & maybe & yes & clear & brown-green & may be gray + brown \\
\hline 34 & $5 b$ & 6 & + & + & 0 & + & 7.7 & 2 & maybe & yes & green & gray-green & may be gray + brown \\
\hline 35 & $10 \mathrm{~b}$ & 6 & + & 0 & + & + & 7.4 & 0 & maybe & yes & clear & brown & may be gray + brown \\
\hline 36 & $11 b$ & 6 & + & + & + & + & 8.2 & 0 & maybe & yes & clear & brown & may be gray + brown \\
\hline
\end{tabular}


For all tests at near $\mathrm{pH} 13$, there was no noticeable formation of $\mathrm{Hg}^{0}$ metal. The appearances of the solutions after heating were similar to the appearances before heating: orange aqueous with orange (HgO) solids. In all of these tests, the dissolved mercury concentration was significantly higher than the solubility of $\mathrm{HgO}$ of about $36 \mathrm{mg} \mathrm{Hg} / \mathrm{L}$ at $25^{\circ} \mathrm{C}$ predicted from the literature. The values measured (81$588 \mathrm{mg} \mathrm{Hg} / \mathrm{L}$ ) all exceed $36 \mathrm{mg} / \mathrm{L}$, and some even exceed the solubility at $100^{\circ} \mathrm{C}$ of $317 \mathrm{mg} \mathrm{Hg} / \mathrm{L}$. The predicted solubilities (OLIAnalyzer) ${ }^{25}$ of $\mathrm{HgO}$ as a function of $\mathrm{pH}$ and of temperature are shown in Figure 4-1 and Figure 4-2, respectively.

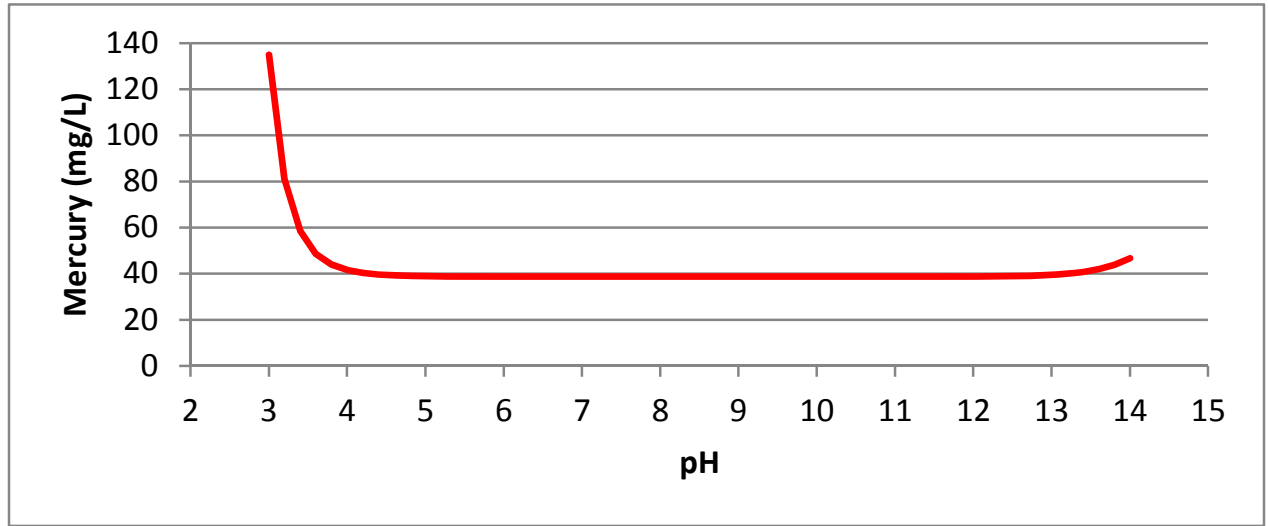

Figure 4-1. Predicted solubility of $\mathrm{HgO}$ versus $\mathrm{pH}$ at $25^{\circ} \mathrm{C}$

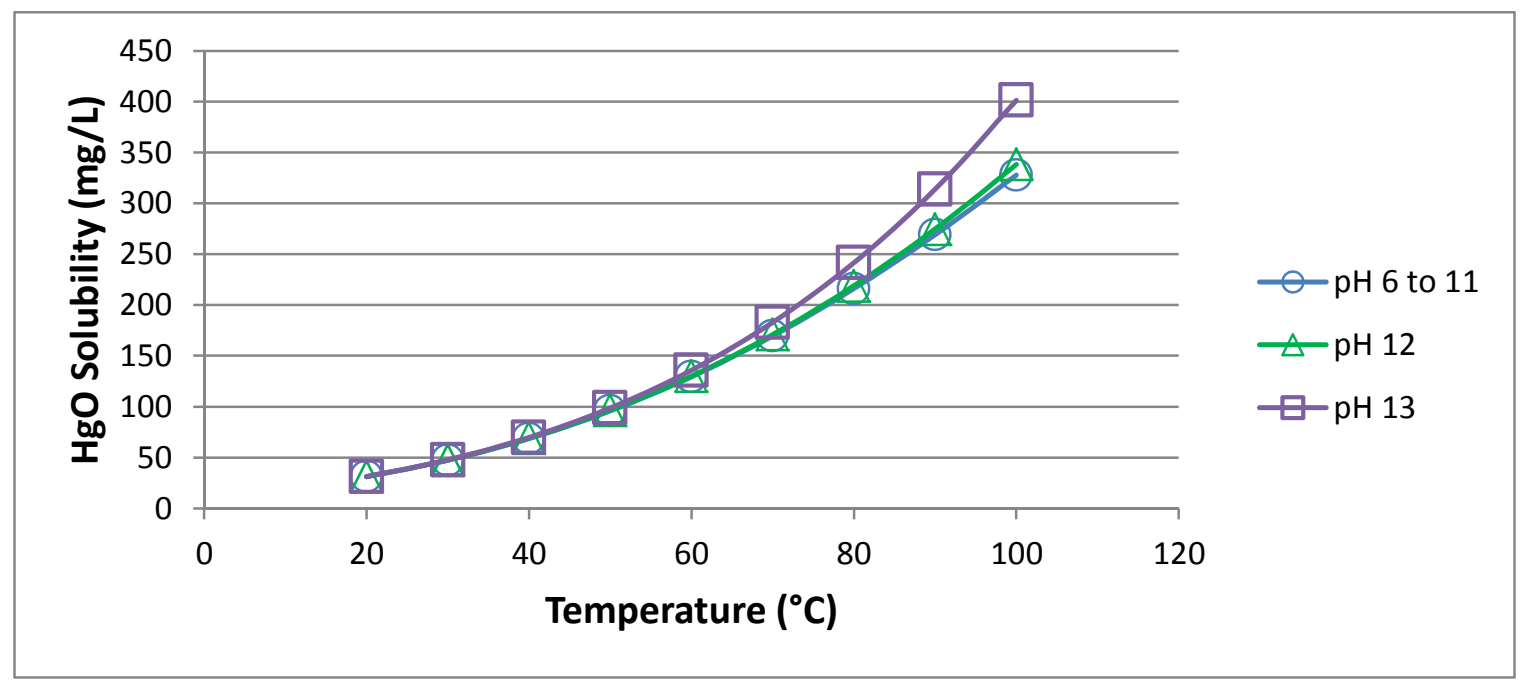

Figure 4-2. Predicted solubility of HgO versus temperature

There was also no evidence of $\mathrm{Hg}^{0}$ formation in water at $\mathrm{pH}$ around 10 and 6 . This result is not unexpected because there is no reducing agent (formate) present. However, the dissolved mercury concentrations were found to vary with $\mathrm{pH}$. Figure 4-3 shows that the dissolved mercury concentration may be enhanced by nitrite at $\mathrm{pH}$ less than 9 . The dissolved mercury concentration in supernate was generally highest at $\mathrm{pH} 13$ with lesser values at $\mathrm{pH} 10$ and $\sim 6$. At $\mathrm{pH}$ 5-8, all concentrations were less than $20 \mathrm{mg} / \mathrm{L}$ except for one point (see Figure 4-4). Figure 4-5 shows that the presence of SRAT heel solids significantly reduced the mercury concentration in supernate simulant at $\mathrm{pH} 13$. The concentration in water at $\mathrm{pH} 13$ with no solids was also higher than in supernate with solids except for one point. These data indicate that dissolved mercury from $\mathrm{HgO}$ is reduced by the presence of solids and increased by the 
presence of the supernate components nitrate and formate. Figure 4-6 shows that the dissolved Hg concentration may be enhanced slightly by the presence of oxalate at $\mathrm{pH} 13$.

With supernate simulant (containing reductant formate) at $\mathrm{pH} 10$ and 6, most of the mercury solubilities were zero or very low; however, $\mathrm{pH} 6$ tests in rows 21-22 in Table 4-1 were unusually high at around 200 $\mathrm{mg} / \mathrm{L}$. The reduction of $\mathrm{HgO}$ to $\mathrm{Hg}^{0}$ metal by formate should be more complete at $\mathrm{pH} 6$ than at $\mathrm{pH} 10$, and the data generally support this prediction. The actual presence of elemental $\mathrm{Hg}^{0}$ in some tests was obvious by the formation of beads of $\mathrm{Hg}$ metal. However, in many tests, as indicated in the comments, the presence of $\mathrm{Hg}$ metal was difficult to determine. When insoluble sodium oxalate was present, the $\mathrm{Hg}$ metal appears to have precipitated from solution to form a gray coating on the oxalate, or the $\mathrm{Hg}^{0} \mathrm{was}$ not reduced and was converted to $\mathrm{HgC}_{2} \mathrm{O}_{4}$ mercuric oxalate. Further tests with oxalate may be warranted due to the expected increase from tank cleaning in the oxalate content of future DWPF batches. With SRAT solids present, the products were brown-green which may have been a mixture of $\mathrm{Hg}$ metal on the surface of the sludge solids and oxalate. The row 23 data at $\mathrm{pH} 10$ with supernate, nitrite, and solids stands out because the products were mostly unreacted $\mathrm{HgO}$ in contrast to all the other tests at $\mathrm{pH} 10$ or less where the $\mathrm{HgO}$ was reduced to $\mathrm{Hg}^{0}$ metal. The row 30 data was also unusual because the product was white like sodium oxalate and there was no evidence of $\mathrm{Hg}^{0}$ metal beads or coating.

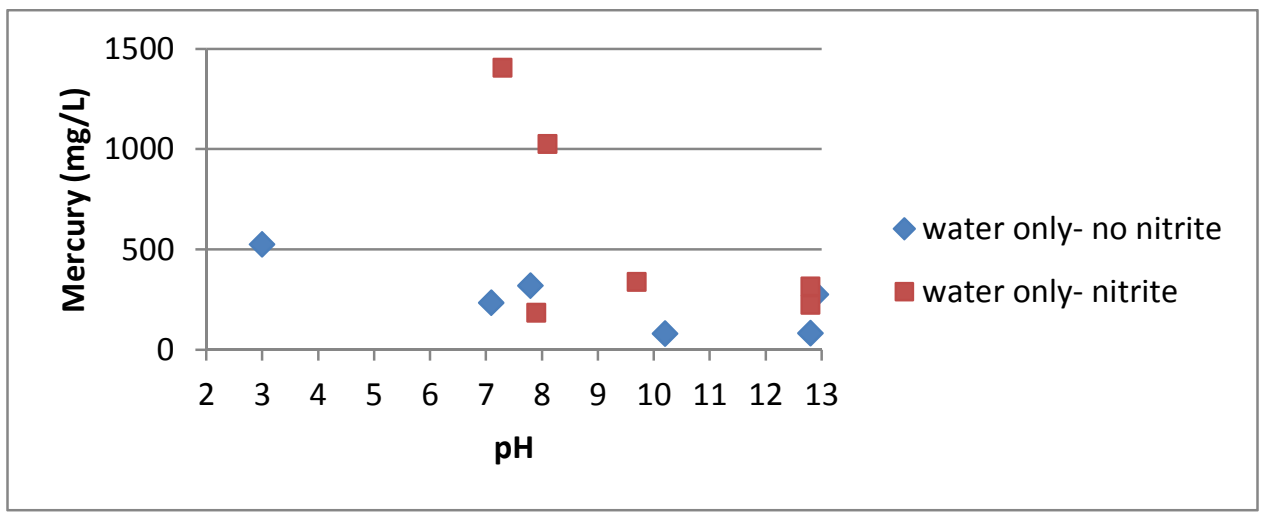

Figure 4-3. Measured mercury concentration in water versus pH for batch reaction tests

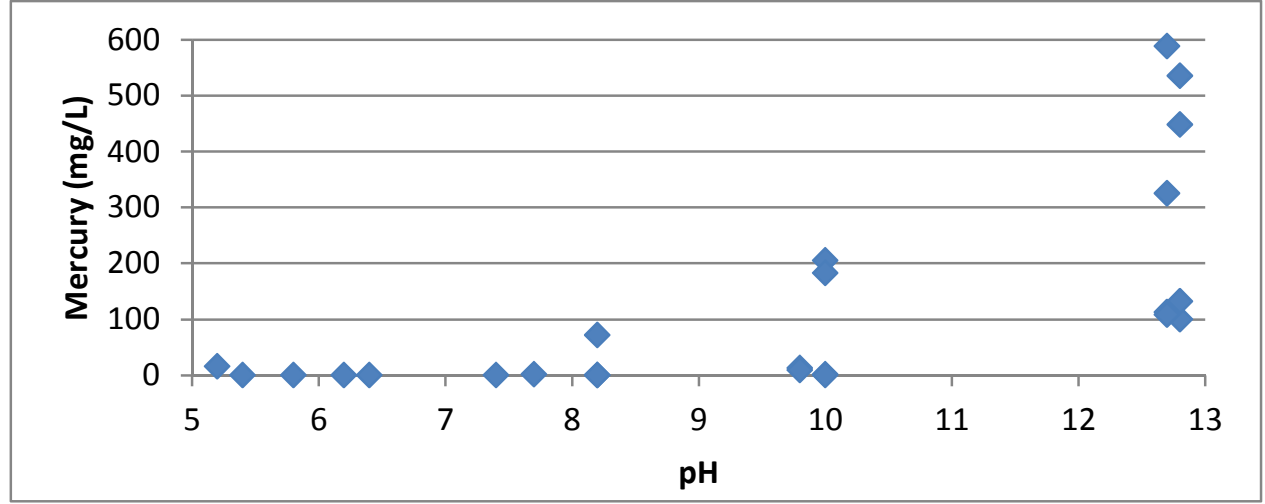

Figure 4-4. Measured mercury concentration in supernate simulant versus pH for batch reaction tests 


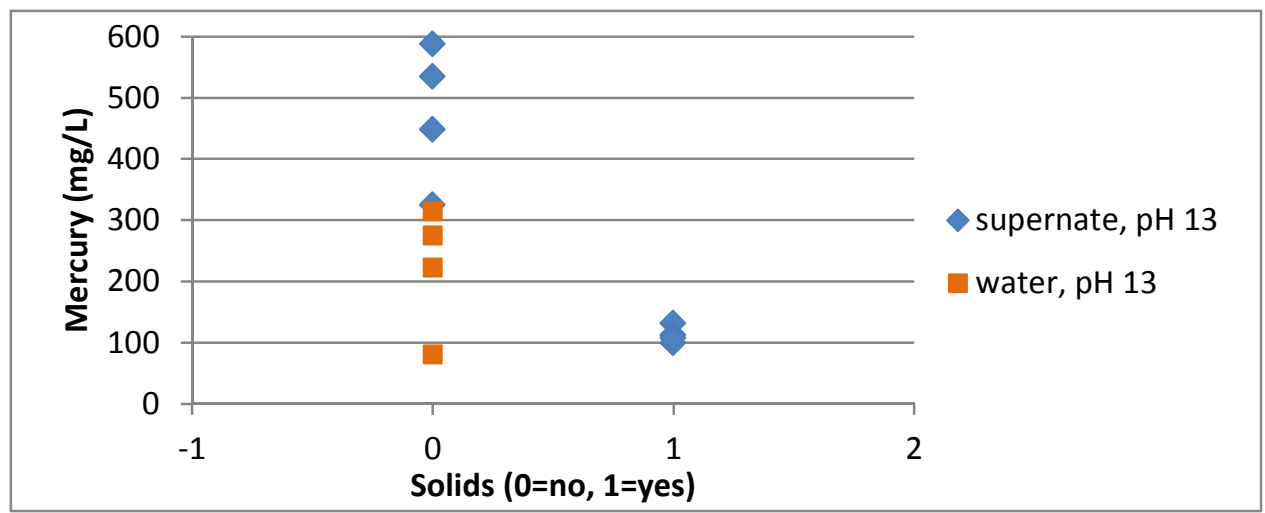

Figure 4-5. Measured dissolved mercury concentration at pH 13 versus presence of solids for batch reaction tests

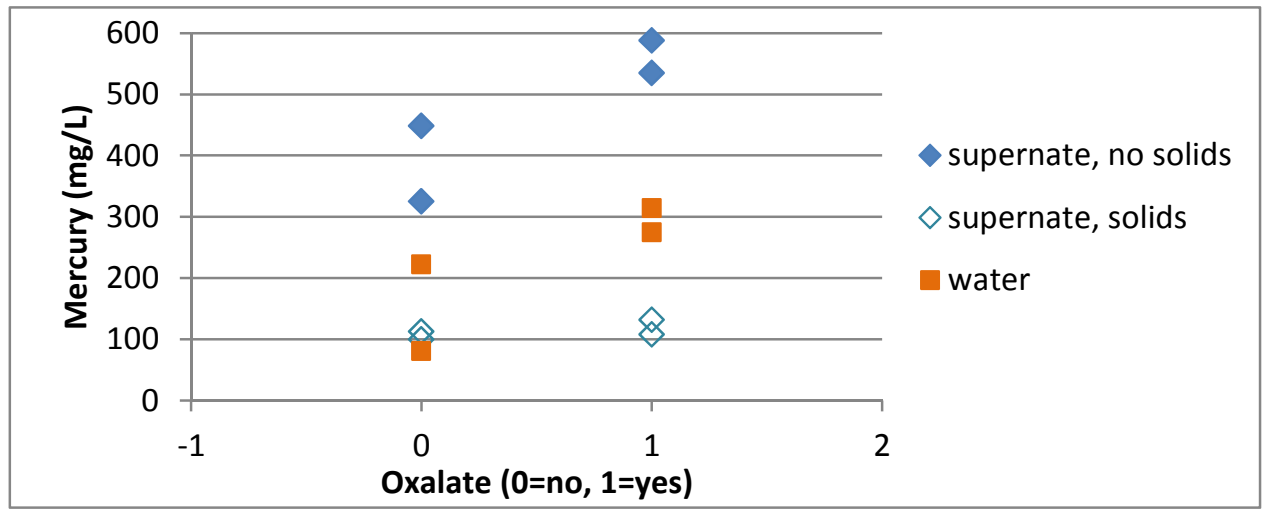

Figure 4-6. Measured dissolved mercury concentration at $\mathrm{pH} 13$ versus presence of sodium oxalate for batch reaction tests

\section{2. $\quad$ Lab-Scale SRAT HG Runs \& Mercury Balances}

\subsubsection{Mercury Recovery and Material Balance}

Data from the HG runs and some data from SB6, SB7a, and glycolic/formic acid (GF) flowsheet testing is discussed below. Careful recovery of elemental Hg from the SRAT or SME products from six of ten SB7a runs and four (of greater than 30) GF runs was performed. To recover as much mercury as possible from the products, the products were dried after slurry samples were taken. The dried products were then examined and segregated elemental mercury was collected and weighed to determine the amount of $\mathrm{Hg}$ not dispersed throughout the slurry. Similar sampling was done for the HG runs, except the segregated elemental mercury was removed from the slurry heels in the vessels.

For the purpose of the discussion of the mercury material balance data, several terms will be defined to more clearly describe what particular mercury location is being discussed. Referring to Figure 4-7, removed (or removal) and stripping are not defined the same. Stripping will correspond to the amount of recovery in the MWWT including the amount in deposits in the MWWT and SRAT condenser. The amounts that collect in the Scrubber (SMECT) liquid and FAVC condensate are generally small compared to the total amount of Hg in the SRAT. Removed is the sum of recovered and segregated, where segregated is the amount of mercury that accumulates as elemental $\mathrm{Hg}$ in the bottom of the SRAT. 
Removal can be considered to be "the mercury that isn't suspended in the slurry any more". The stripping factor, or recovery factor is then the amount of water evaporation required per amount of $\mathrm{Hg}$ recovered. Similarly, the removal factor is the amount of water evaporation required per amount of $\mathrm{Hg}$ removed by stripping and segregation The amount of mercury retained is the amount measured in a slurry sample analysis. The Hg added should be equal to recovered + segregated + retained, but this will only be true if the material balance closure is $100 \%$. The presence of unreacted $\mathrm{HgO}$ in some runs results in the overestimation of the amount of $\mathrm{Hg}^{0}$ segregated in the SRAT bottom because it is counted with the reduced $\mathrm{Hg}^{0}$, when it should really not be included at all; the amount of unreacted $\mathrm{HgO}$ was not quantified.

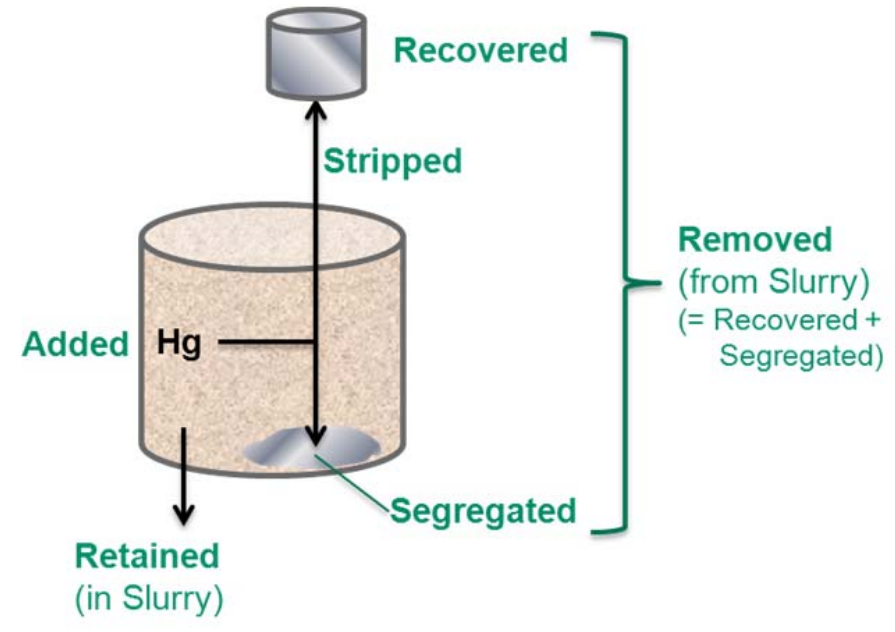

Figure 4-7. Terminology for distribution of mercury in the CPC

Figure 4-8 shows the Hg recovered in the Mercury Water Wash Tank as the percentage of the amount added to the SRAT. The total time at boiling for each run was about 18 hours. Any mercury that deposited in the SRAT condenser or MWWT was included in the amount for the last sample. This is very apparent for the HG8 run, where a significant amount of the Hg collected in the offgas system as deposits. For many of the runs, the accumulation rate of $\mathrm{Hg}$ in the MWWT decreased to a steady rate at about 5-7 hours after the end of formic acid addition. Note that for the HG5 run, that used the heel from HG3 that contained all the segregated $\mathrm{Hg}$ from that run, there was some accumulation of $\mathrm{Hg}$ in the MWWT during formic acid addition. For some of the other runs, very small amounts of Hg were seen during formic acid addition, but the amounts were too small to be measured. The HG7 run, where too much formic acid was used, had a significant amount of Hg in the MWWT at the end of formic acid addition. The reason for this is the formic acid addition lasted about six hours which would give sufficient time for some $\mathrm{Hg}$ to be stripped even at $93^{\circ} \mathrm{C}$. 


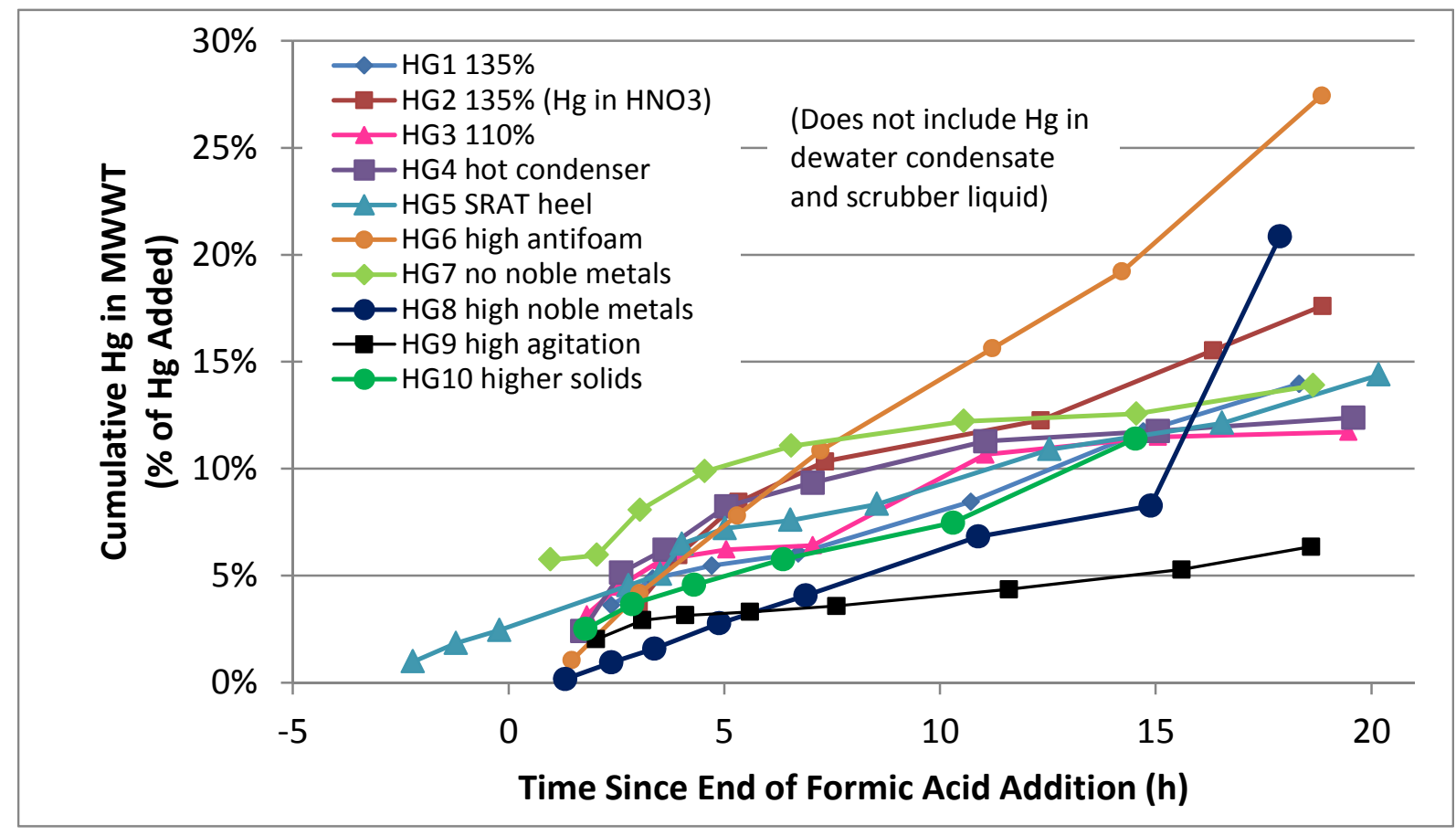

Figure 4-8. Percent recovery of mercury in the MWWT + SRAT condenser

The high noble metals HG8 and high antifoam HG6 runs had the highest Hg recovery in the MWWT + SRAT condenser. A significant portion of the Hg in HG8 was stuck to condenser and MWWT walls and was not counted until the final data point, hence the large jump after $15 \mathrm{~h}$. Surprisingly, the high agitation run HG9 had the lowest recovery. Except for these three runs, all of the recoveries were between 12-17\%.

Because the data from the SB6 and SB7a runs were for total boiling times of about 36 hours, data from the HG runs data was extrapolated to 36 hours using the same slopes as the last several data points. Although it is not known whether the rate of accumulation of $\mathrm{Hg}$ in the MWWT would continue as assumed, this extrapolation was the only way to compare the data on a similar basis. There was data for the SB6 and SB7a runs for the amount of Hg found in the slurry samples, but there was no data for the amount of Hg in the MWWT as a function of time; only final MWWT masses were recorded. Figure 4-9 shows the HG runs data extrapolated to 36 hours. 


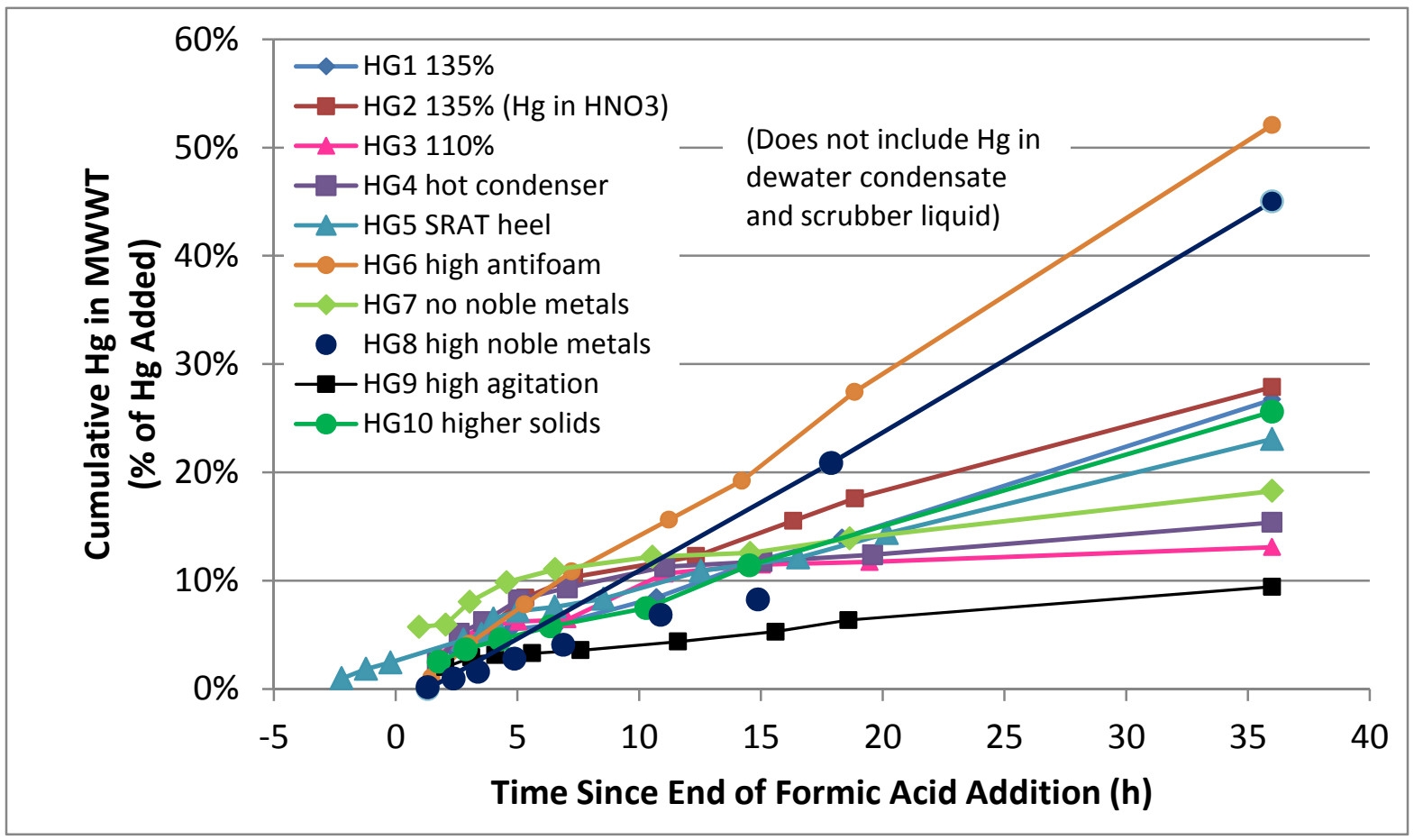

Figure 4-9. Extrapolated percent recovery of mercury in the MWWT + SRAT condenser

The extrapolated recovery data and data from the SB6, SB7a, and GF runs are shown in Table 4-2. In this table, the recovery of $\mathrm{Hg}$ in the offgas system is tabulated rather than just the recovery in the MWWT. The HG runs data are shown from highest to lowest MWWT recovery. For these comparisons, the amount of $\mathrm{Hg}$ in the SRAT slurry and segregated in the bottom were assumed to be the measured (unextrapolated) values. Because the material balances did not close to $100 \%$, there was no way to know how to extrapolate these values. A comparison of the un-extrapolated and extrapolated recovery data is given in Table 4-3. 
Table 4-2. Distribution of mercury in SRAT or SME products for HG, SB6, and SB7a runs.

Percentages are percent of $\mathrm{Hg}$ added to SRAT

\begin{tabular}{|c|c|c|c|c|c|c|c|c|c|}
\hline SRAT(/SME) RUN & $\begin{array}{c}\text { Found in } \\
\text { Offgas } \\
\text { System }^{\circledR} \\
(\%)\end{array}$ & \begin{tabular}{|c|} 
Not \\
Found in \\
Offgas \\
System \\
$(\%)$ \\
\end{tabular} & $\begin{array}{l}\text { Found } \\
\text { in } \\
\text { SRAT } \\
(\%)\end{array}$ & $\begin{array}{c}\text { Segregated } \\
\text { in SRAT as } \\
\mathrm{Hg}^{0} \text { Metal } \\
(\%)\end{array}$ & $\begin{array}{c}\text { Retained } \\
\text { in SRAT } \\
\text { Slurry } \\
(\%)\end{array}$ & $\begin{array}{c}\text { Segregated } \\
+ \\
\text { Recovered } \\
(\%)\end{array}$ & $\begin{array}{c}\text { Material } \\
\text { Balance } \\
\text { Closure } \\
(\%)\end{array}$ & $\begin{array}{c}\text { Material } \\
\text { Balance } \\
\text { Closure } \\
\text { w/o Hg } \\
(\%)\end{array}$ & $\begin{array}{c}\text { Acid } \\
\text { Stoich. } \\
(\%) \\
\end{array}$ \\
\hline HG6 (high antifoam) & $48 \%$ & $52 \%$ & $49 \%$ & $9 \%$ & $40 \%$ & $57 \%$ & $97 \%$ & $88 \%$ & 110 \\
\hline HG8 (high noble metals) & $44 \%$ & $56 \%$ & $36 \%$ & $4 \%$ & $32 \%$ & $48 \%$ & $81 \%$ & $76 \%$ & 110 \\
\hline $\mathrm{HG} 2\left(\mathrm{Hg}\left(\mathrm{NO}_{3}\right)_{2}\right)$ & $30 \%$ & $70 \%$ & $29 \%$ & $24 \%$ & $5 \%$ & $54 \%$ & $59 \%$ & $36 \%$ & 135 \\
\hline HG1 & $29 \%$ & $71 \%$ & $39 \%$ & $31 \%$ & $8 \%$ & $60 \%$ & $68 \%$ & $38 \%$ & 135 \\
\hline HG5 (heel) & $26 \%$ & $74 \%$ & $73 \%$ & $71 \%$ & $2 \%$ & $97 \%$ & $99 \%$ & $28 \%$ & 110 \\
\hline HG3 & $22 \%$ & $78 \%$ & $2 \%$ & NA* & $2 \%$ & NA & NA & $24 \%$ & 110 \\
\hline HG7 (no noble metals) & $18 \%$ & $82 \%$ & $79 \%$ & $77 \%$ & $1 \%$ & $95 \%$ & $96 \%$ & $19 \%$ & 170 \\
\hline HG4 (hot condenser) & $13 \%$ & $87 \%$ & $53 \%$ & $51 \%$ & $2 \%$ & $64 \%$ & $66 \%$ & $15 \%$ & 110 \\
\hline HG10 (high solids) & $12 \%$ & $88 \%$ & $47 \%$ & $40 \%$ & $7 \%$ & $52 \%$ & $59 \%$ & $19 \%$ & 110 \\
\hline HG9 (high agitation) & $9 \%$ & $91 \%$ & $57 \%$ & $51 \%$ & $6 \%$ & $60 \%$ & $66 \%$ & $14 \%$ & 110 \\
\hline AVERAGE & $25 \%$ & $75 \%$ & $46 \%$ & $40 \%$ & $11 \%$ & $65 \%$ & $72 \%$ & $36 \%$ & \\
\hline GF17 (G/F=40/60) & $34 \%$ & $66 \%$ & $29 \%$ & $0 \%$ & $29 \%$ & $34 \%$ & $63 \%$ & $63 \%$ & 125 \\
\hline GF18 $(\mathrm{G} / \mathrm{F}=50 / 50)$ & $63 \%$ & $37 \%$ & $8 \%$ & $0 \%$ & $8 \%$ & $63 \%$ & $70 \%$ & $70 \%$ & 125 \\
\hline GF20 (G/F=60/40) & $19 \%$ & $81 \%$ & $63 \%$ & $44 \%$ & $19 \%$ & $63 \%$ & $82 \%$ & $38 \%$ & 125 \\
\hline GF19 $(\mathrm{G} / \mathrm{F}=70 / 30)$ & $48 \%$ & $52 \%$ & $40 \%$ & $2 \%$ & $37 \%$ & $50 \%$ & $88 \%$ & $85 \%$ & 125 \\
\hline AVERAGE & $41 \%$ & $59 \%$ & $35 \%$ & $12 \%$ & $23 \%$ & $53 \%$ & $76 \%$ & $64 \%$ & \\
\hline \multicolumn{10}{|l|}{ SB7 are SME Products } \\
\hline SB7-1 & $34 \%$ & $66 \%$ & $56 \%$ & $53 \%$ & $2 \%$ & $87 \%$ & $90 \%$ & $36 \%$ & 100 \\
\hline SB7-5 & $33 \%$ & $67 \%$ & $53 \%$ & $44 \%$ & $10 \%$ & $77 \%$ & $87 \%$ & $43 \%$ & 100 \\
\hline SB7-3 & $30 \%$ & $70 \%$ & $12 \%$ & $8 \%$ & $4 \%$ & $38 \%$ & $41 \%$ & $33 \%$ & 110 \\
\hline SB7-4 & $25 \%$ & $75 \%$ & $22 \%$ & $19 \%$ & $2 \%$ & $44 \%$ & $47 \%$ & $27 \%$ & 110 \\
\hline SB7-8 & $24 \%$ & $76 \%$ & $68 \%$ & $64 \%$ & $4 \%$ & $88 \%$ & $92 \%$ & $28 \%$ & 110 \\
\hline SB7-6 & $16 \%$ & $84 \%$ & $45 \%$ & $44 \%$ & $1 \%$ & $60 \%$ & $61 \%$ & $17 \%$ & 150 \\
\hline AVERAGE & $27 \%$ & $73 \%$ & $43 \%$ & $39 \%$ & $4 \%$ & $66 \%$ & $70 \%$ & $31 \%$ & \\
\hline & & & & & & & & & \\
\hline SB6-21 & $77 \%$ & $23 \%$ & $\dagger$ & & $7 \%$ & & & $84 \%$ & 96 \\
\hline SB6-12 & $61 \%$ & $39 \%$ & & & $14 \%$ & & & $75 \%$ & 100 \\
\hline SB6-10 & $47 \%$ & $53 \%$ & & & $41 \%$ & & & $89 \%$ & 103 \\
\hline SB6-24 & $58 \%$ & $42 \%$ & & & $21 \%$ & & & $79 \%$ & 112 \\
\hline SB6-14 & $54 \%$ & $46 \%$ & & & $19 \%$ & & & $73 \%$ & 117 \\
\hline SB6-23 & $49 \%$ & $51 \%$ & & & $12 \%$ & & & $61 \%$ & 113 \\
\hline SB6-15 & $21 \%$ & $79 \%$ & & & $11 \%$ & & & $32 \%$ & 133 \\
\hline SB6-11 & $19 \%$ & $81 \%$ & & & $4 \%$ & & & $23 \%$ & 150 \\
\hline SB6-13 & $19 \%$ & $81 \%$ & $32 \%$ & $26 \%$ & $6 \%$ & $45 \%$ & $50 \%$ & $25 \%$ & 150 \\
\hline SB6-22 & $18 \%$ & $82 \%$ & & & $1 \%$ & & & $19 \%$ & 150 \\
\hline AVERAGE & $42 \%$ & $58 \%$ & & & $14 \%$ & & & $56 \%$ & \\
\hline
\end{tabular}

${ }^{\circledR}$ HG runs data extrapolated to $36 \mathrm{~h}$ boiling

* NA: not available because heel was used in HG5 run

† blank cells: not measured 


\section{Table 4-3. Comparison of extrapolated and un-extrapolated distribution of mercury in SRAT products for HG runs.}

Percentages are percent of $\mathrm{Hg}$ added to SRAT

\begin{tabular}{|c|c|c|c|c|c|c|c|c|c|}
\hline SRAT(/SME) RUN & \begin{tabular}{|c} 
Found in \\
Offgas \\
System ${ }^{\circ}$ \\
$(\%)$ \\
\end{tabular} & \begin{tabular}{|c|} 
Not Found \\
in Offgas \\
System \\
$(\%)$
\end{tabular} & $\begin{array}{c}\text { Found } \\
\text { in } \\
\text { SRAT } \\
(\%)\end{array}$ & $\begin{array}{c}\text { Segregated } \\
\text { in SRAT as } \\
\mathrm{Hg}^{0} \text { Metal } \\
(\%)\end{array}$ & $\begin{array}{c}\text { Retained } \\
\text { in SRAT } \\
\text { Slurry } \\
(\%) \\
\end{array}$ & \begin{tabular}{|c} 
Segregated \\
+ \\
Recovered \\
$(\%)$
\end{tabular} & $\begin{array}{c}\text { Material } \\
\text { Balance } \\
\text { Closure } \\
(\%) \\
\end{array}$ & $\begin{array}{c}\text { Material } \\
\text { Balance } \\
\text { Closure w/o } \\
\mathbf{H g}^{\mathbf{0}}(\%) \\
\end{array}$ & \begin{tabular}{|c} 
Acid \\
Stoich \\
$(\%)$ \\
\end{tabular} \\
\hline \multicolumn{10}{|c|}{\begin{tabular}{|l|l|l|l|l|l|} 
EXTRAPOLATED & & & & & \\
\end{tabular}} \\
\hline HG6 (high antifoam) & $48 \%$ & $52 \%$ & $49 \%$ & $9 \%$ & $40 \%$ & $57 \%$ & $97 \%$ & $88 \%$ & 110 \\
\hline HG8 (high noble metals) & $44 \%$ & $56 \%$ & $36 \%$ & $4 \%$ & $32 \%$ & $48 \%$ & $81 \%$ & $76 \%$ & 110 \\
\hline $\mathrm{HG} 2\left(\mathrm{Hg}\left(\mathrm{NO}_{3}\right)_{2}\right)$ & $30 \%$ & $70 \%$ & $29 \%$ & $24 \%$ & $5 \%$ & $54 \%$ & $59 \%$ & $36 \%$ & 135 \\
\hline HG1 & $29 \%$ & $71 \%$ & $39 \%$ & $31 \%$ & $8 \%$ & $60 \%$ & $68 \%$ & $38 \%$ & 135 \\
\hline HG5 (heel) & $26 \%$ & $74 \%$ & $73 \%$ & $71 \%$ & $2 \%$ & $97 \%$ & $99 \%$ & $28 \%$ & 110 \\
\hline HG3 & $22 \%$ & $78 \%$ & $2 \%$ & NA & $2 \%$ & NA & NA & $24 \%$ & 110 \\
\hline HG7 (no noble metals) & $18 \%$ & $82 \%$ & $79 \%$ & $77 \%$ & $1 \%$ & $95 \%$ & $96 \%$ & $19 \%$ & 170 \\
\hline HG4 (hot condenser) & $13 \%$ & $87 \%$ & $53 \%$ & $51 \%$ & $2 \%$ & $64 \%$ & $66 \%$ & $15 \%$ & 110 \\
\hline HG10 (high solids) & $12 \%$ & $88 \%$ & $47 \%$ & $40 \%$ & $7 \%$ & $52 \%$ & $59 \%$ & $19 \%$ & 110 \\
\hline HG9 (high agitation) & $9 \%$ & $91 \%$ & $57 \%$ & $51 \%$ & $6 \%$ & $60 \%$ & $66 \%$ & $14 \%$ & 110 \\
\hline AVERAGE & $25 \%$ & $75 \%$ & $46 \%$ & $40 \%$ & $11 \%$ & $65 \%$ & $72 \%$ & $36 \%$ & \\
\hline \multicolumn{10}{|l|}{ UN-EXTRAPOLATED } \\
\hline HG6 (high antifoam) & $31 \%$ & $69 \%$ & $49 \%$ & $9 \%$ & $40 \%$ & $40 \%$ & $80 \%$ & $71 \%$ & 110 \\
\hline HG8 (high noble metals) & $22 \%$ & $78 \%$ & $36 \%$ & $4 \%$ & $32 \%$ & $26 \%$ & $59 \%$ & $54 \%$ & 110 \\
\hline HG2 $\left(\mathrm{Hg}\left(\mathrm{NO}_{3}\right)_{2}\right)$ & $20 \%$ & $80 \%$ & $29 \%$ & $24 \%$ & $5 \%$ & $44 \%$ & $48 \%$ & $25 \%$ & 135 \\
\hline HG1 & $15 \%$ & $85 \%$ & $73 \%$ & $71 \%$ & $2 \%$ & $98 \%$ & $88 \%$ & $17 \%$ & 110 \\
\hline HG5 (heel) & $15 \%$ & $85 \%$ & $2 \%$ & NA & $2 \%$ & NA & NA & $17 \%$ & 110 \\
\hline HG3 & $15 \%$ & $85 \%$ & $39 \%$ & $31 \%$ & $8 \%$ & $46 \%$ & $54 \%$ & $23 \%$ & 135 \\
\hline HG7 (no noble metals) & $14 \%$ & $86 \%$ & $79 \%$ & $77 \%$ & $1 \%$ & $91 \%$ & $93 \%$ & $15 \%$ & 170 \\
\hline HG4 (hot condenser) & $13 \%$ & $87 \%$ & $53 \%$ & $51 \%$ & $2 \%$ & $64 \%$ & $65 \%$ & $15 \%$ & 110 \\
\hline HG10 (high solids) & $11 \%$ & $89 \%$ & $47 \%$ & $40 \%$ & $7 \%$ & $51 \%$ & $58 \%$ & $18 \%$ & 110 \\
\hline HG9 (high agitation) & $6 \%$ & $94 \%$ & $57 \%$ & $51 \%$ & $6 \%$ & $57 \%$ & $63 \%$ & $12 \%$ & 110 \\
\hline AVERAGE & $16 \%$ & $84 \%$ & $46 \%$ & $40 \%$ & $11 \%$ & $56 \%$ & $63 \%$ & $27 \%$ & \\
\hline
\end{tabular}

The second column in Table 4-2 and Table 4-3 is 100\% minus the amount recovered in the offgas system. The third column is the total amount found in the SRAT, which is equal to the sum of the next two columns: segregated and retained. The segregated $\mathrm{Hg}^{0}$ metal and $\mathrm{Hg}^{0}$ recovered in the MWWT are summed in the next column. The $7^{\text {th }}$ and $8^{\text {th }}$ columns give the material balance closure with and without adding in the segregated $\mathrm{Hg}^{0}$ metal.

The HG runs material balance closure ranged from 12-71\% (un-extrapolated) without segregated Hg, and from $48-93 \%$ when the segregated Hg in SRAT bottom is considered. The recovery values ranged from 6$31 \%$, the amount retained in the slurry was $1-40 \%$, and the amount found segregated was $4-77 \%$. The SB6 and GF runs had higher recoveries in the MWWT. All had low amounts retained in the slurry, but the GF runs were noticeably higher. Note that the SB7a retained in slurry values are for the SRAT products, but that the segregated Hg values are for the SME products. The sums of the segregated and recovered amounts were similar for the HG, GF, and SB7a runs, even though the splits between 
segregated and recovered were different. Material balance closures were similar for the HG, GF and SB7a runs when segregated mercury was included.

The percentage of mercury in the slurry and the total $\mathrm{Hg}$ found (slurry $\mathrm{Hg}+$ segregated $\mathrm{Hg}+\mathrm{Hg}$ in offgas) are shown in Figure 4-10 and Figure 4-11, respectively. In two runs (HG3, HG4), the HgO added appears to have been 18-36\% higher than targeted. The initial measured $\mathrm{Hg}$ concentrations for four runs are $40-60 \%$ of the target, which has often occurred due to inhomogeneous distribution of HgO. Figure 4-10 shows that the high antifoam HG6 and high noble metals HG8 runs had the highest slurry Hg contents at the end of the runs. The remaining runs had much sharper drops in the concentration of slurry Hg. Figure 4-11 is a graphical representation of the $\mathrm{Hg}$ material balance closure versus time. The large jump in some of the percentages at the last data point is due to adding in the segregated $\mathrm{Hg}$ found at the end of the run. The mercury concentration endpoints are given in Table 4-4.

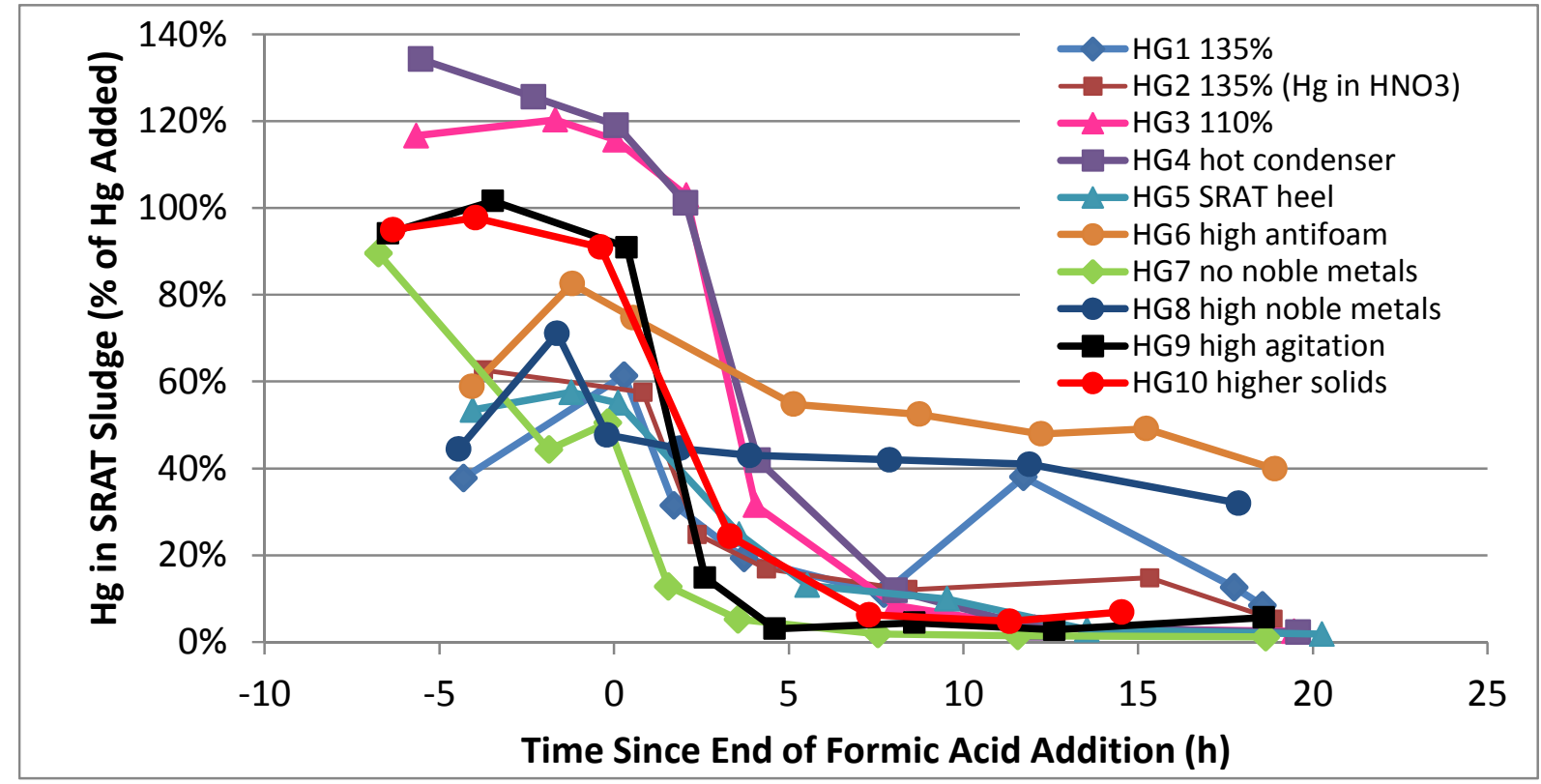

Figure 4-10. HG Runs mercury retained in sludge versus time 


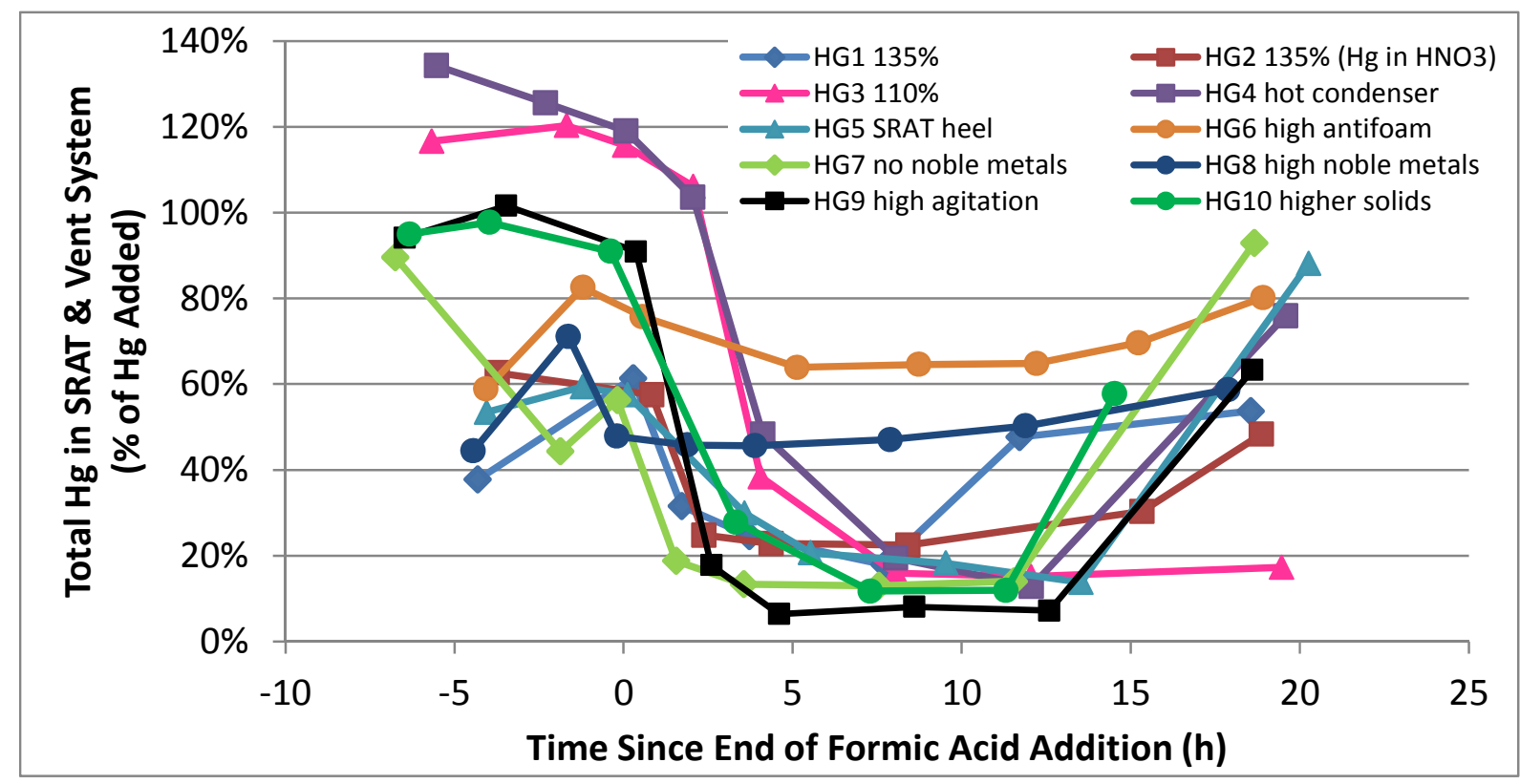

Figure 4-11. HG Runs total mercury material balance versus time

Table 4-4. HG runs final concentration of mercury in SRAT products

\begin{tabular}{|c|c|c|}
\hline Run & & $\begin{array}{c}\text { Final Slurry Hg } \\
\text { Concentration } \\
\text { (wt \% of total solids) }\end{array}$ \\
\hline HG1 & Baseline, $135 \%$ acid & $0.13 \%$ \\
\hline HG2 & Dissolved Hg, $135 \%$ acid & $0.08 \%$ \\
\hline HG3 & Baseline, $110 \%$ acid & $0.04 \%$ \\
\hline HG4 & Hot Condenser, $110 \%$ acid & $0.04 \%$ \\
\hline HG5 & Effect of Heel (from HG3), $110 \%$ acid & $0.05 \%$ \\
\hline HG6 & Excess Antifoam, $110 \%$ acid & $0.63 \%$ \\
\hline HG7 & No Noble Metals, $170 \%$ acid & $0.02 \%$ \\
\hline HG8 & High Noble Metals, $110 \%$ acid & $0.51 \%$ \\
\hline HG9 & High Agitation Rate, $110 \%$ acid & $0.09 \%$ \\
\hline HG10 & High Solids, $110 \%$ acid & $0.10 \%$ \\
\hline
\end{tabular}

For the HG runs, the high antifoam run HG6 had the highest recovery at 31\%, the highest amount of mercury retained in the slurry at $40 \%$, and the highest final $\mathrm{Hg}$ slurry concentration at $0.63 \mathrm{wt} \%$. It appears that high antifoam additions result in better suspension of the elemental mercury. Better suspension results in higher recovery by stripping, but also increases the time to reach the slurry concentration target. These results are consistent with recent DWPF operations; in SB6, very large additions of antifoam were being used at DWPF that were higher than used in previous batches. In SB6, Hg removal (by stripping or segregation) was difficult, requiring longer times than expected. At the end of SB6 processing, the antifoam additions were reduced significantly, and the rate of mercury removal from the slurry in SB7a has been much higher. 
The high noble metals run HG8 had the second highest recovery and retention. The HG runs with the lowest recovery had the lowest retention. These data indicate that higher $\mathrm{Hg}$ recovery in the MWWT correlates with higher measured Hg concentrations in the slurry. This correlation makes sense if it is assumed that $\mathrm{Hg}$ dispersed in the slurry will be more likely to be evaporated than $\mathrm{Hg}$ that has segregated on the bottom of the vessel. This correlation could not be done for the SB6 and SB7a runs because the amount of mercury in the MWWT as a function of time was not measured.

To compare on a similar basis, the amount of $\mathrm{Hg}$ in the slurry for the SB6 and SB7a data was determined from the available data. Because no data on the intermediate amount of Hg in the MWWT was available, this amount was estimated as follows.

The Hg masses in the slurry and in the MWWT as the percent of total added are plotted for several runs in Figure 4-12. Runs HG6 and HG8 slurry Hg concentrations slowly declined from their initial values, while the MWWT mercury amounts increased steadily. For HG4 and 9 where the slurry Hg concentrations decreased quickly, the rate of the MWWT Hg accumulation decreased with time. These data show that Hg must remain suspended in the slurry for stripping to the MWWT to continue without declining in rate.

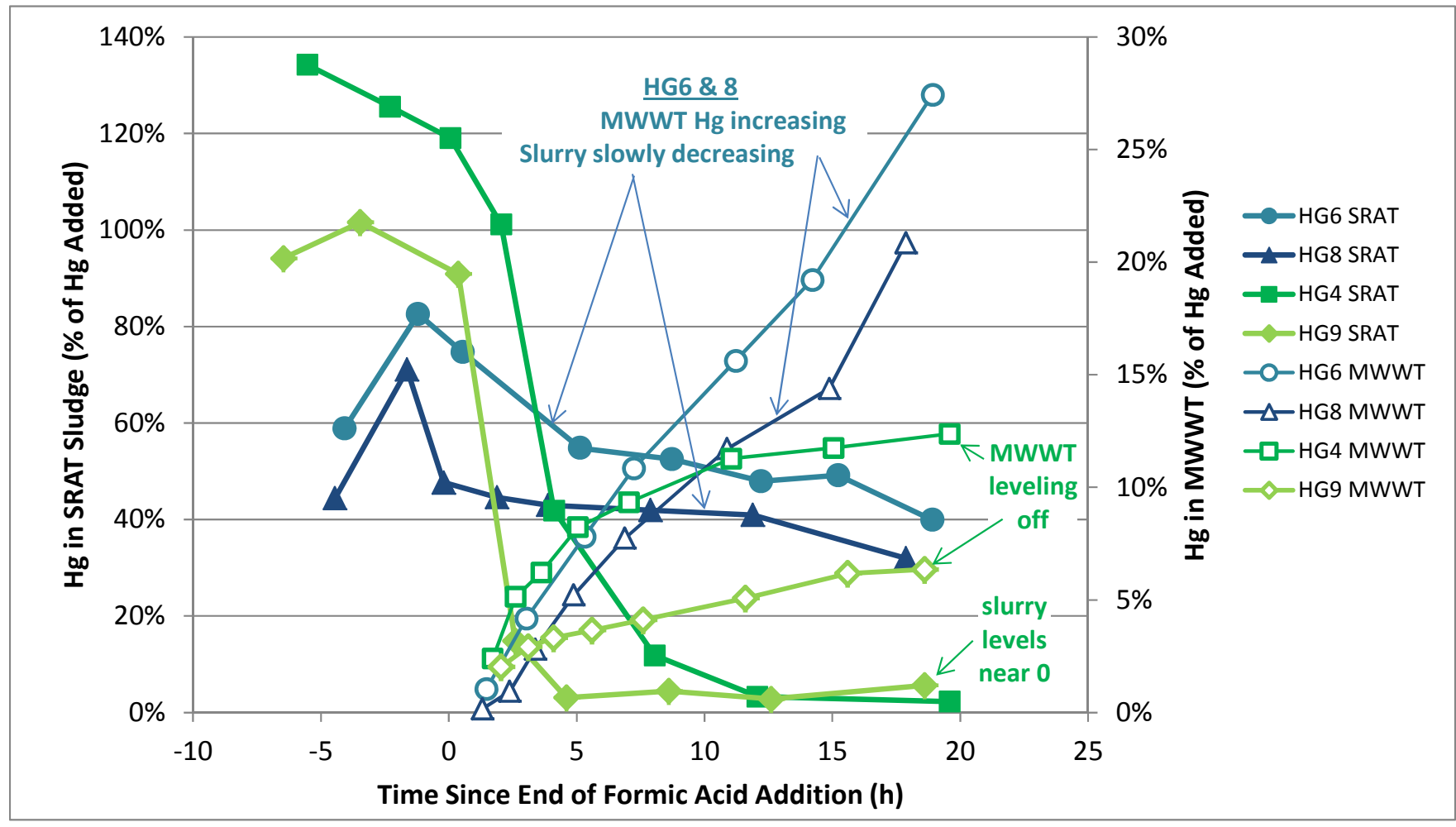

Figure 4-12. $\quad$ MWWT and SRAT Slurry mercury distributions

The correspondence between the decline in slurry concentration and the MWWT accumulation was used to approximate the amounts of $\mathrm{Hg}$ in the MWWT for the SB6 and SB7a data. To estimate the MWWT Hg at any intermediate time, two assumptions were made. If the decline in slurry $\mathrm{Hg}$ was steady similar to HG6 and 8, the MWWT Hg was estimated to be a fraction of the final amount; e.g., for MWWT Hg data at $36 \mathrm{~h}$, to approximate the amount present at $18 \mathrm{~h}$, the MWWT amount at $36 \mathrm{~h}$ was multiplied by 18/36. For cases where the slurry $\mathrm{Hg}$ declined rapidly as in HG 4 and 9, the amount of $\mathrm{Hg}$ at the intermediate time was assumed to be equal to the final amount. It would of course be better to have actual data at 
corresponding times. In the future, efforts will be made to get data at specific times during SRAT simulations so that Hg data can be compared on a consistent basis.

The results of these estimates of MWWT Hg are shown in Figure 4-13. Recall that the following material balance applies:

$$
\mathrm{Hg}_{\text {TOTAL }}=\mathrm{Hg}_{\text {recovered }}+\mathrm{Hg}_{\text {retained }}+\mathrm{Hg}_{\text {segregated }}
$$

The top graph shows the Hg recovery in the MWWT versus Hg remaining in the slurry (the SB6 and 7 data are the adjusted data). This graph indicates that there is a correlation between $\mathrm{Hg}$ recovery in the MWWT and the slurry Hg concentration. The amount of mercury recovered is somewhat proportional to the concentration of $\mathrm{Hg}$ in the slurry; the line shown is a linear fit of all the data. The bottom graph in Figure 4-13 shows the recovery versus $\mathrm{Hg}$ segregated from the slurry. Most of the recovery data is in the $10-30 \%$ range regardless of the amount segregated. The highest recoveries found all correspond to segregation of less than $15 \%$.

The implication of these correlations is that to remove Hg by stripping, the Hg must remain suspended in the slurry. If the $\mathrm{Hg}$ segregates quickly and settles to the bottom, then the stripping rate will quickly decline. However, if the goal is only to reduce the slurry $\mathrm{Hg}$ concentration, then it does not matter whether the $\mathrm{Hg}$ is stripped to the MWWT or if it segregates to the SRAT bottom. The HG run data and the previous SB6 and SB7a data show that the reduction of slurry Hg concentration by segregation, when it occurs, happens much more rapidly than the removal of $\mathrm{Hg}$ by stripping. In general, higher acid stoichiometry promotes segregation over recovery. 


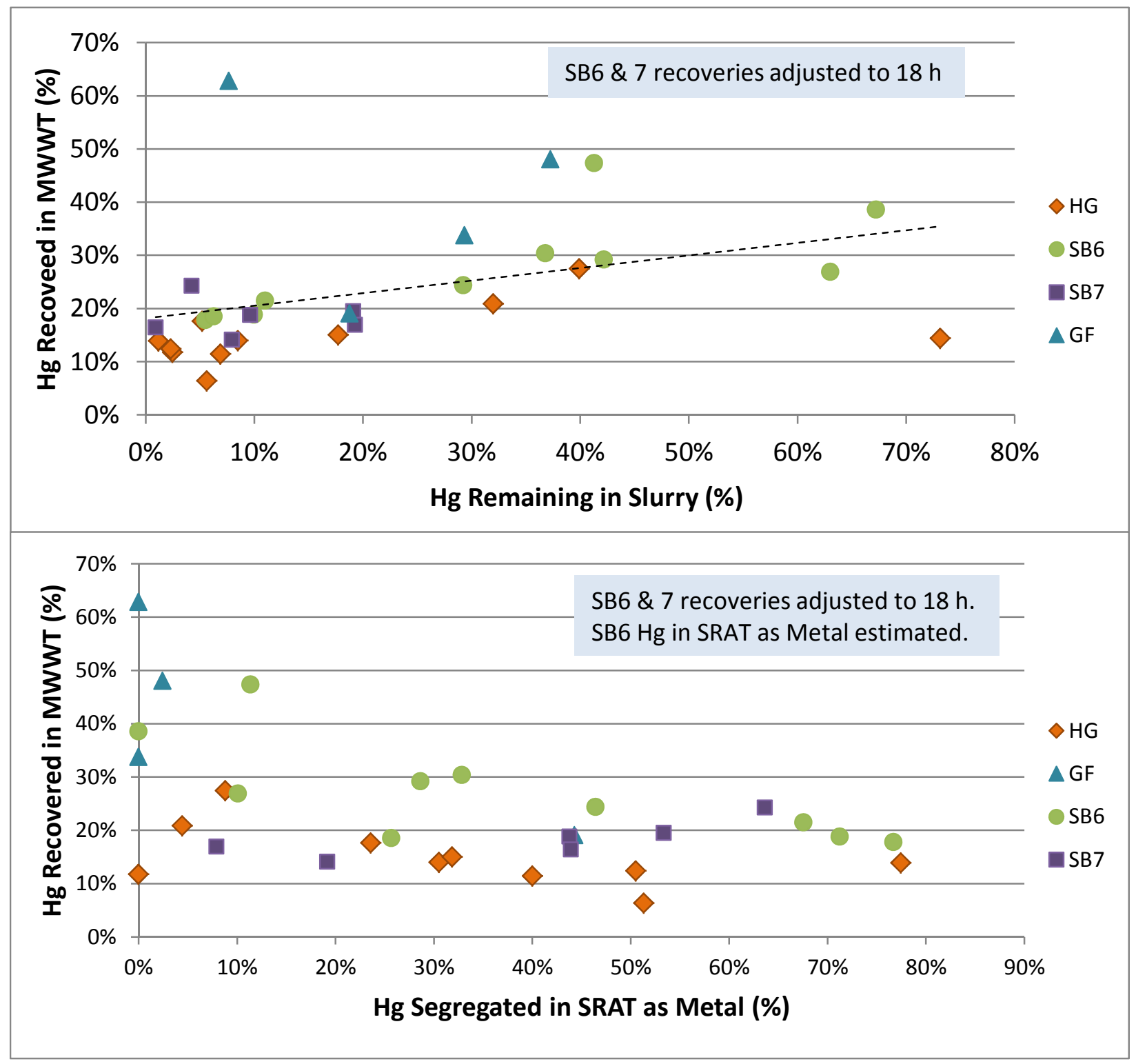
Figure 4-13. Mercury in MWWT correlation with mercury remaining in slurry and segregated
in SRAT as Hg metal

The stripping and removal factors versus time were calculated for several of the runs. The "stripping factor" is defined to be the mass of water evaporated per mass of Hg stripped. The theoretical stripping factor is 250 and the assumed design basis factor is $750{ }^{26}$ Several runs with higher and lower mercury recoveries in the MWWT are shown in Figure 4-14. For the two runs with the highest recoveries, HG6 and 8, the stripping factors remained steadily in the 1000-2000 g/g range, except at the very beginning of formic acid addition where the values were higher as expected. It was assumed that the evaporation rate was about $1 \mathrm{~g} / \mathrm{min}$ during formic acid addition and about $4 \mathrm{~g} / \mathrm{min}$ during boiling. The actual measured boilup rates were generally in the 3.7-4.2 g/min range. In the low recovery runs, HG3, 4, and 9, the initial stripping factors up until around 1-2 hours into boiling were similar to those in HG 6 and 8, but then quickly degraded to $4000 \mathrm{~g} / \mathrm{g}$ or higher, which is consistent with the low recovery. 


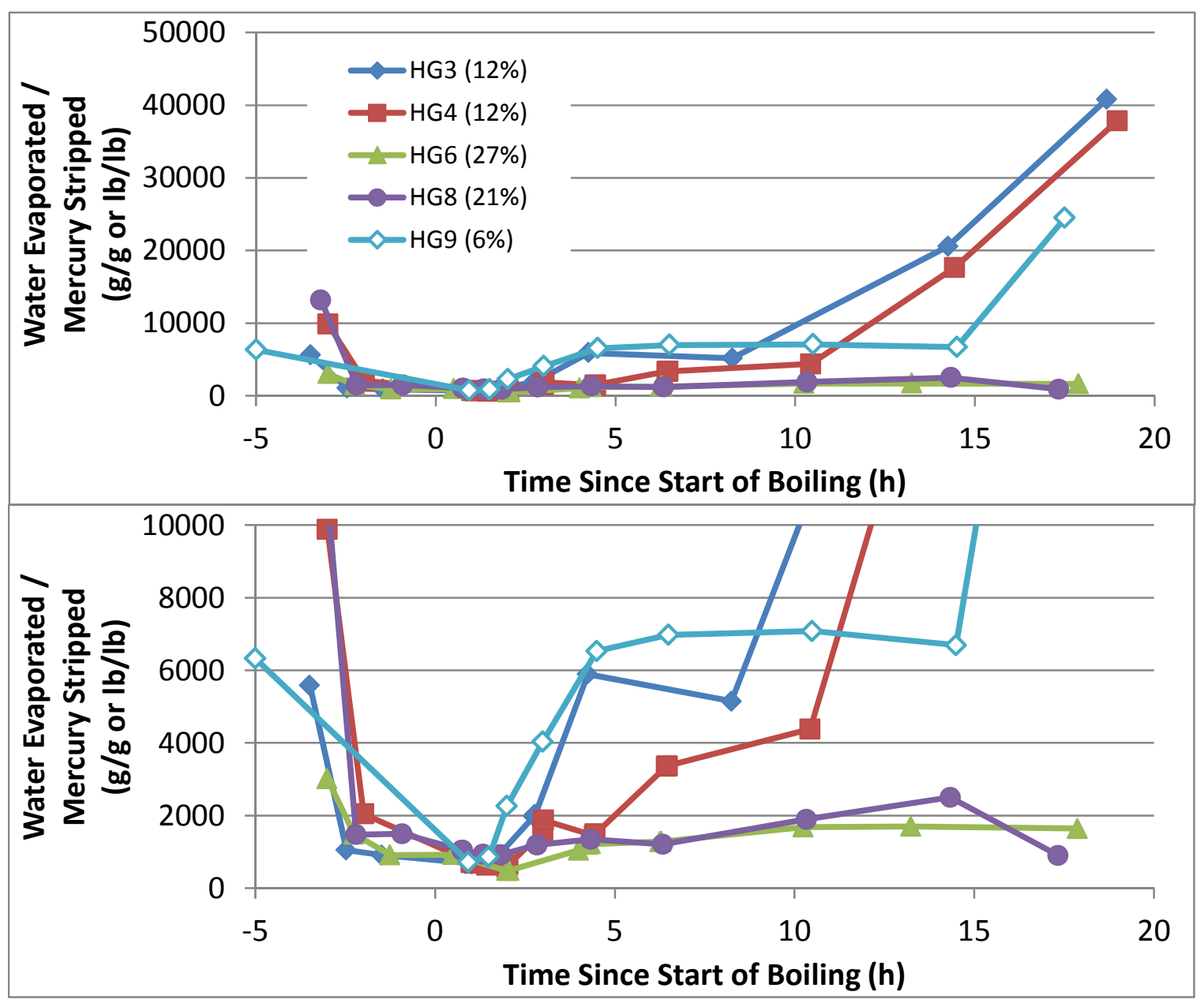

Figure 4-14. Mercury stripping factors

The ratio of water evaporated to mercury removed ("removal factor") for runs HG3 and 6 is shown in addition to the stripping factor in Figure 4-15. This value is different than the stripping factor; the stripping factor is based on the mercury that is actually evaporated, whereas the removal factor is based on the amount of mercury removed from the SRAT by stripping plus segregation. This "removal factor" is what is generally referred to as the stripping factor in DWPF (because the actual mercury stripped is not known). For HG3, with low recovery of $\mathrm{Hg}$ in the MWWT, the stripping factor value is twice as large or higher than the removal factor after about two hours boiling. In HG6, where the Hg recovery was higher and the Hg remained suspended in the slurry more, the stripping and removal factors are about the same; when these values are equal it means that there was very little segregation of $\mathrm{Hg}$ in the SRAT bottom. 


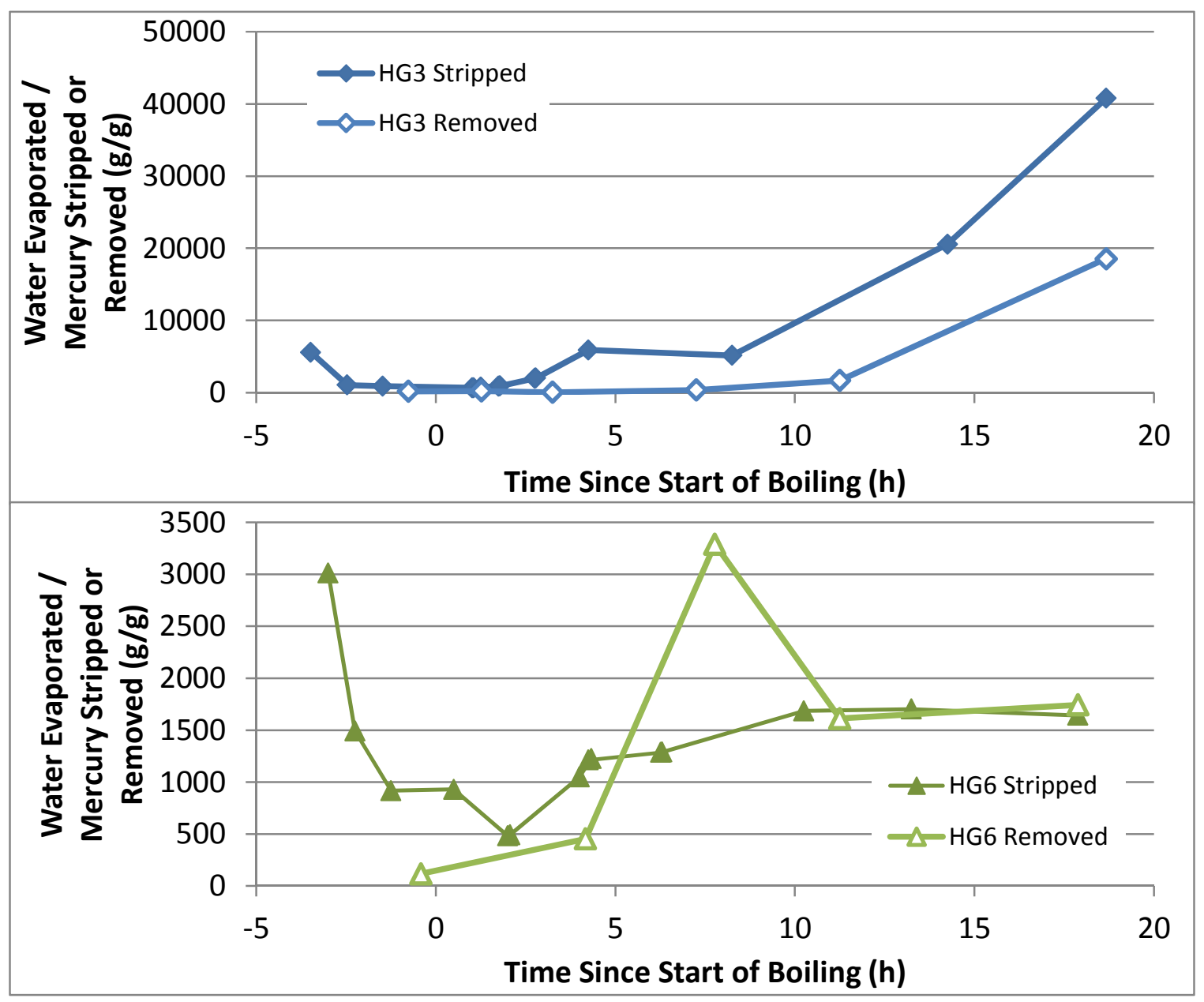

Figure 4-15. Mercury stripping and removal factors

In an evaporation test using only deionized water and pure elemental mercury, the stripping factor was extremely low at about $10,000 \mathrm{~g} / \mathrm{g}$. In this test, the $\mathrm{Hg}$ was present in the agitated vessel in about 10 drops of about $0.5 \mathrm{~g}$ each, so the total surface area was very small compared to what would be present with highly dispersed $\mathrm{Hg}$. This test shows that the stripping factor of pure $\mathrm{Hg}$ is very low when only large drops are present. A test using highly dispersed pure mercury was planned but could not be done due to equipment problems. This test may be done in the future.

Figure 4-16 is based on some representative DWPF data provided by DWPF Engineering. The data are rough averages for steam added versus $\mathrm{Hg}$ present in a SRAT batch. The data show two cases: one starting with $150 \mathrm{lb} \mathrm{Hg}$ in the sludge and the other starting at $100 \mathrm{lb}$. The heavy lines show the average steam to $\mathrm{Hg}$ removed ratio as a function of time for both cases. Comparison shows that the stripping factor from 100 to $20 \mathrm{lb}$ when starting at $150 \mathrm{lb} \mathrm{Hg}$ is less than when starting at $100 \mathrm{lb} \mathrm{Hg}$. The amount of steam required for the $150 \mathrm{lb}$ case is $165,000 \mathrm{lb}$ compared to 138,000 lb for the $100 \mathrm{lb}$ case. The total time required is also longer at about $26 \mathrm{~h}$ versus $19 \mathrm{~h}$. These results are consistent with the simulant data and the conclusion that as mercury coalesces into larger drops, it becomes harder to remove. Another possibility is that the settling rate of $\mathrm{Hg}$ drops might be expected to decelerate because of increases in slurry consistency as $\mathrm{pH}$ goes up during reflux due to catalytic destruction of formic acid. 


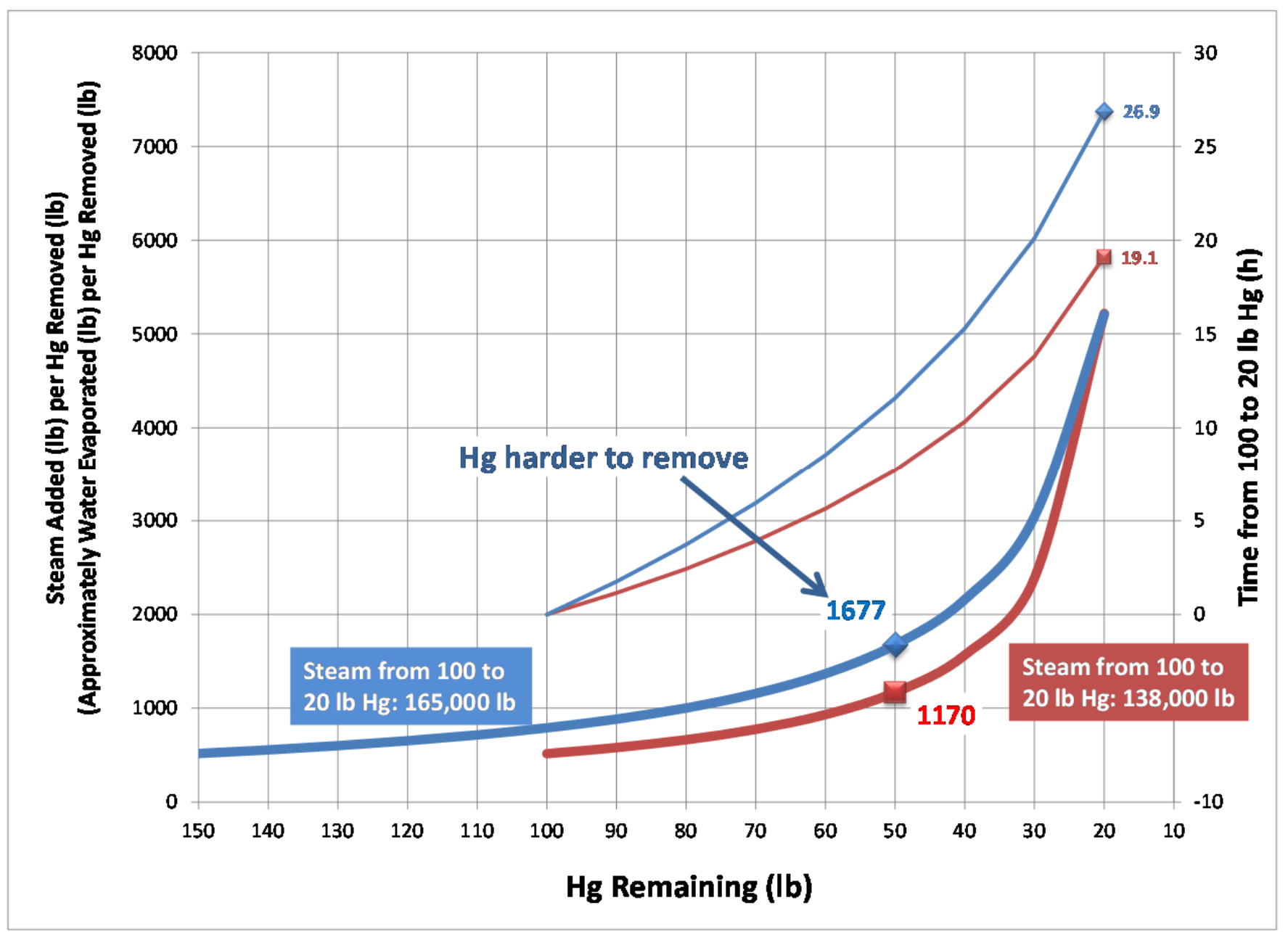

Figure 4-16. Steam required to remove mercury

\subsubsection{Effect of Rheology and Acid Stoichiometry on Mercury Removal}

It has been suspected that mercury recovery may be dependent on the slurry rheology. Higher percent stoichiometric acid usually results in slurries with lower yield stress and consistency. Figure 4-17 shows mercury recovery in the MWWT and mercury removal from the sludge versus slurry consistency for SB6, SB7a and the HG runs. For all three data sets, the Hg recovered increased with consistency, although the HG runs data was very scattered. The HG and SB7a runs slopes were very different from the SB6 data, so even though there is a correlation between the recovery and consistency, it is not necessarily the same for different sludges. There must be additional variables that affect the behavior of $\mathrm{Hg}$ in the slurries that are not accounted for by the rheological properties alone. Note that the SB6 recoveries were exceptionally high ( 3 pts. $>50 \%$ ). The $\mathrm{Hg}$ removal data shows that there tends to be more removal at lower consistencies, which is consistent with the idea that the $\mathrm{Hg}^{0}$ settles faster in thinner slurries. 


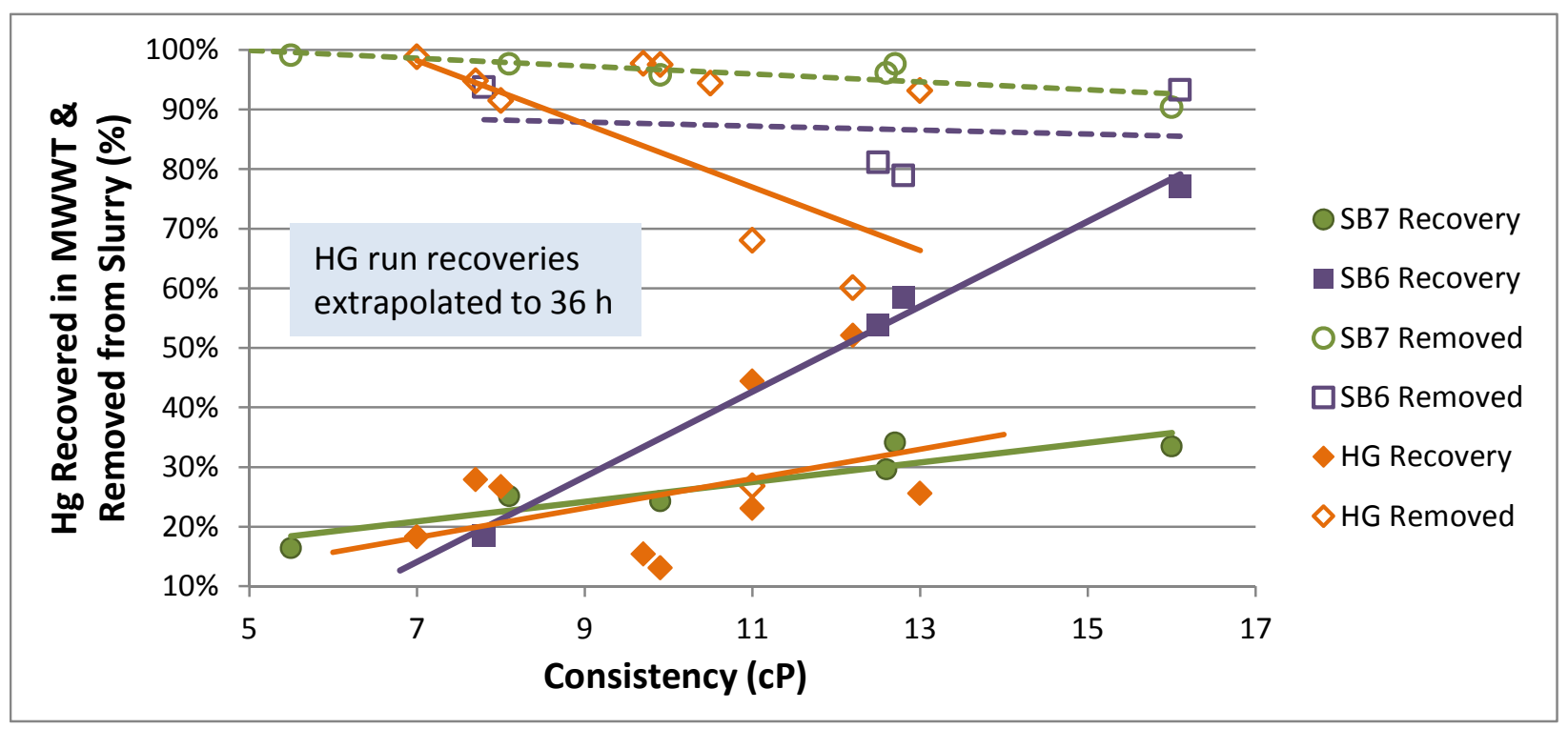
Figure 4-17. Elemental mercury found in MWWT and mercury removed from slurry versus
slurry consistency

Figure 4-18 shows the recoveries and removals versus yield stress. For all the data, the correlations are much weaker than the correlation versus consistency.

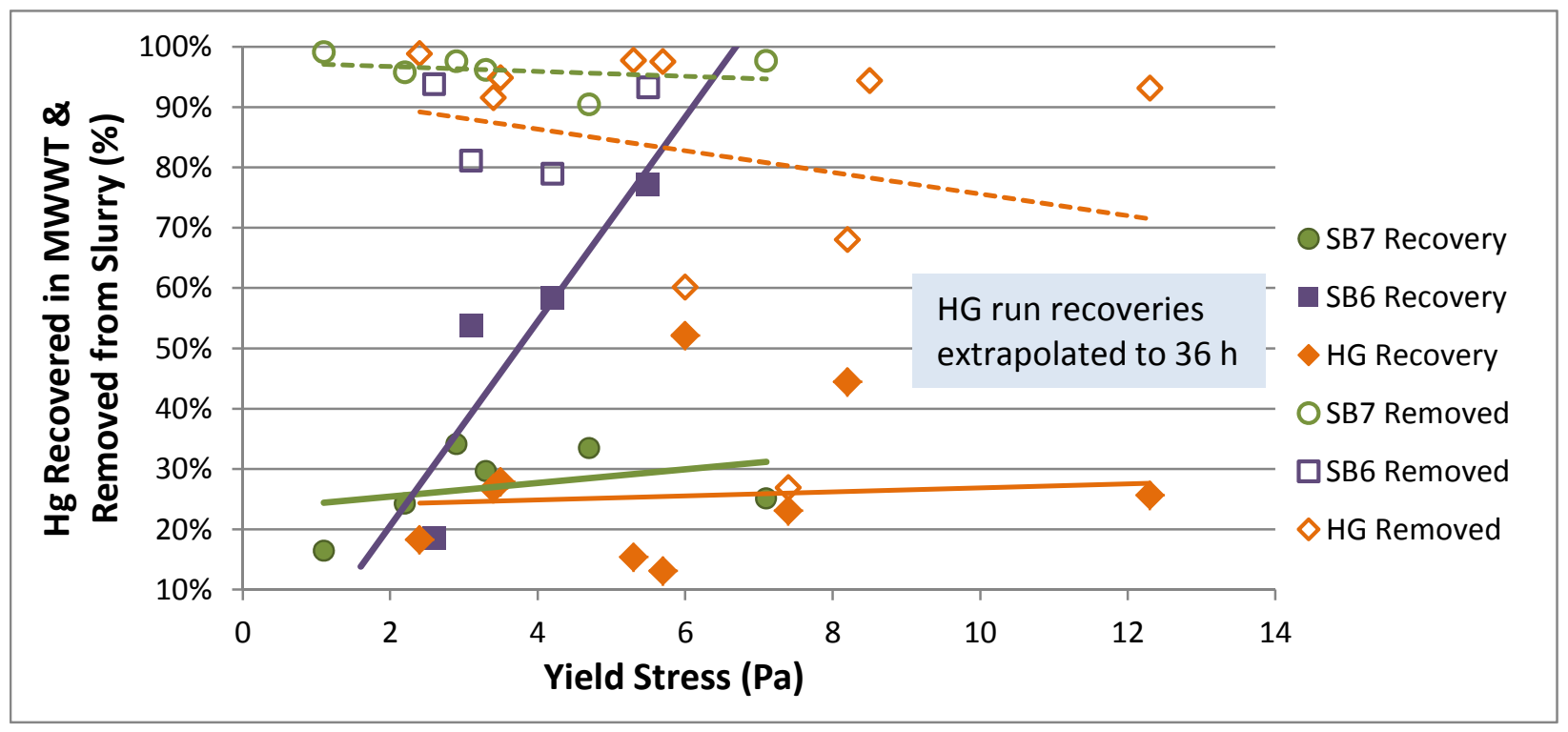

\section{Figure 4-18. Elemental mercury found in MWWT and mercury removed from slurry versus slurry yield stress}

The correlations with acid stoichiometry are shown in Figure 4-19. The correlations for the HG runs are poor due to the wide range of recoveries and removals at $110 \%$ acid caused by changing factors other than acid stoichiometry. The four SB6 data points plotted in the consistency and yield stress graphs are shown as the larger rectangles. No rheology data were available for the other SB6 data. In general, the Hg recovery decreases with increasing acid stoichiometry. Consistency and yield stress both decrease with 
increased acid stoichiometry so the actual physical reason for the decreased recovery may be mostly due to the rheological properties. However, higher acid stoichiometry could have a secondary effect of causing $\mathrm{Hg}^{0}$ metal to coalesce faster. From the data available, there is no way to tell if this effect actually occurs.

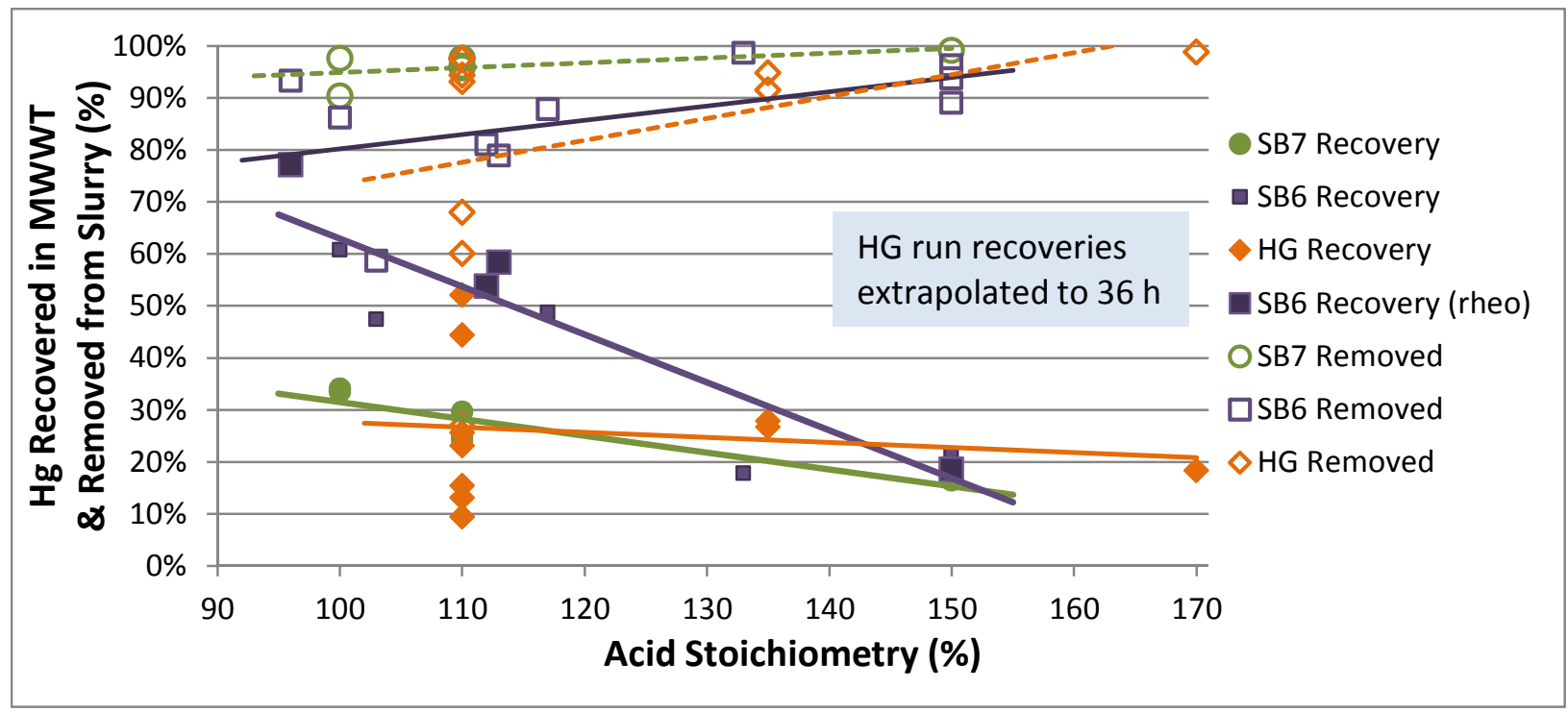

Figure 4-19. Elemental mercury found in MWWT and mercury removed from slurry versus acid stoichiometry

\subsubsection{Soluble Mercury in Sludge and Condensates}

Soluble mercury was measured in the sludge supernate as a function of time. The initial slurry solubilities measured ranged from 40-140 mg/kg supernate. Some of the initial samples were taken after the SRAT had started heating up, so the solubility would be expected to be higher. Figure 4-20 shows the measured soluble $\mathrm{Hg}$ concentrations versus the temperature at which the samples were taken and the predicted solubilities using the OLIAnalyzer. ${ }^{25}$ The predicted solubilities are for $\mathrm{pH}$ 13.5. Note that the OLI predictions use the OLI properties Mixed Solvent Electrolyte database with updated mercury compound data that was initiated as part of this work. The measured concentrations are slightly high except at $93^{\circ} \mathrm{C}$ and for the $\mathrm{HgO}$ dissolved in $\mathrm{HNO}_{3}$ run; in this run, it is not surprising that the $\mathrm{HgO}$ could be above the solubility because it was added dissolved and the sample may have been taken before equilibrium could be achieved.

Figure 4-21 shows that the solubility of $\mathrm{Hg}$ at end of nitric acid addition is about what would be expected at $93^{\circ} \mathrm{C}$. The $\mathrm{pH}$ at end of nitric acid addition was about 10.6 in all runs. Figure 4-20 also shows the measured and predicted concentrations at $\mathrm{pH}$ 10.6. After formic acid addition begins, the solubility drops to less than $50 \mathrm{mg} / \mathrm{kg}$ supernate within 1.5 hours, and continues to decrease. This indicates that $\mathrm{Hg}$ is being reduced to the virtually insoluble $\mathrm{Hg}^{0}$ metal. Solubilities at the end were all $<2 \mathrm{mg} / \mathrm{kg}$ supernate except HG8-10 with up to $7 \mathrm{mg} / \mathrm{kg}$ supernate. 


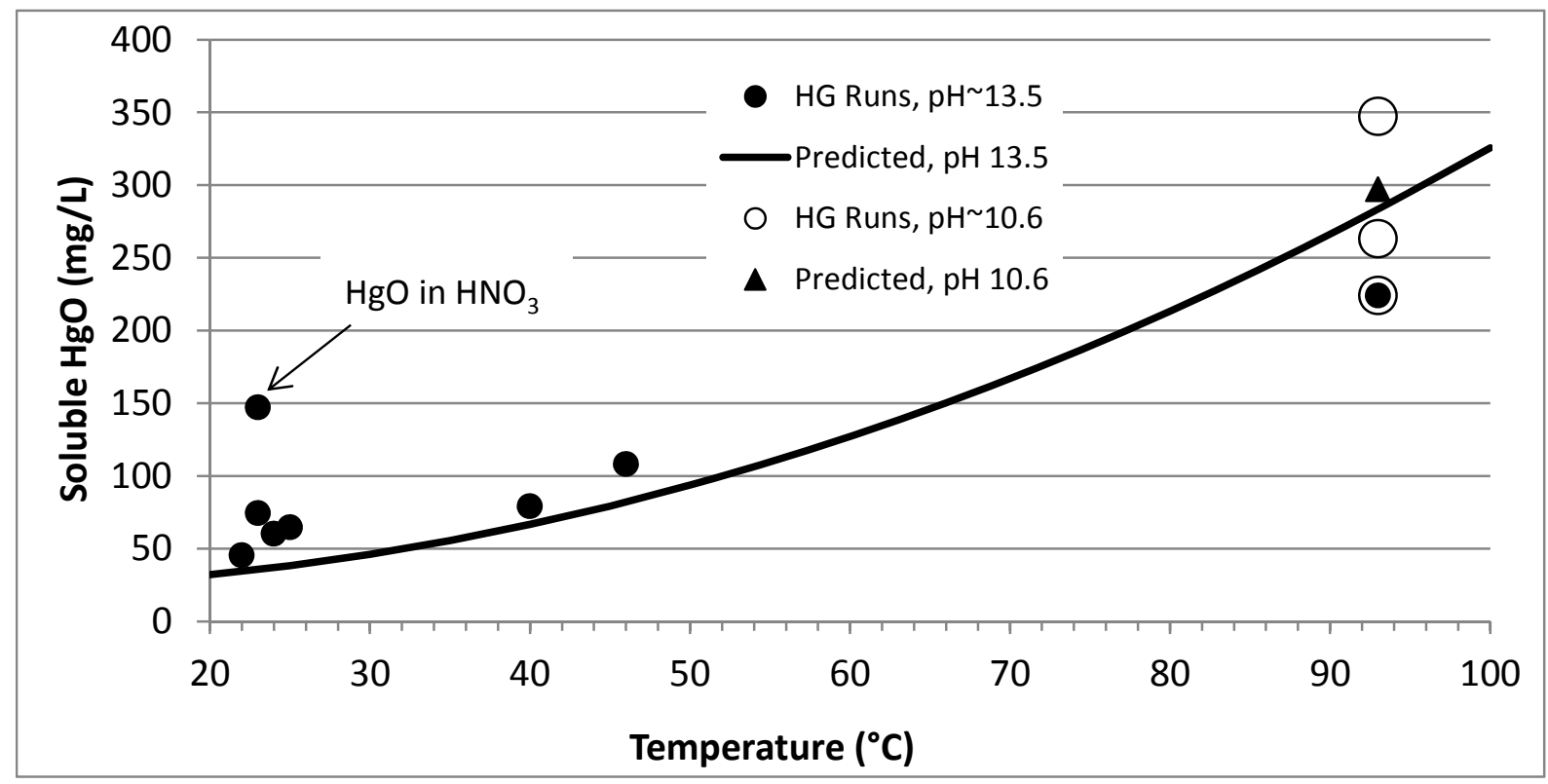

Figure 4-20. Measured and predicted solubility of mercury in initial SRAT slurry

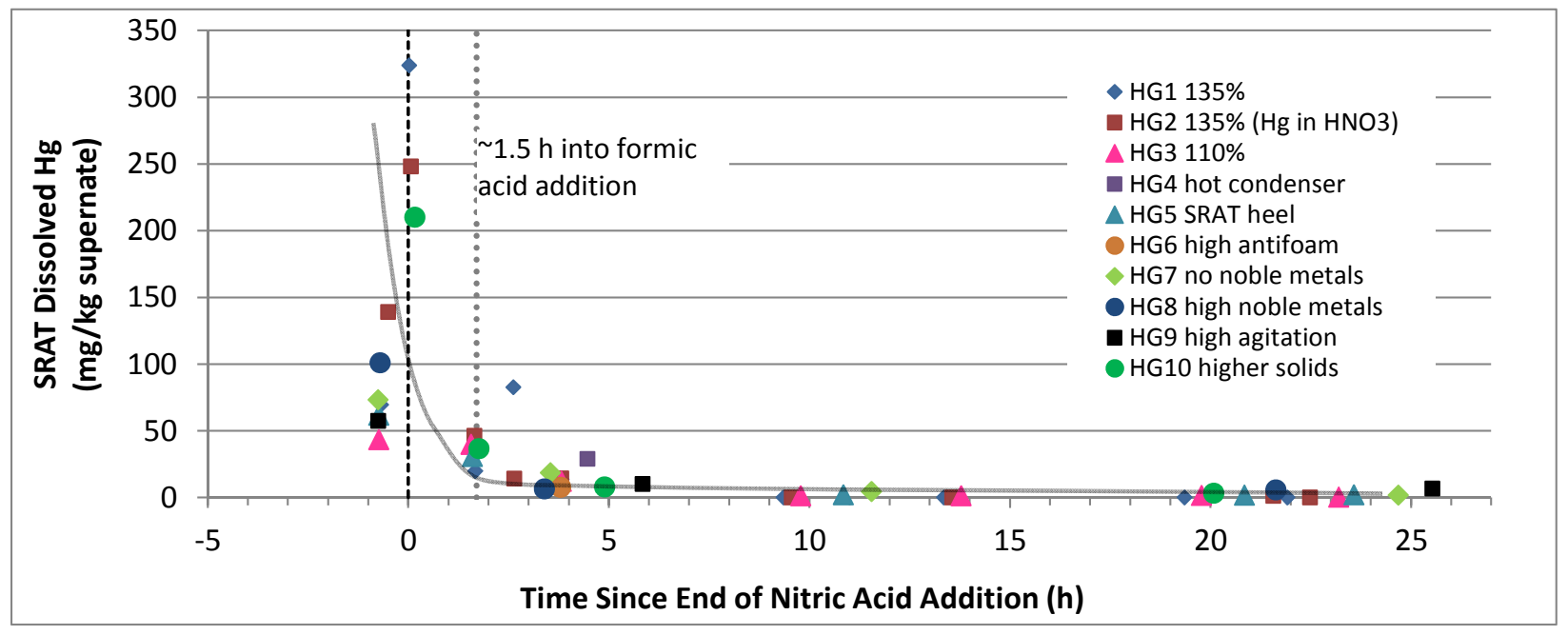

Figure 4-21. Dissolved Hg in SRAT slurry

The soluble Hg in the MWWT reached as high as $1400 \mathrm{mg} / \mathrm{kg}$ as shown in Figure 4-22. (One point at $2800 \mathrm{mg} / \mathrm{kg} \mathrm{Hg}$ during HG10 was omitted so the majority of the data points could be seen clearly; this point corresponds to the nitrate point at $110,000 \mathrm{mg} / \mathrm{kg}$ that is also not shown). The highest dissolved $\mathrm{Hg}$ concentrations corresponded to high nitrate (nitric acid) concentrations. Both peak near the end of formic addition where generation of $\mathrm{NO}_{\mathrm{x}}$, which forms nitric acid in the condensate, is highest. 


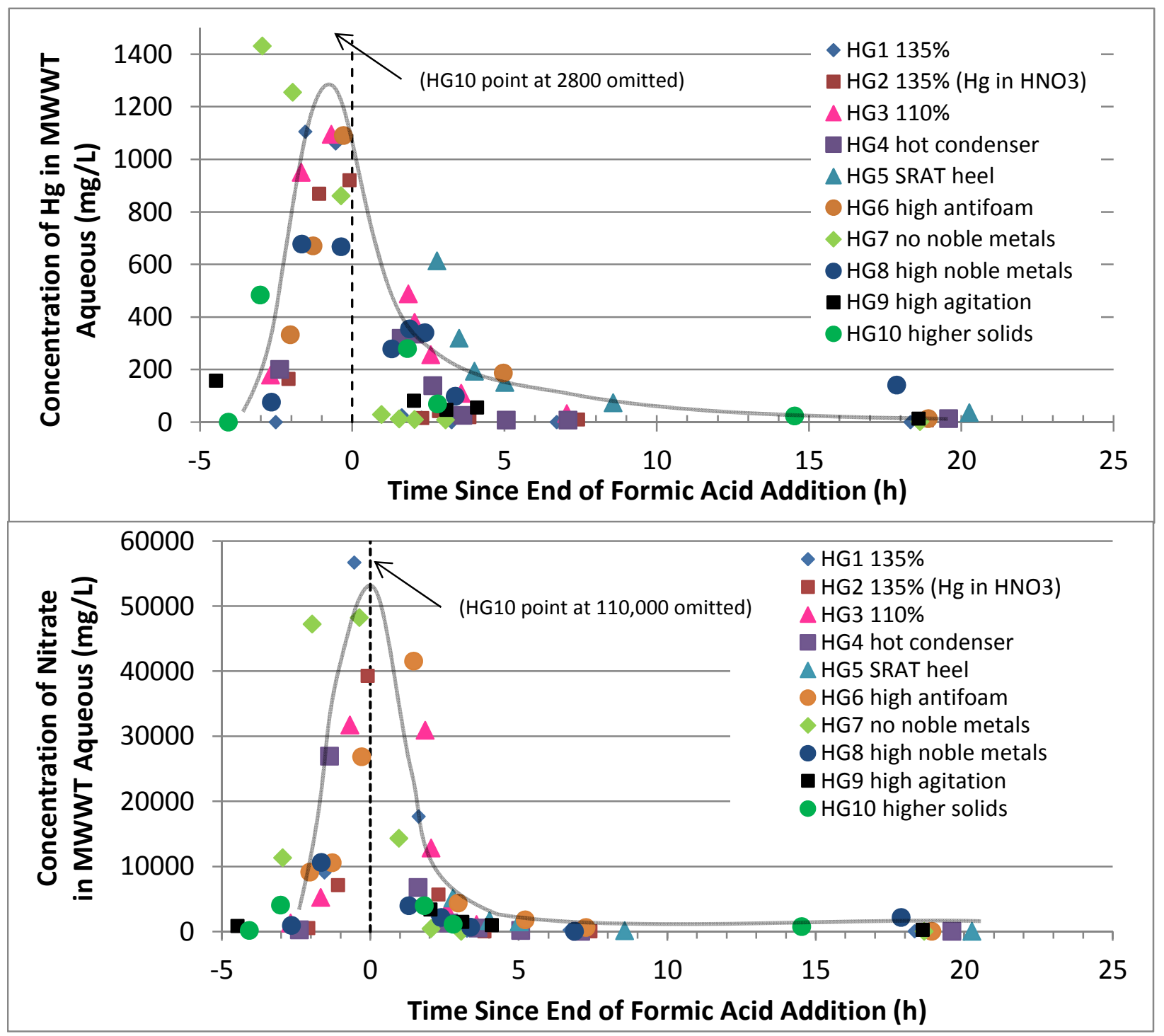

Figure 4-22. Dissolved mercury and nitrate concentrations in condensate

Figure 4-23 shows the range of rates of mercury metal accumulation in the MWWT and mercury that is refluxed or concentrated to the scrubber reservoir as dissolved $\mathrm{Hg}$. By integrating under the dissolved $\mathrm{Hg}$ curve, from $10-36 \%$ of the total $\mathrm{Hg}$ evaporated was refluxed. Most of the reflux occurs just after the end of formic acid addition when the condensate is still acidic. This amount of mercury refluxed is a significant portion of the total known to have reached the MWWT. However, because the amount reaching the MWWT was only 8-35\% of the mercury added, the amount refluxed ranged from 1.6-7.0\% of the total Hg added. There was no correlation between the amount that was refluxed and the amount recovered as elemental mercury in the MWWT. 


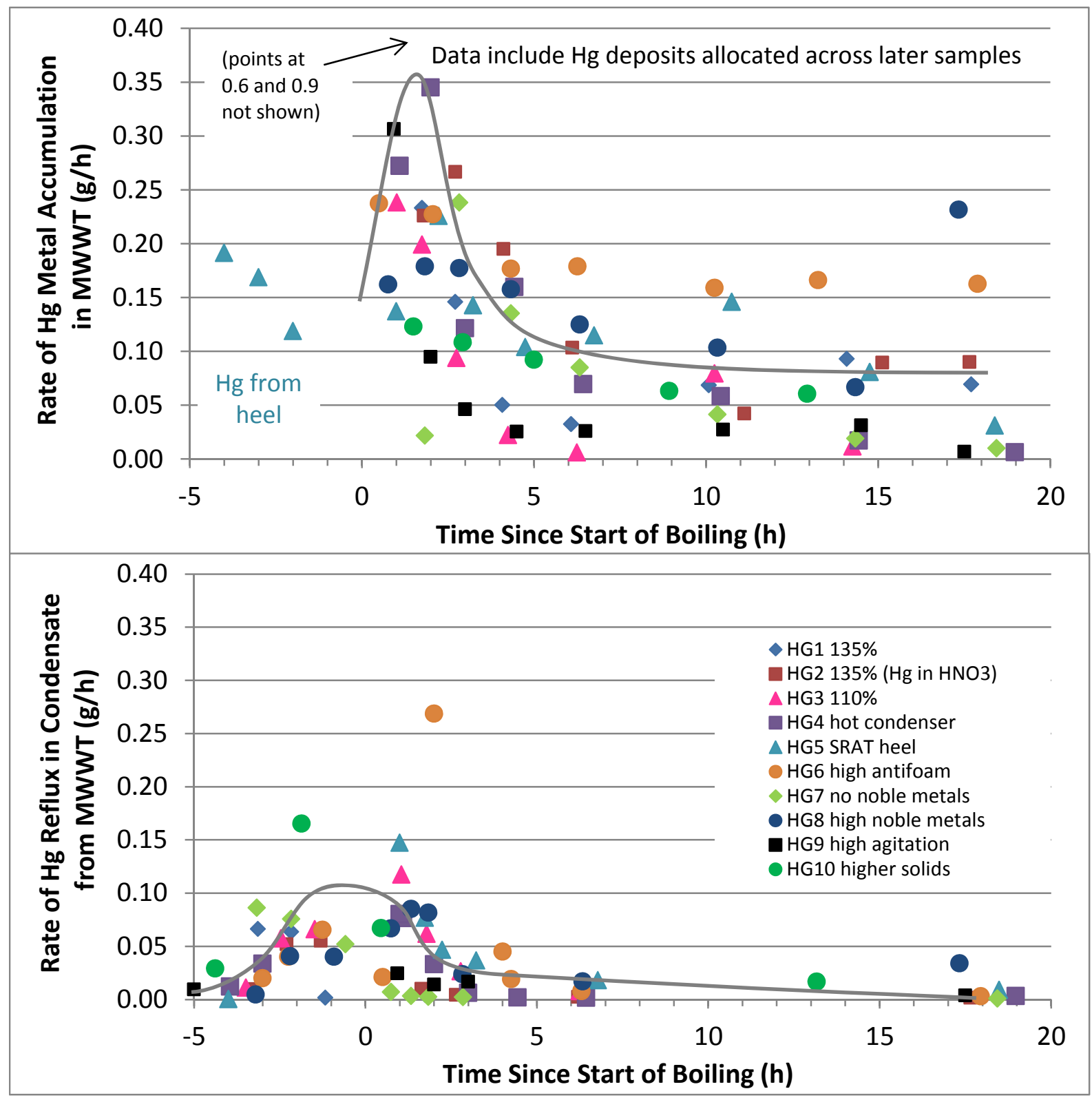

Figure 4-23. Rates of mercury accumulation and reflux in the MWWT

Figure 4-24 shows that the concentration of dissolved $\mathrm{Hg}$ is higher at higher nitrate (nitric acid) concentrations. The solubility of $\mathrm{Hg}$, as some $\mathrm{Hg}^{2+}$ species, increases with nitric acid concentration. ${ }^{27}$ As shown, the actual solubility of $\mathrm{Hg}$ in nitric acid is about 100 times the concentrations that were measured; therefore, the capacity of the condensate to dissolve Hg is much higher than was actually seen. In DWPF, it is possible that the nitric acid refluxed in succeeding runs could dissolve a significant amount of Hg previously collected in the MWWT. In the laboratory tests, no runs were done where there was a 'heel' of Hg in the MWWT, and such runs are normally not performed. 


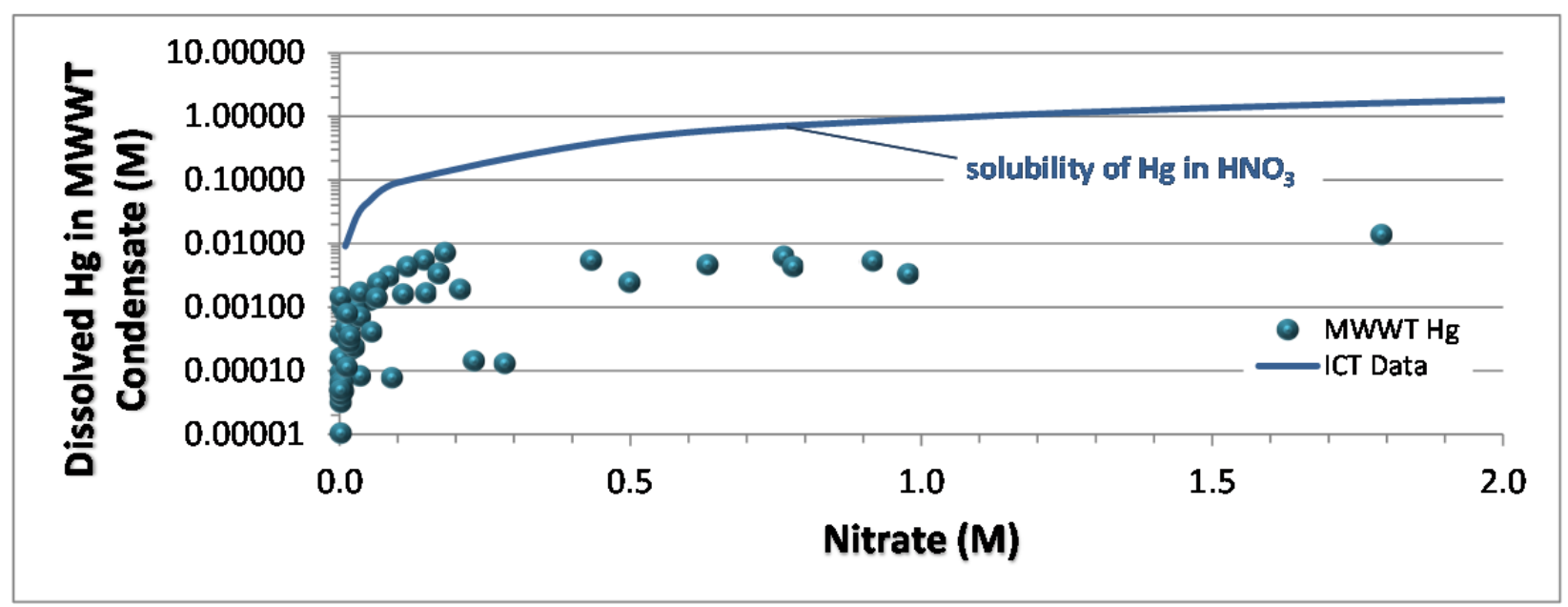

Figure 4-24. Dissolved mercury in condensate versus nitrate

The distribution of mercury in the offgas system is given in Table 4-5. For example, for HG4, $12 \%$ of the $\mathrm{Hg}$ added was recovered in the MWWT. This $12 \%$ metal accounted for $81 \%$ of the total $\mathrm{Hg}$ in the offgas system (so about $19 \%$ of the added Hg was found throughout the offgas system). Of the remaining $19 \%$, about $7 \%$ was found in the SRAT dewater, $12 \%$ in the scrubber liquid (SMECT), and $0.5 \%$ in the FAVC condensate. Runs HG3 and HG4 had similar distributions. Higher amounts of Hg downstream of the SRAT condenser were expected for the hot condenser run HG4, but no reason was found for why HG3 would also have significant $\mathrm{Hg}$ in the condensates. The concentrations of $\mathrm{Hg}$ in the SRAT dewater and scrubber ranged from 12-379 and 36-311 mg/L, respectively. The last three runs, HG8-10 had the highest amount of Hg deposits on the SRAT condenser and MWWT walls.

Table 4-5. Distribution of mercury in the offgas system

\begin{tabular}{|c|c|c|c|c|c|c|c|c|c|c|}
\hline Run & Description & $\begin{array}{c}\text { Stoich. } \\
\text { Acid } \\
(\%) \\
\end{array}$ & $\begin{array}{c}\text { Hg in } \\
\text { MWWT } \\
\text { (\% of } \\
\text { Added) }\end{array}$ & \begin{tabular}{|c} 
Hg in \\
Offgas \\
System \\
(\% of \\
Added) \\
\end{tabular} & $\begin{array}{c}\text { Hg in } \\
\text { MWWT } \\
(\%)\end{array}$ & $\begin{array}{c}\text { Hg in } \\
\text { Dewater } \\
(\%)\end{array}$ & $\begin{array}{c}\text { Hg in } \\
\text { Scrubber } \\
(\%)\end{array}$ & $\begin{array}{c}\text { Hg in } \\
\text { FAVC } \\
\text { Cond. } \\
(\%)\end{array}$ & $\begin{array}{c}\text { Hg in } \\
\text { MWWT as } \\
\text { Deposits } \\
\text { (\% of } \\
\text { MWWT } \\
\text { Total) } \\
\end{array}$ & $\begin{array}{c}\text { Hg } \\
\text { Refluxed } \\
\text { (\% of } \\
\text { Total } \\
\text { Added) } \\
\end{array}$ \\
\hline HG1 & & $135 \%$ & $14 \%$ & $15 \%$ & $95 \%$ & $0.4 \%$ & $4 \%$ & $0.3 \%$ & negligible & $1.8 \%$ \\
\hline HG2 & $\mathrm{Hg}$ in $\mathrm{HNO}_{3}$ & $135 \%$ & $18 \%$ & $20 \%$ & $90 \%$ & $0.2 \%$ & $9 \%$ & $0.1 \%$ & negligible & $2.0 \%$ \\
\hline HG3 & & $110 \%$ & $12 \%$ & $15 \%$ & $79 \%$ & $8 \%$ & $13 \%$ & $0.3 \%$ & negligible & $4.8 \%$ \\
\hline HG4 & hot condenser & $110 \%$ & $12 \%$ & $13 \%$ & $81 \%$ & $7 \%$ & $12 \%$ & $0.5 \%$ & $4 \%$ & $2.8 \%$ \\
\hline HG5 & heel & $110 \%$ & $14 \%$ & $15 \%$ & $93 \%$ & $3 \%$ & $4 \%$ & $0.1 \%$ & $15 \%$ & $2.8 \%$ \\
\hline HG6 & excess antifoam & $110 \%$ & $27 \%$ & $31 \%$ & $87 \%$ & $4 \%$ & $9 \%$ & $0.1 \%$ & $9 \%$ & $7.0 \%$ \\
\hline HG7 & no noble metals & $\sim 170 \%$ & $14 \%$ & $14 \%$ & $97 \%$ & $0.3 \%$ & $2 \%$ & $0.1 \%$ & $9 \%$ & $2.2 \%$ \\
\hline HG8 & $\begin{array}{l}\text { high noble } \\
\text { metals }\end{array}$ & $110 \%$ & $21 \%$ & $22 \%$ & $93 \%$ & $5 \%$ & $1 \%$ & $0.1 \%$ & $35 \%$ & $5.8 \%$ \\
\hline HG9 & high agitation & $110 \%$ & $6 \%$ & $6 \%$ & $76 \%$ & $11 \%$ & $12 \%$ & $0.5 \%$ & $20 \%$ & $1.6 \%$ \\
\hline HG10 & $\begin{array}{c}\text { high solids } \\
\text { (28 vs } 23 \%)\end{array}$ & $110 \%$ & $11 \%$ & $11 \%$ & $85 \%$ & NA & $15 \%$ & $0.8 \%$ & $25 \%$ & $6.1 \%$ \\
\hline
\end{tabular}


In run HG4, the SRAT condenser was operated with $65{ }^{\circ} \mathrm{C}$ cooling water rather than the normal $25{ }^{\circ} \mathrm{C}$ water. It was expected that the amount of mercury condensed in the SRAT condenser and ultimately ending up in the MWWT and dewater would be less at the higher condenser temperature. Conversely, the amount that would be found in the ammonia scrubber liquid was expected to be higher. Table 4-6 shows that the predicted $\mathrm{Hg}$ condensed in the SRAT condenser decreases from $99.5 \%$ to $91.3 \%$ at the higher temperature and that the amount in the scrubber increases from zero to $8.2 \%$. These predictions assume thermodynamic equilibrium and do not account for the chemical reactions of $\mathrm{NO}_{\mathrm{x}}$ with water and mercury dissolution. The scrubber temperature was assumed to be $25^{\circ} \mathrm{C}$. The predicted amount of mercury in the scrubber with the condenser operating at $25^{\circ} \mathrm{C}$ is therefore zero. For both SRAT condenser temperatures and the scrubber temperature of $25^{\circ} \mathrm{C}$, the predicted $\mathrm{Hg}$ in the FAVC is the same.

The actual distributions of mercury measured are also given in Table 4-6. For several runs (HG1, 5, 7, 8) the mercury distributions are close to the predictions. Because the contact time in the SRAT condenser is not necessarily long enough to reach equilibrium, less $\mathrm{Hg}$ condensed than predicted is expected. Two runs (HG2, 6) had distributions very close to what was predicted for the $65^{\circ} \mathrm{C}$ condenser temperature even though the condenser temperature was $25^{\circ} \mathrm{C}$. The HG3, 9, and 10 runs, also at $25^{\circ} \mathrm{C}$, had even lower amounts of mercury condensation that were approximately equal to the HG4 high temperature run results. The HG3, 4, 9, and 10 results all had less $\mathrm{Hg}$ in the condensate and more in the scrubber liquid than predicted. No reason could be found for why the HG3, 9, and 10 results would be close to the high temperature condenser results. The actual condenser gas and condensate temperatures for these runs ranged from a few degrees less than $25{ }^{\circ} \mathrm{C}$ to about $35{ }^{\circ} \mathrm{C}$ in some cases, with most data between 23 $30^{\circ} \mathrm{C}$.

The hot condenser data suggest that higher condenser temperature results in less condensed $\mathrm{Hg}$ as predicted, but the HG3, 9, and 10 data indicate that there may be other factors beyond temperature that affect $\mathrm{Hg}$ condensation. Overall, the results are inconclusive about the effect of SRAT condenser temperature on mercury condensation.

Table 4-6. Comparison of predicted and measured distribution of mercury in offgas system

\begin{tabular}{|c|c|c|c|c|c|c|c|c|}
\hline & \multicolumn{3}{|c|}{$\begin{array}{l}\text { Predicted Hg } \\
\end{array}$} & & \multicolumn{3}{|c|}{ Measured Hg } & \\
\hline $\begin{array}{c}\text { SRAT } \\
\text { Condenser } \\
\text { Temp. }\left({ }^{\circ} \mathrm{C}\right)\end{array}$ & $\begin{array}{c}\text { Condensed } \\
\text { in SRAT } \\
\text { Condenser } \\
(\%)\end{array}$ & $\begin{array}{c}\text { Scrubber } \\
(\%)\end{array}$ & $\begin{array}{c}\text { FAVC } \\
(\%)\end{array}$ & Run & $\begin{array}{c}\text { Condensed } \\
\text { in SRAT } \\
\text { Condenser* } \\
(\%)\end{array}$ & $\begin{array}{c}\text { Scrubber } \\
(\%)\end{array}$ & $\begin{array}{c}\text { FAVC } \\
(\%)\end{array}$ & $\begin{array}{c}\text { Total in } \\
\text { Offgas } \\
\text { System } \\
\text { (\% of added) }\end{array}$ \\
\hline \multirow{9}{*}{25} & \multirow{9}{*}{99.5} & \multirow{9}{*}{0} & \multirow{9}{*}{0.4} & HG7 & 98 & 2 & 0.1 & 14 \\
\hline & & & & HG8 & 98 & 1 & 0.1 & 22 \\
\hline & & & & HG5 & 96 & 4 & 0.1 & 15 \\
\hline & & & & HG1 & 95 & 4 & 0.3 & 15 \\
\hline & & & & HG2 & 91 & 9 & 0.1 & 20 \\
\hline & & & & HG6 & 91 & 9 & 0.1 & 31 \\
\hline & & & & HG9 & 88 & 12 & 0.5 & 6 \\
\hline & & & & HG3 & 87 & 13 & 0.3 & 15 \\
\hline & & & & HG10 & 85 & $15 \dagger$ & 0.8 & 11 \\
\hline 65 & 91.3 & 8.2 & 0.4 & HG4 & 88 & 12 & 0.5 & 13 \\
\hline
\end{tabular}

Percent is \% of total evaporated; *measured in SRAT condenser includes dewater; scrubber liquid assumed to be at $25^{\circ} \mathrm{C}$; †no dewater, so expected to be higher. 


\subsubsection{Form of Mercury in the Offgas System}

The HG runs used the ABC simulant that was produced for the hydrogen program. This simulant had a very small amount of sodium iodide (NaI) added. Iodide has not been added to most recent simulants, including the SB6 and SB7 and glycolic/formic (GF) simulants. The presence of radioactive ${ }^{129}$ I in actual tank waste is measured, but no total iodine measurement is made.

The amount of chloride in the simulants also varied. In the simulants, ruthenium is added as $\mathrm{RuCl}_{3}$, so this contributes additional chloride. The chloride and iodide compositions of several simulants and several DWPF sludge batches are given in Table 4-7. The GF (SB6-H) simulants had the highest Cl, while the SB7 simulants intentionally had the lowest (prior to $\mathrm{RuCl}_{3}$ addition). The SB6-E and SB6-Phase II simulants were also low in Cl. Prior to discovering the significant effect of the presence of chloride and iodide on the behavior of mercury in the SRAT and SME, the additions of small amounts of these anions ( $350 \mathrm{mg} / \mathrm{kg} \mathrm{Cl}, 100 \mathrm{mg} / \mathrm{kg}$ I) were deemed to be of no consequence.

The chloride content of the DWPF sludge batches does not include any chloride that may be added with the ARP or MCU streams or in process water additions. Also, the measured chloride in the DWPF sludge batches was either from a supernate sample or a diluted filtered slurry sample; no attempts have been made to determine if there are any undissolved chlorides that do not dissolve upon dilution.

Comparison of the simulant and radioactive chloride compositions do show that for many simulants, the amount of chloride is probably too high. If the SB1-3 values apply, then all simulants are too high in chloride once ruthenium chloride is added. However, the presence of $\mathrm{Hg}_{2} \mathrm{Cl}_{2}$ in DWPF melter offgas system deposits does show that there has been sufficient chloride in DWPF feeds for this compound to form. ${ }^{28}$ The ABC simulant with a low addition of noble metals and the SB7 simulant that had no chloride added are the lowest simulants tested. The SB6-H simulant is the highest in chloride.

Table 4-7. Chloride and iodide content of simulants and radioactive sludge batches

\begin{tabular}{|c|c|c|c|}
\hline Simulant & $\begin{array}{c}\mathrm{Cl} \\
\text { (mg/kg slurry) }\end{array}$ & $\begin{array}{c}\text { Total I } \\
\text { (mg/kg slurry) }\end{array}$ & \\
\hline SB6-E, SB6-Phase II ${ }^{2}$ & $175-224$ & none added & measured \\
\hline SB6-H (GF runs) $)^{6,29}$ & 776 & none added & target \\
\hline SB6-H + noble metals & $900-1200$ & none added & measured \\
\hline $\mathrm{SB7a}^{5}$ & $<100$ & none added & target, measured \\
\hline SB7a + noble metals & $194-490$ & none added & measured \\
\hline ABC simulant ${ }^{18}$ & 349 & 81 & target \\
\hline HG7 (ABC, no noble metals) & 310 & NA & measured \\
\hline HG runs $(\mathrm{ABC})+$ noble metals (HG1-6,9,10) & $414-478$ & NA & measured \\
\hline HG8 high noble metals & 586 & NA & measured \\
\hline \multicolumn{4}{|l|}{ DWPF Sludge Batch } \\
\hline SB1a Qualification washed sample ${ }^{30}$ & 33 & NA & measured \\
\hline SB2 Qualification washed sample ${ }^{31}$ & 13 & NA & measured \\
\hline SB3 WAPS sample ${ }^{32}$ & 23 & NA & measured \\
\hline SB4 WAPS sample ${ }^{33}$ & $<523$ & NA & measured \\
\hline SB5 WAPS sample ${ }^{34}$ & $<310$ & NA & measured \\
\hline SB6 WAPS sample ${ }^{35}$ & 47 & NA & measured \\
\hline SB7a Qualification washed sample ${ }^{36}$ & $<216$ & NA & measured \\
\hline SB7b Tank 51 sample $^{37}$ & $<181$ & NA & measured \\
\hline
\end{tabular}


The physical form of mercury collected in the MWWT and offgas system ranged from large beads of Hg in the MWWT to a dispersion of Hg beads to blackish solids. Runs HG1-6 all resulted, for the most part, in small clean beads of elemental Hg in the MWWT and very little deposition elsewhere. These beads were very small as shown in Figure 4-25. When collected into a vial, the small beads coalesced. Because the Hg was drained periodically, it may not have achieved sufficient mass to coalesce as has occurred in previous runs. The SB6 and SB7 tests have produced mostly clean mercury beads in the MWWT, but numerous small beads packed together have also been seen. Figure 4-25 also shows the mercury in the MWWT at the end of run HG6 with high antifoam. Near the end of the run, the Hg collected started to form a "fluffy" green coating on its surface that did not drain from the MWWT. A sample of this green material could not be isolated. This sort of green deposit only occurred during the high antifoam run.

Figure 4-26 shows additional photos of mercury in the offgas system for the high antifoam run HG6. The condenser tubes had many deposits of very finely divided elemental mercury. These small beads of $\mathrm{Hg}$ tended to concentrate in crevices such as the small area between the condenser tube and the thermocouple. Careful examination of these beads indicated that they were not actually blackish; the dull gray tint is due to the very small size of the beads. Also shown are sticky deposits at the bottom of the MWWT and the start of the green layer above the Hg beads. The high antifoam run had the most deposition of mercury in the SRAT condenser of all the runs that produced shiny mercury in the MWWT. 


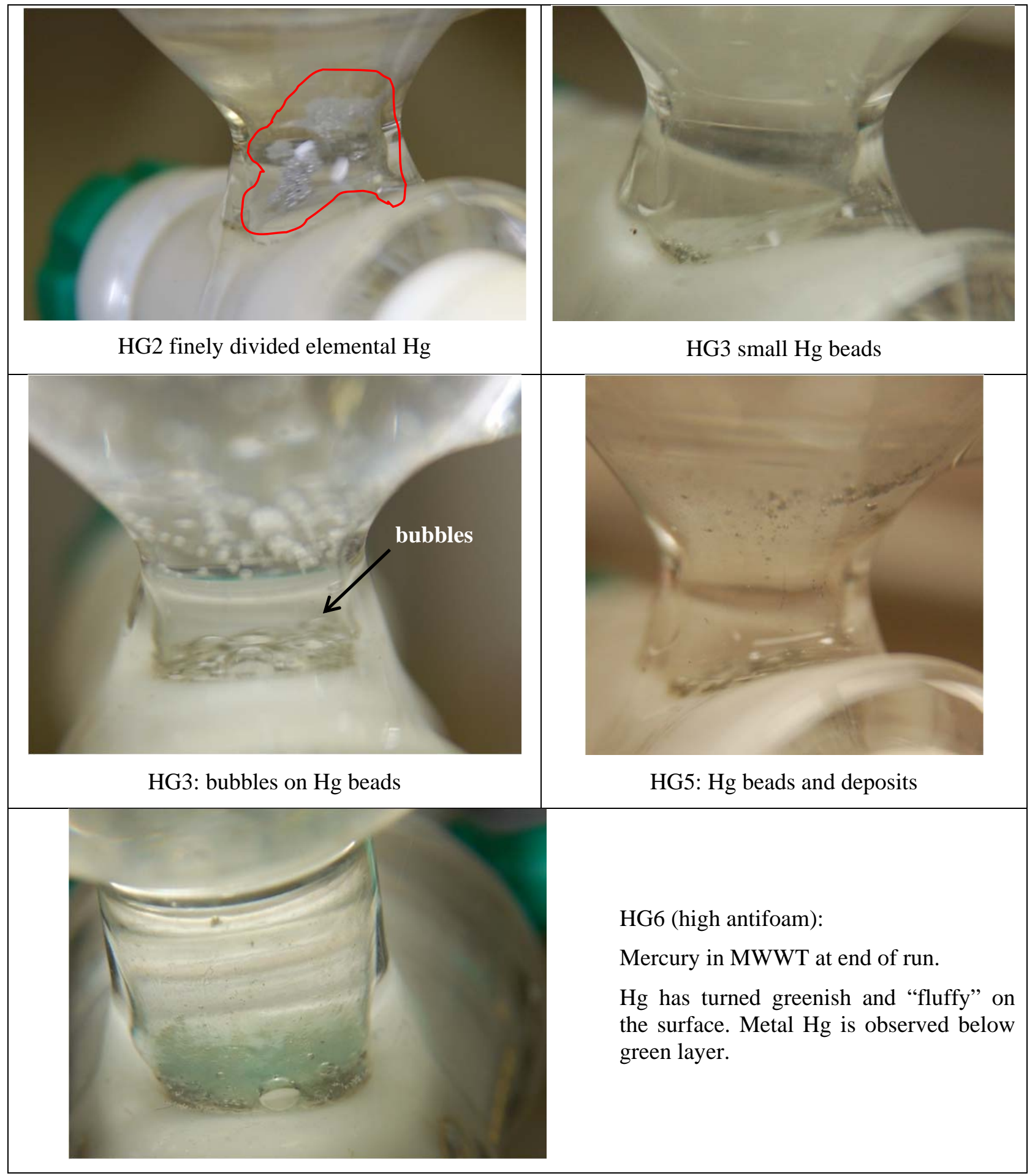

Figure 4-25. Runs HG2 to HG6 MWWT Hg photos 


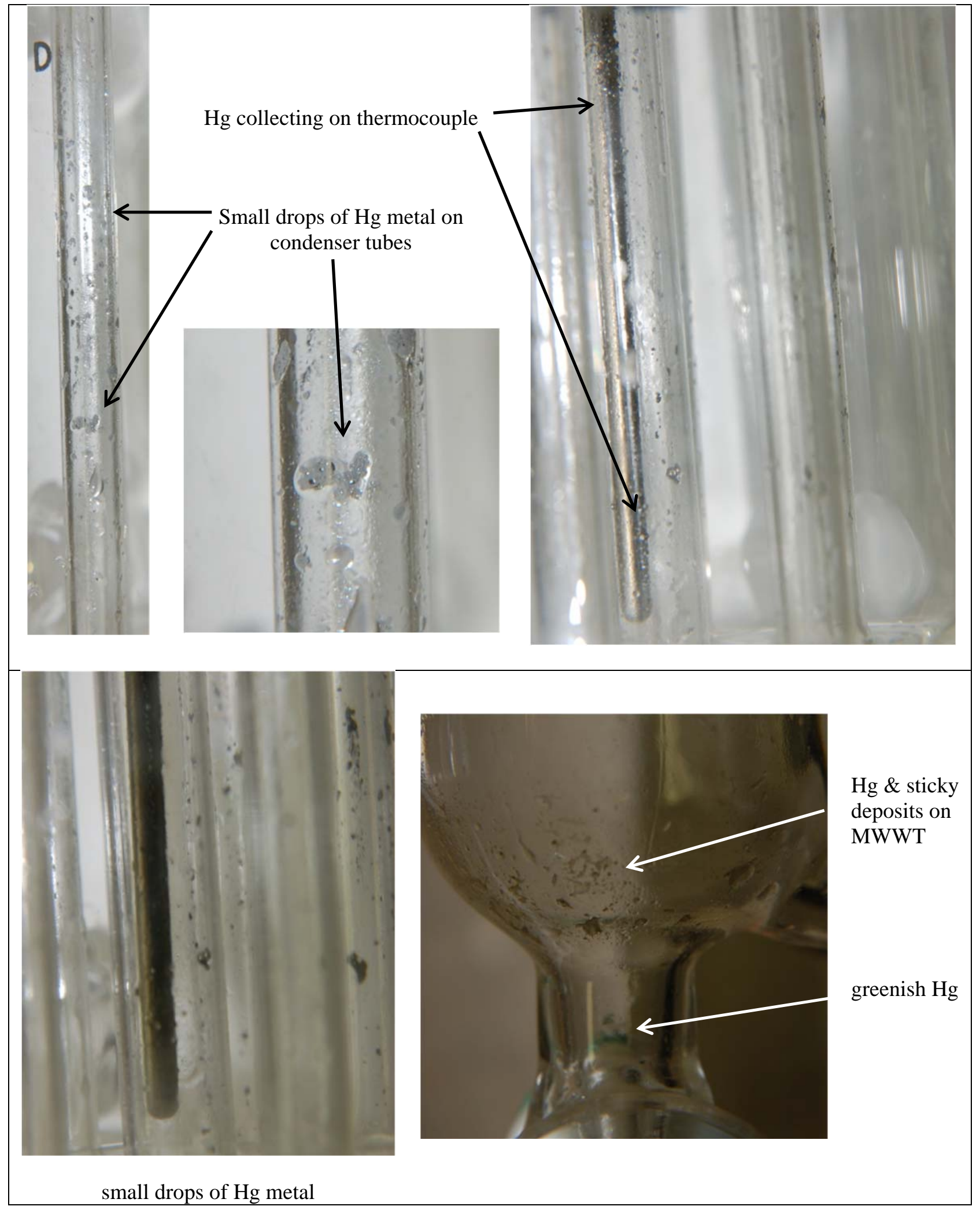

Figure 4-26. Mercury deposits in offgas system in Run HG6 
Photos of the offgas components for HG7 are shown in Figure 4-27. The upper left photo shows that organics had deposited on the SRAT condenser downcomer; this photo was taken after the glassware had been soaked in 8M nitric acid for several days. The other photos show that the condenser tubes, MWWT walls, and the collected mercury all contained blackish mercury deposits. The form of mercury in the MWWT was small beads covered in blackish deposits. Some of this material was analyzed by X-ray diffraction (XRD) and was found to be mercurous iodide $\mathrm{Hg}_{2} \mathrm{I}_{2}$. The XRD and X-ray fluorescence (XRF) data are shown in Figure 4-28. This material is very similar in appearance to the mercurous chloride $\mathrm{Hg}_{2} \mathrm{Cl}_{2}$ that has been found in previous runs (and discussed below). Some of this material was found to occasionally float on top of the condensate in the MWWT. 


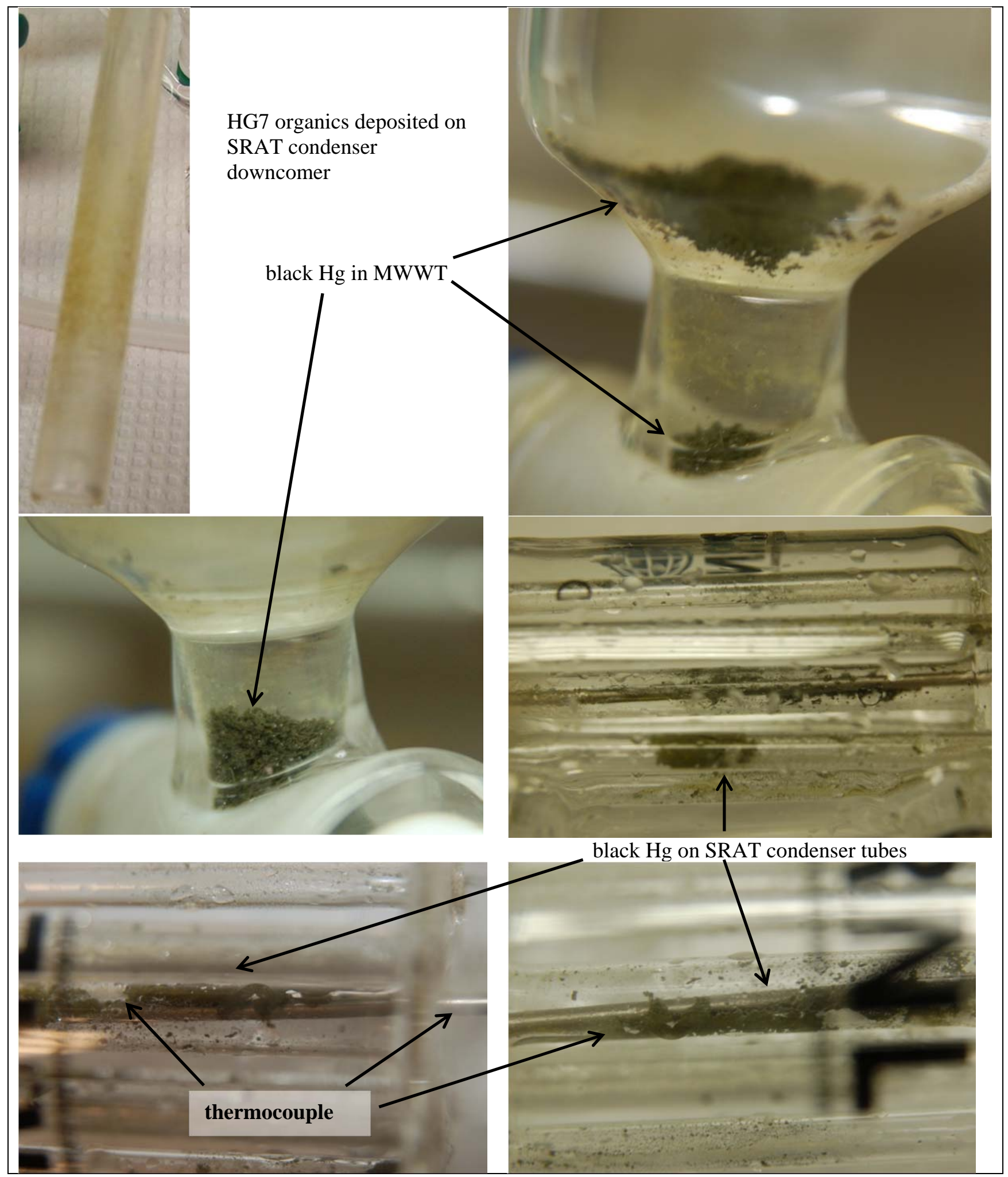

Figure 4-27. Black mercury deposits from run HG7 

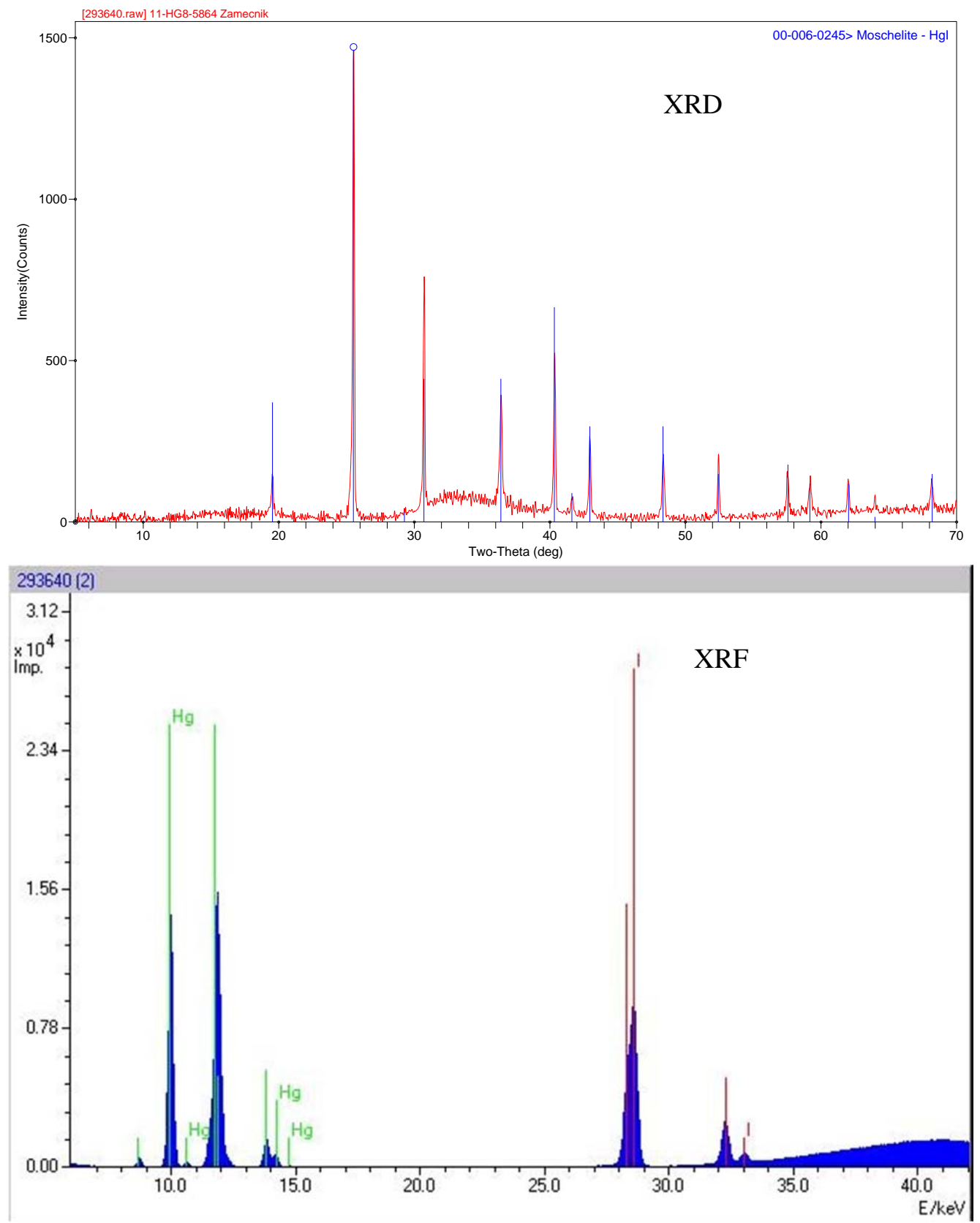

Figure 4-28. XRD and XRF analyses of Run HG7 offgas deposits

The mercurous iodide deposited in the MWWT in run HG8 is shown on the left in Figure 4-29. The same deposits during cleaning with 8M nitric acid are shown in the right side of Figure 4-29. The blackish deposits have turned bright orange which was most likely mercuric oxide HgO. Eventually, all of the orange solids completely dissolved in the acid. These photos are shown because similar behavior might be seen in the MWWT during a subsequent SRAT cycle formic acid addition step where nitric acid condensate is formed. 

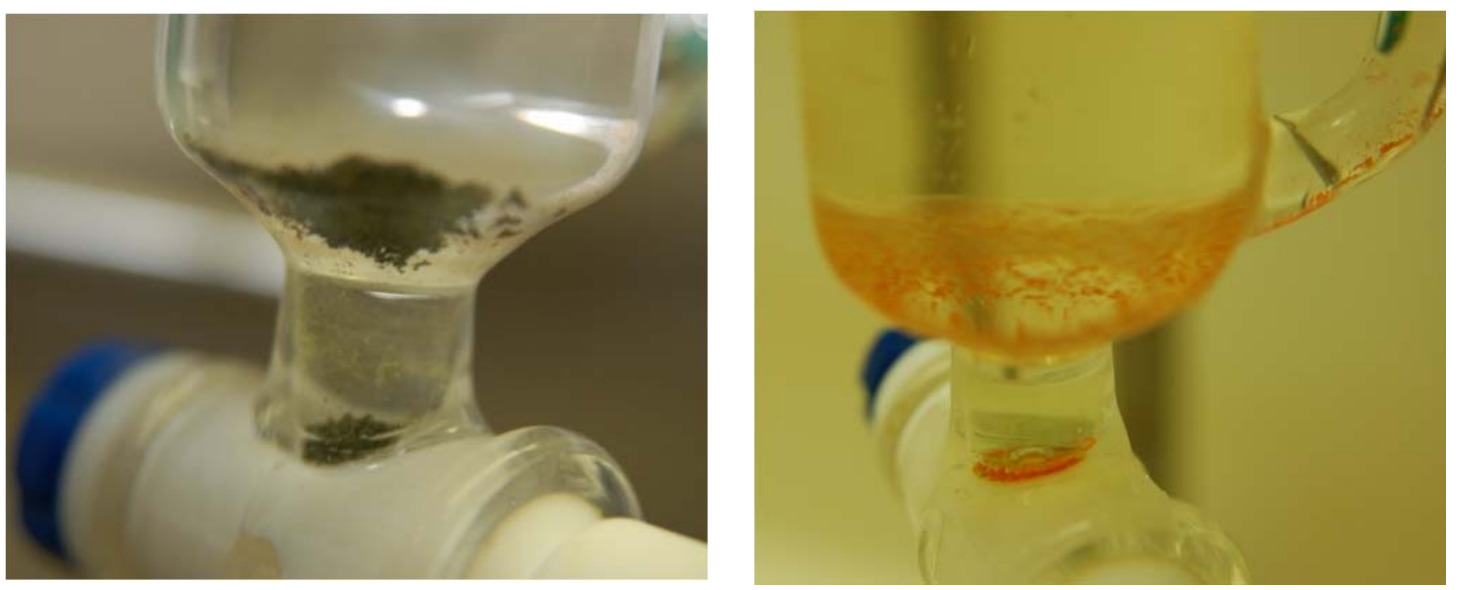

Figure 4-29. HG8 mercury deposits in MWWT before and during cleaning with 8M nitric acid

Finding the iodide was very surprising and led to discovering that the ABC simulant formulation contained a small amount of added NaI. The target concentration of iodide in this simulant was approximately $110 \mathrm{mg} / \mathrm{L}$. The total iodine measured in several slurry feed samples, SRAT product slurry samples, and in the MWWT condensate at the end of the run are shown in Table 4-8. These analyses show that there probably was iodine present in all runs as expected from the simulant formulation.

Table 4-8. Total iodine in slurry samples

\begin{tabular}{|c|c|c|c|}
\hline Sample & $\begin{array}{c}\text { Feed } \\
\text { Iodine } \\
\text { mg/L }\end{array}$ & $\begin{array}{c}\text { SRAT Product } \\
\text { Iodine } \\
\text { mg/L }\end{array}$ & $\begin{array}{c}\text { MWWT End } \\
\text { of Run Iodine } \\
\text { mg/L }\end{array}$ \\
\hline ABC Simulant Target & 110 & - & - \\
\hline HG1 & 68.2 & 112 & 0.1 \\
\hline HG3 & 75.1 & 111 & NA \\
\hline HG4 & NA & NA & 0.6 \\
\hline HG8 & 48.7 & 29.6 & 2.3 \\
\hline HG10 & 36.1 & 88.7 & 1.4 \\
\hline
\end{tabular}

The formation of mercuric chloride and iodide $\left(\mathrm{HgCl}_{2}\right.$ and $\left.\mathrm{HgI}_{2}\right)$ is quite possible in the SRAT because $\mathrm{HgO}$ is in the same oxidation state as the mercuric compounds (+2) so that it probably forms some intermediate such as $\mathrm{Hg}^{2+}$ ion as it dissolves that can react with chloride and iodide. Both $\mathrm{HgCl}_{2}$ and $\mathrm{HgI}_{2}$ have significant vapor pressures compared to elemental $\mathrm{Hg}$ at $100^{\circ} \mathrm{C}$ because they exist as undissociated molecules in solution. The vapor pressures are 0.113 torr for $\mathrm{HgCl}_{2}$, approximately 0.100 torr for $\mathrm{HgI}_{2}$, and 0.273 torr for $\mathrm{Hg}$ metal. The addition of nitric acid may be sufficient to oxidize iodide to iodine $\mathrm{I}_{2}$, which is much more volatile, with a vapor pressure at $100^{\circ} \mathrm{C}$ of about 30 torr. If oxidation occurs, a significant amount of iodine would be expected to end up in the offgas condensate.

No reason has been found for why the mercury in the MWWT would be present as mercurous iodide in HG7-10 and not in the previous six HG runs. The ABC simulant was also used for run NGS-3 (next generation solvent) which was a test of the new SRAT equipment that repeated a previous NGS run; in this run, the mercury collected was also blackish as in runs HG7-10. 
Only the concentration of radioactive ${ }^{129}$ I is normally analyzed in the DWPF WAPS samples; the ${ }^{129}$ I concentration in the SB7a WAPS sample was $<2 \mathrm{mg} / \mathrm{kg}$ slurry. Total iodine has not been measured, so it is unknown if the iodine concentration could approach the amount present in the ABC simulant. Further investigation of the iodine content of wastes processed may be warranted due to the significant effect of small amounts of iodine on the offgas chemistry of mercury.

Figure 4-30 shows the SRAT condenser downcomer for several runs. The top two photos are from run GF3-17. Here small mercury beads initially deposited on the horizontal section and then later blackish deposits formed upstream closer to the condenser. Similar deposits collected from other GF runs were identified as mercurous chloride $\mathrm{Hg}_{2} \mathrm{Cl}_{2}$. In the GF runs, the chloride content was much higher than in other runs, as shown in Table 4-7. The bottom left photo shows mercury bead buildup in run SB6-23. Here the beads appear to be extremely finely dispersed Hg that because of their small size looks gray to black in color. These deposits do not appear to be mercurous halides. The bottom right photo shows buildup of finely divided $\mathrm{Hg}$ on the downcomer of a test with only elemental $\mathrm{Hg}$ in deionized water using newly fabricated equipment. This result shows that even with only $\mathrm{Hg}$ present and clean equipment, $\mathrm{Hg}$ metal can eventually deposit on surfaces. 


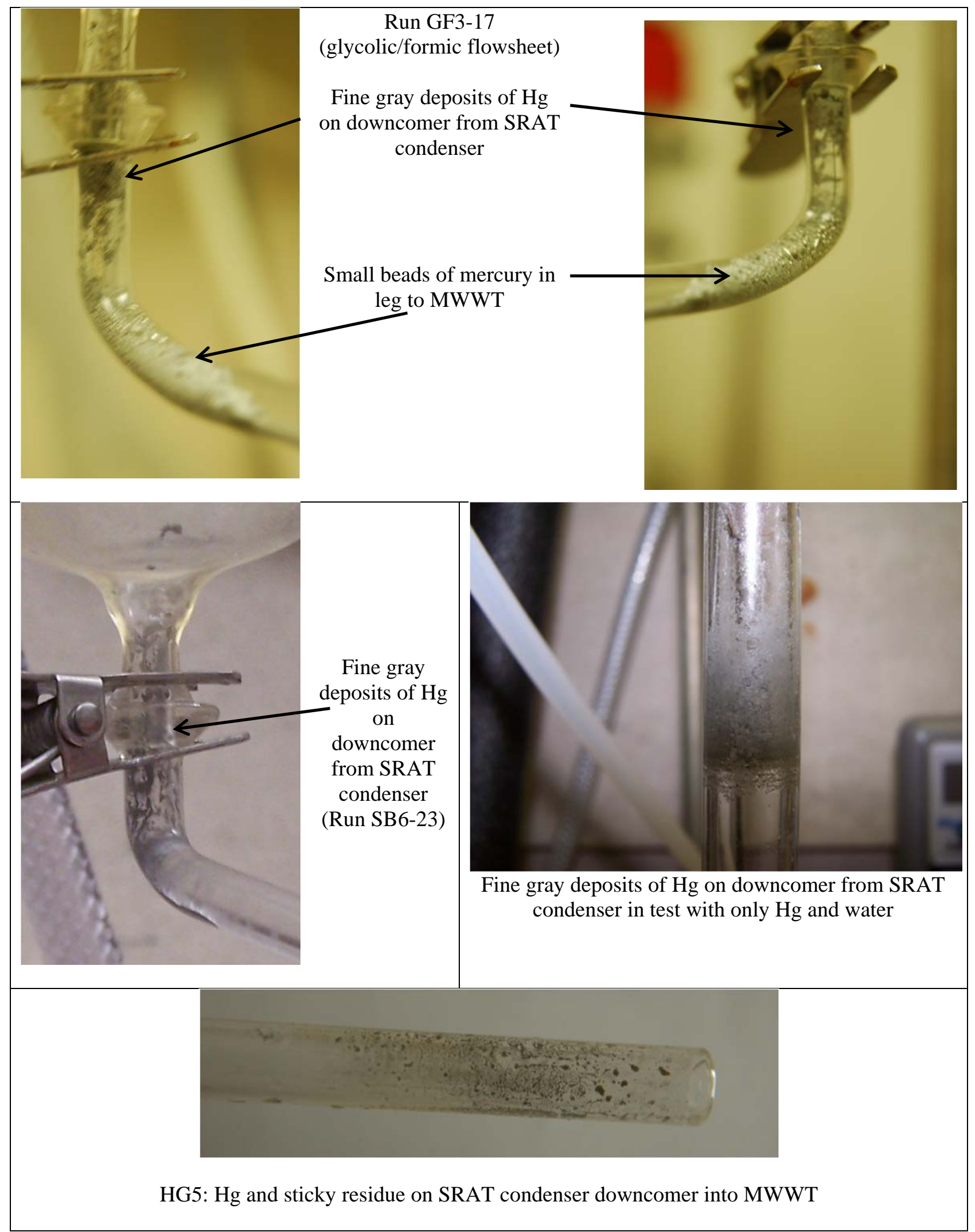

Figure 4-30. Mercury deposits in SRAT condenser downcomer for various runs 
Additional examples showing the range of forms of $\mathrm{Hg}$ that have been seen in the MWWT are shown in Figure 4-31. In SB7b-2, NGS-3, and NGS-SP the Hg has collected as very small beads. The NGS-3 run has sludge above the $\mathrm{Hg}$ collected due to a foam-over. These beads of $\mathrm{Hg}$ also appear to contain some $\mathrm{Hg}_{2} \mathrm{I}_{2}$. The photo of SB6-23 shows a single large mass of $\mathrm{Hg}$ metal that is not separated into smaller beads. This SB6 run used the simulant that was low in chloride (175-224 mg/kg slurry).

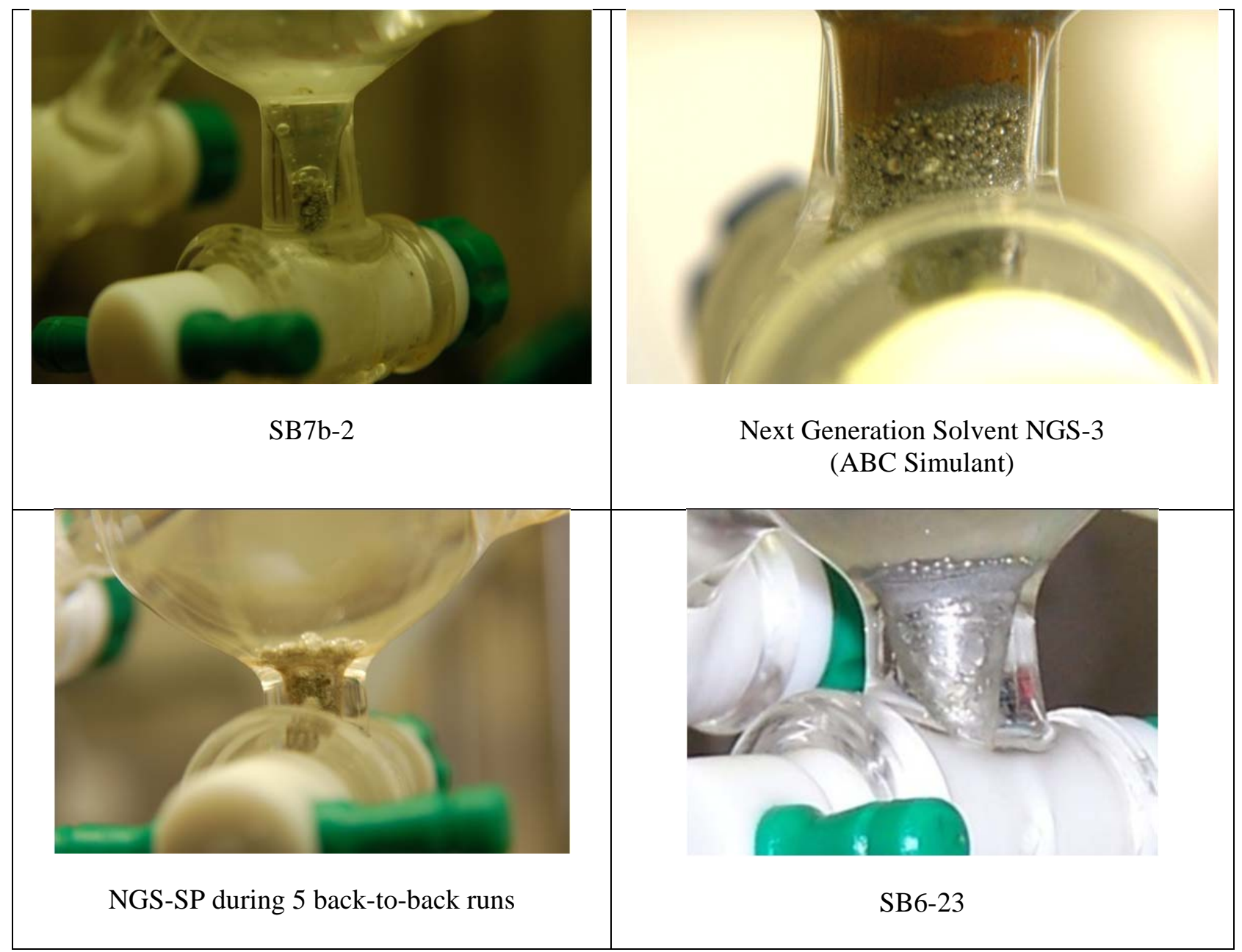

Figure 4-31. $\quad$ Mercury collected in MWWT for various runs

The effect of significant buildup of antifoam and antifoam degradation products is shown in Figure 4-32 for the five back-to-back NGS runs. In these runs, the SRAT condenser and MWWT were not cleaned between runs. There were significant deposits of antifoam on the condensate line and these antifoam deposits coated some of the mercury.

The blackish mercury collected from several of the GF runs was examined by XRD and optical microscopy. The photos are shown in Figure 4-33 at several magnifications. The mercury was found in a wide range of bead sizes; going to higher magnifications found smaller and smaller beads. The photo from GF8 shows clearly that the Hg beads were coated with a blackish material. This material was found by XRD to be mercurous chloride, $\mathrm{Hg}_{2} \mathrm{Cl}_{2}$. The XRD spectrum is shown in Figure 4-34. 


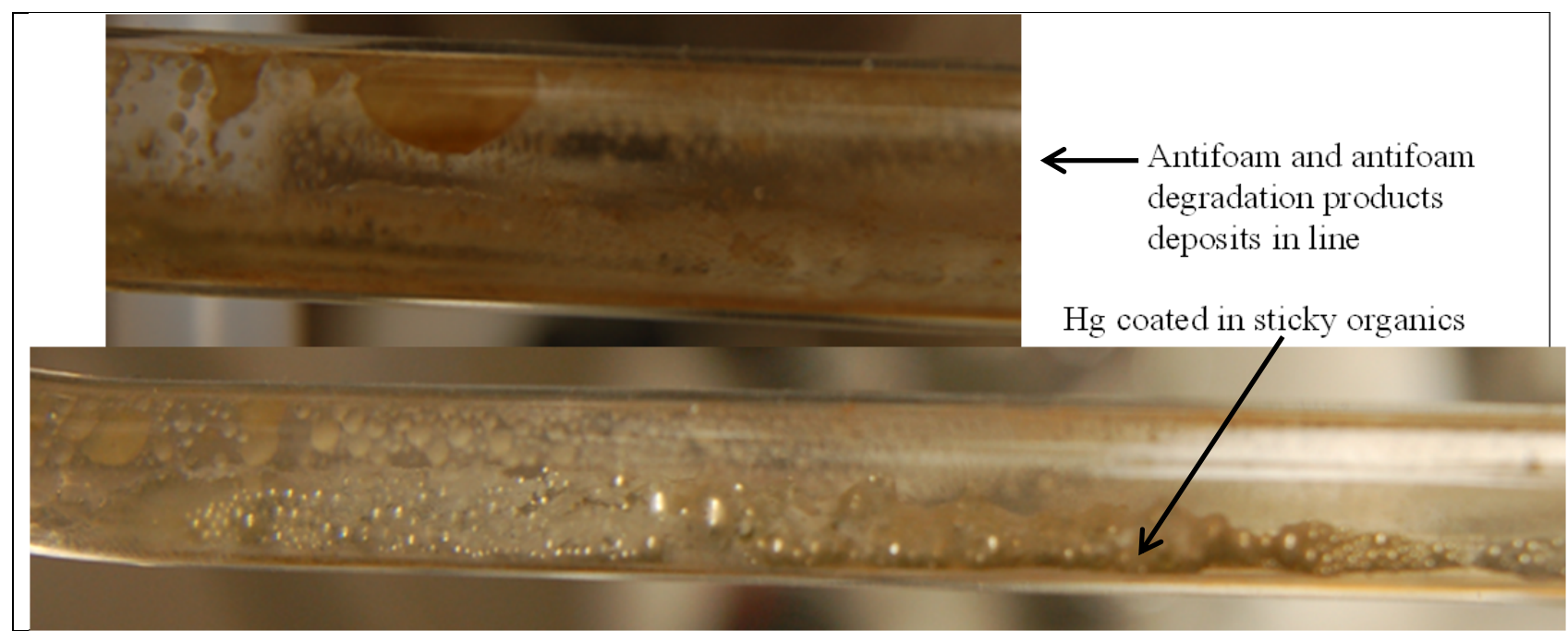

Figure 4-32. Organics buildup on SRAT condenser to MWWT line during NGS back-to-back runs

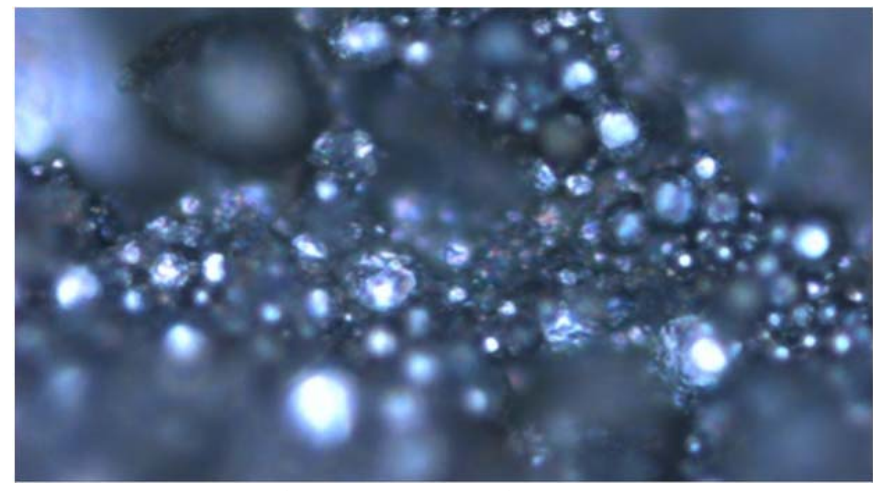

Mercury from MWWT for Run GF18 (40X magnification)

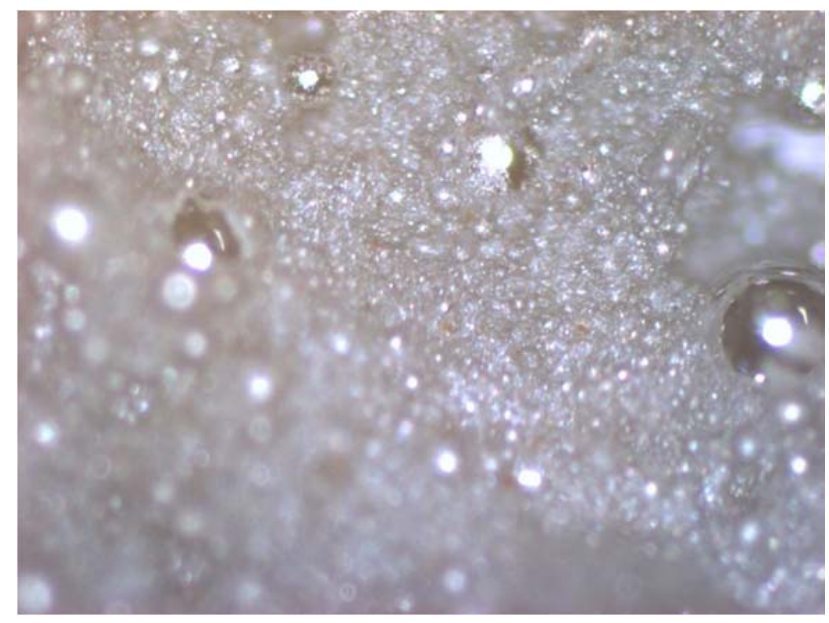

Mercury from MWWT for Run GF5 (10X magnification)

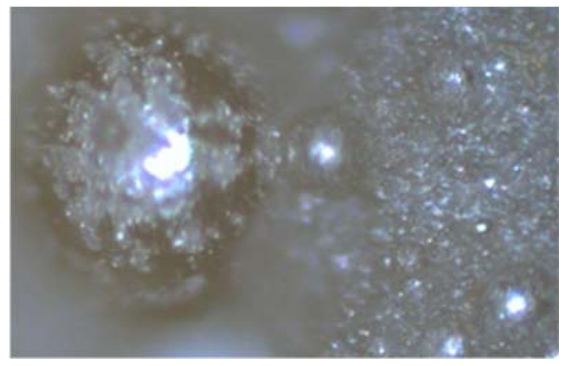

Mercury from MWWT for Run GF8 (10X magnification)

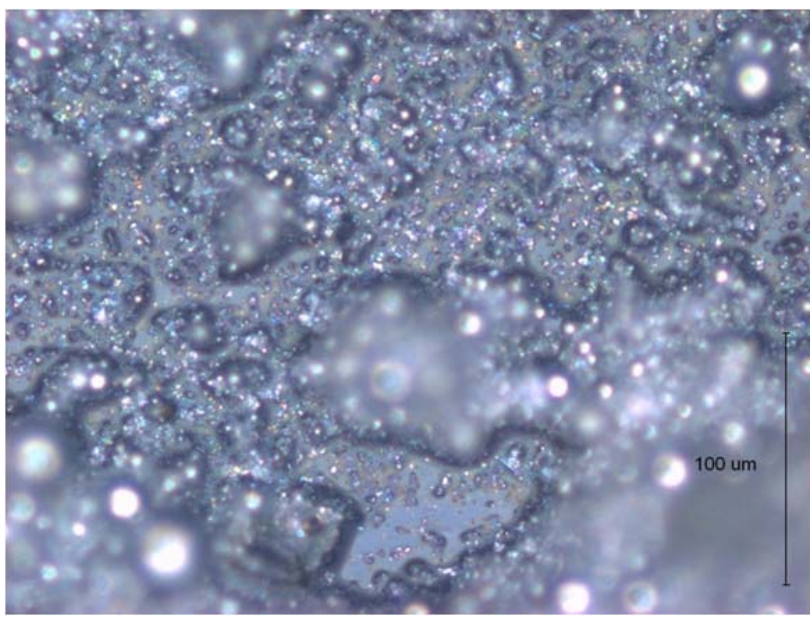

Mercury from MWWT for Run GF5 (20X magnification)

Figure 4-33. Microscope photos of mercury from MWWT in glycolic/formic runs 


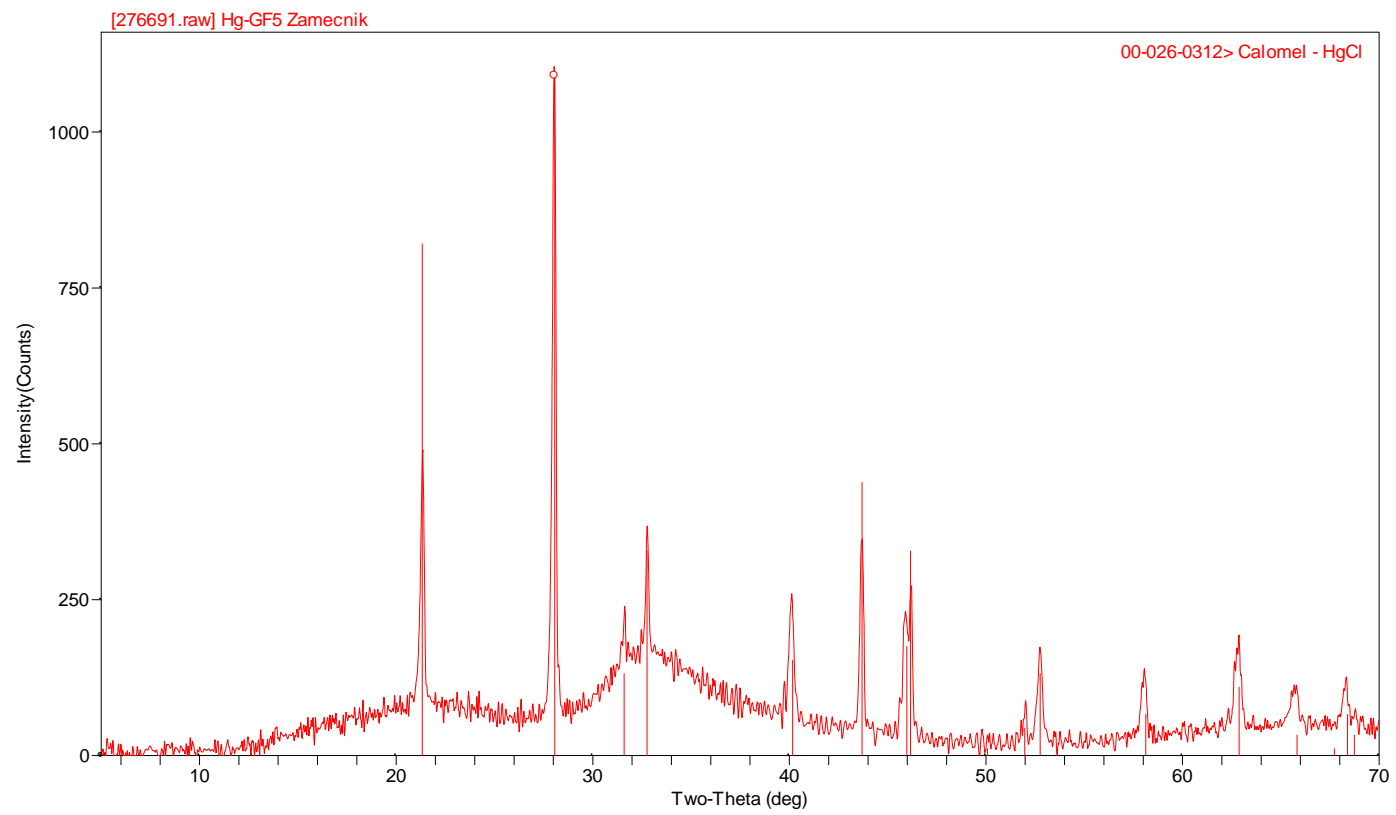

Figure 4-34. XRD spectrum of offgas deposit $\mathrm{Hg}_{2} \mathrm{Cl}_{2}$

Figure 4-35 and Table 4-9 show unusual results from run SB7b-10. This run was the first time where a significant amount of what was apparently colloidal elemental mercury was found in the MWWT. This material was found at the end of processing when the condensate contained no detectable anions. The condensate in the MWWT was totally transparent but it was also tinted with what can best be described as dark gray. The MWWT contents were placed in a vial and allowed to stand for several hours. During this time, very finely divided $\mathrm{Hg}$ began to precipitate out of solution. These solids settled very slowly; the next day the solids were found to be a grayish coating on the bottom of the vial. The middle photo shows that there were still extremely small particles suspended in the liquid. The photos also show that the most of the mercury was collected as a clean bead. This unusual behavior would lead to a significant amount of $\mathrm{Hg}$ being refluxed back to the SRAT in either lab tests or in DWPF. It is not known if this behavior has occurred in any previous runs because the attention given to the mercury in the MWWT has not always been high. 


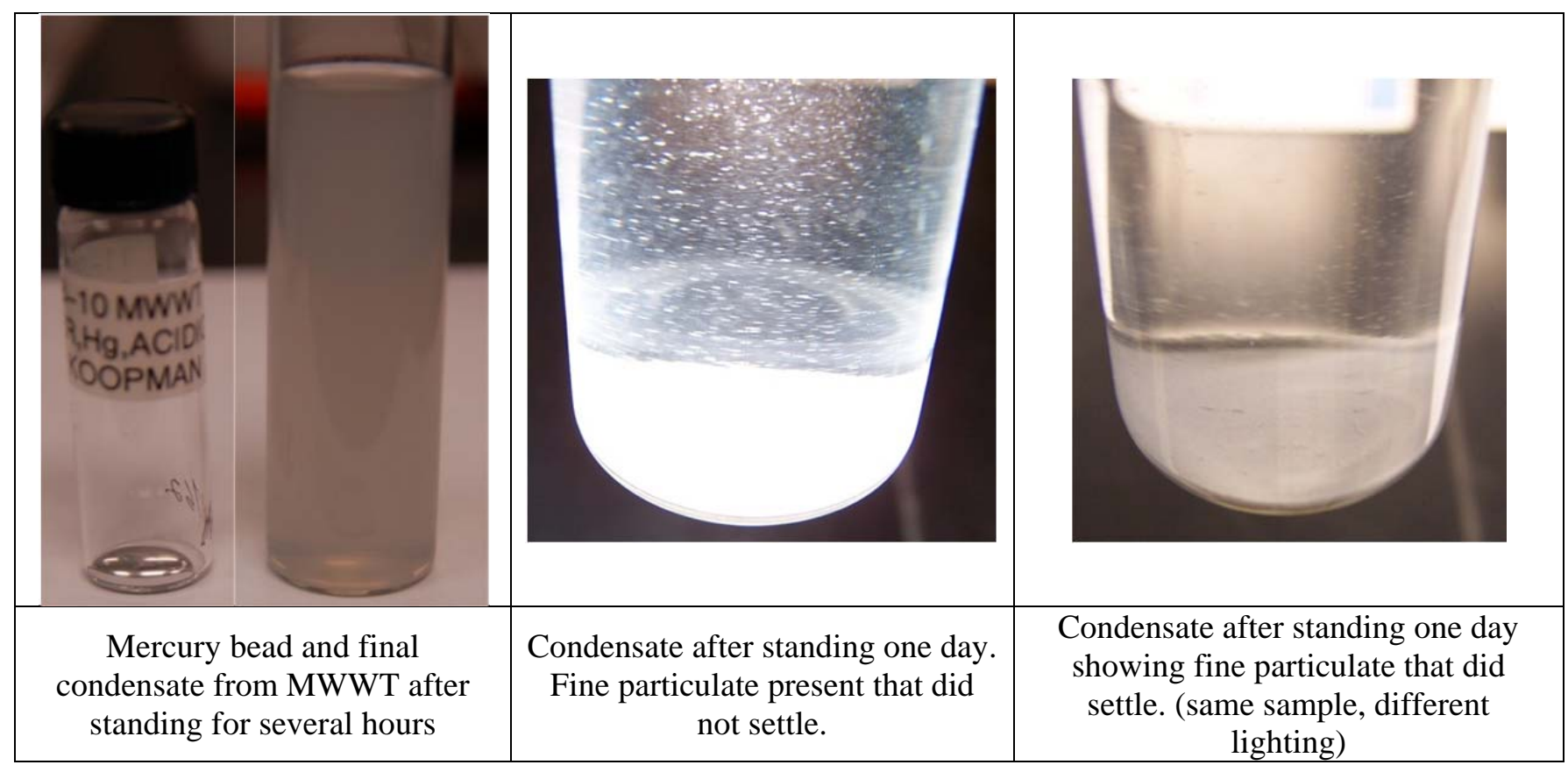

Figure 4-35. Mercury collected from MWWT in run SB7b-10

Table 4-9. Composition of MWWT sample from run SB7b-10

\begin{tabular}{|c|c|c|c|}
\hline & $\begin{array}{c}\text { Density } \\
(\mathbf{k g} / \mathbf{L})\end{array}$ & $\begin{array}{c}\mathbf{H g} \\
(\mathbf{m g} / \mathbf{L})\end{array}$ & $\begin{array}{c}\mathbf{C l}^{-}, \mathbf{N O}_{\mathbf{2}}^{-}, \mathbf{N O}_{\mathbf{3}}^{-}, \\
\mathbf{S O}_{\mathbf{4}}^{2-}, \mathbf{C O O H}^{-} \\
\mathbf{( m g / L )}\end{array}$ \\
\hline Total Sample & 1.12 & 150 & All $<100$ \\
\hline Supernate & 1.03 & 5.3 & All $<100$ \\
\hline
\end{tabular}

\subsubsection{Form of Mercury in the SRAT}

Samples of mercury were recovered from the bottom of the SRAT from the HG runs, from dried SRAT product for several GF runs, and from SME product from SB7a runs. Samples of Hg from the bottom of the SRAT in the HG runs were for the most part very similar. There were some larger Hg beads and many very small beads that appeared to be granular. Photos from run HG8 are shown in Figure 4-36. There was one large $\mathrm{Hg}$ bead and many smaller beads in addition to the granular material. The granular material may just be extremely finely divided $\mathrm{Hg}$ beads. This sample after drying is shown in Figure 4-37. Unreacted $\mathrm{HgO}$ was also found in this run and in HG6 and HG7; this unreacted HgO was easily visible at about 1/16" diameter and smaller. Extremely granular mercury from the HG6 run is shown in Figure 4-38. The Hg here has the consistency of a heavy mud and is very difficult to move. Unreacted HgO can also be seen. Unreacted $\mathrm{HgO}$ was not noticed in the mercury collected from earlier runs, but because the mercury formed larger beads in these runs, it was removed from the sludge more easily and decreased the likelihood of finding unreacted $\mathrm{HgO}$. The presence of unreacted $\mathrm{HgO}$ indicates that the method of addition of $\mathrm{HgO}$ should be improved. In the small batch tests, $\mathrm{HgO}$ was dispersed finely in water quite easily; this may be an improvement to the addition method for SRAT batches that would reduce the amount of unreacted HgO. The presence of unreacted HgO also results in the over-estimation of the amount of $\mathrm{Hg}^{0}$ segregated in the SRAT bottom because it is counted with the reduced $\mathrm{Hg}^{0}$. 

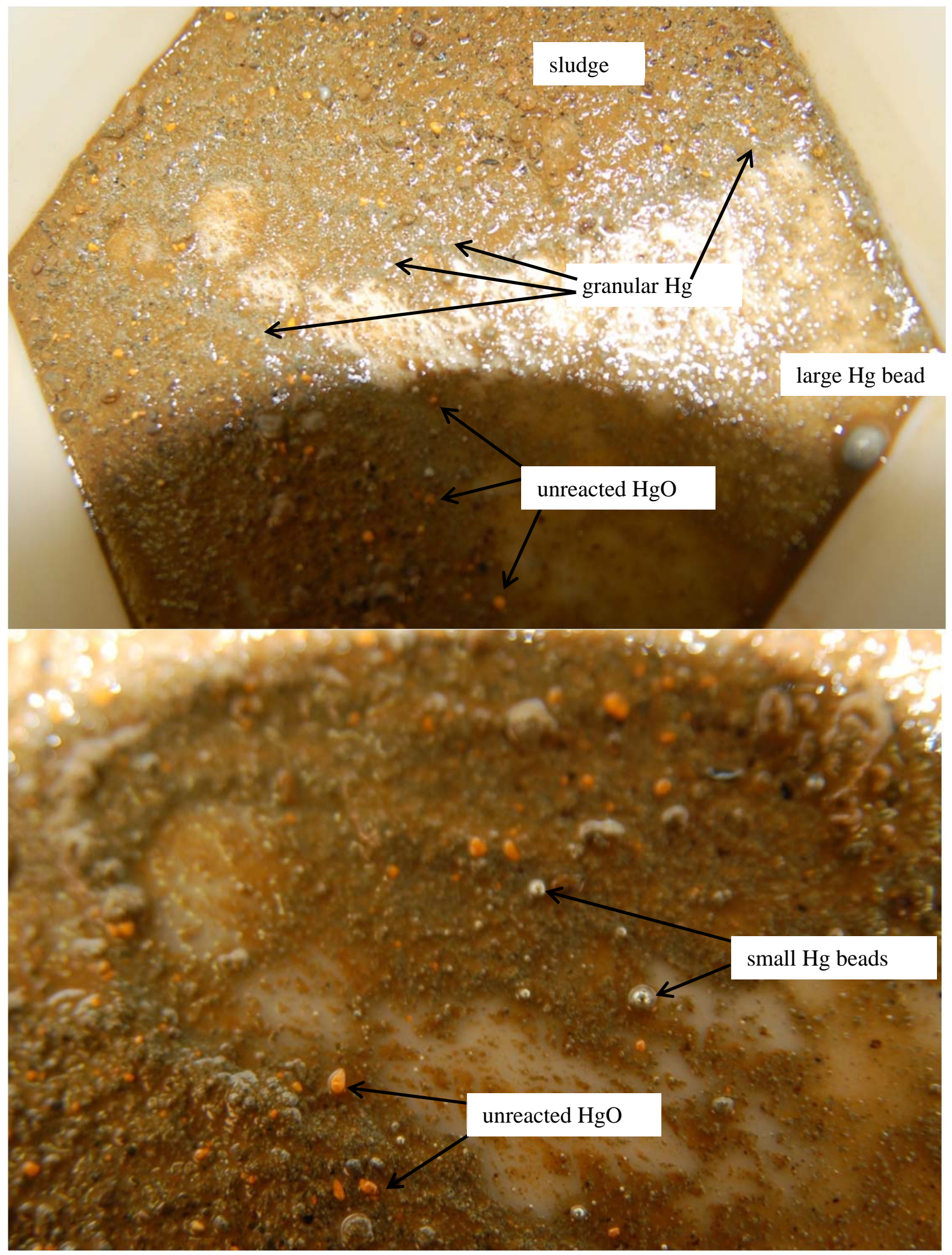

Figure 4-36. Mercury recovered from SRAT bottom for run HG8 


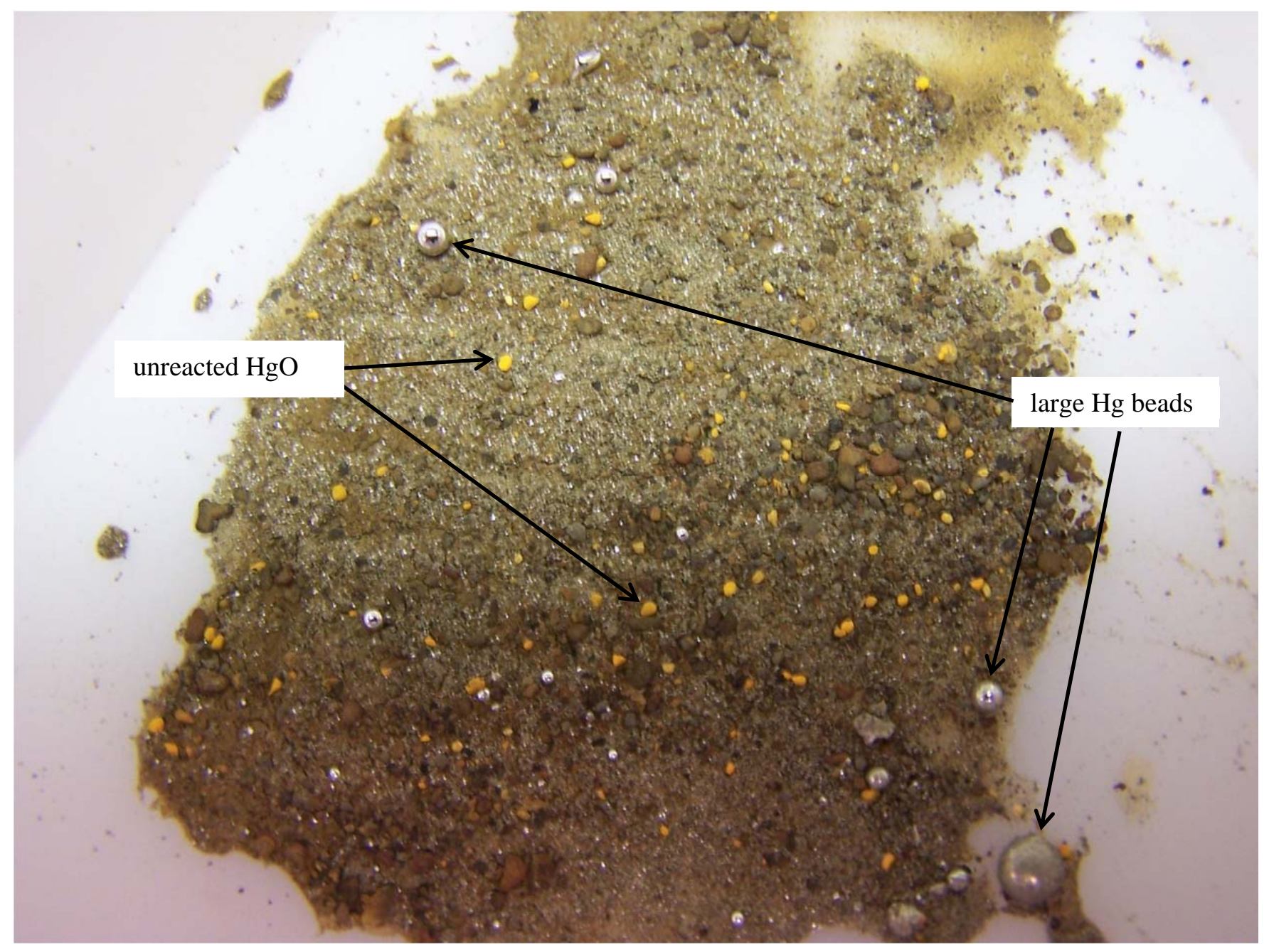

Figure 4-37. Mercury recovered from SRAT bottom for run HG8 - dried sample 


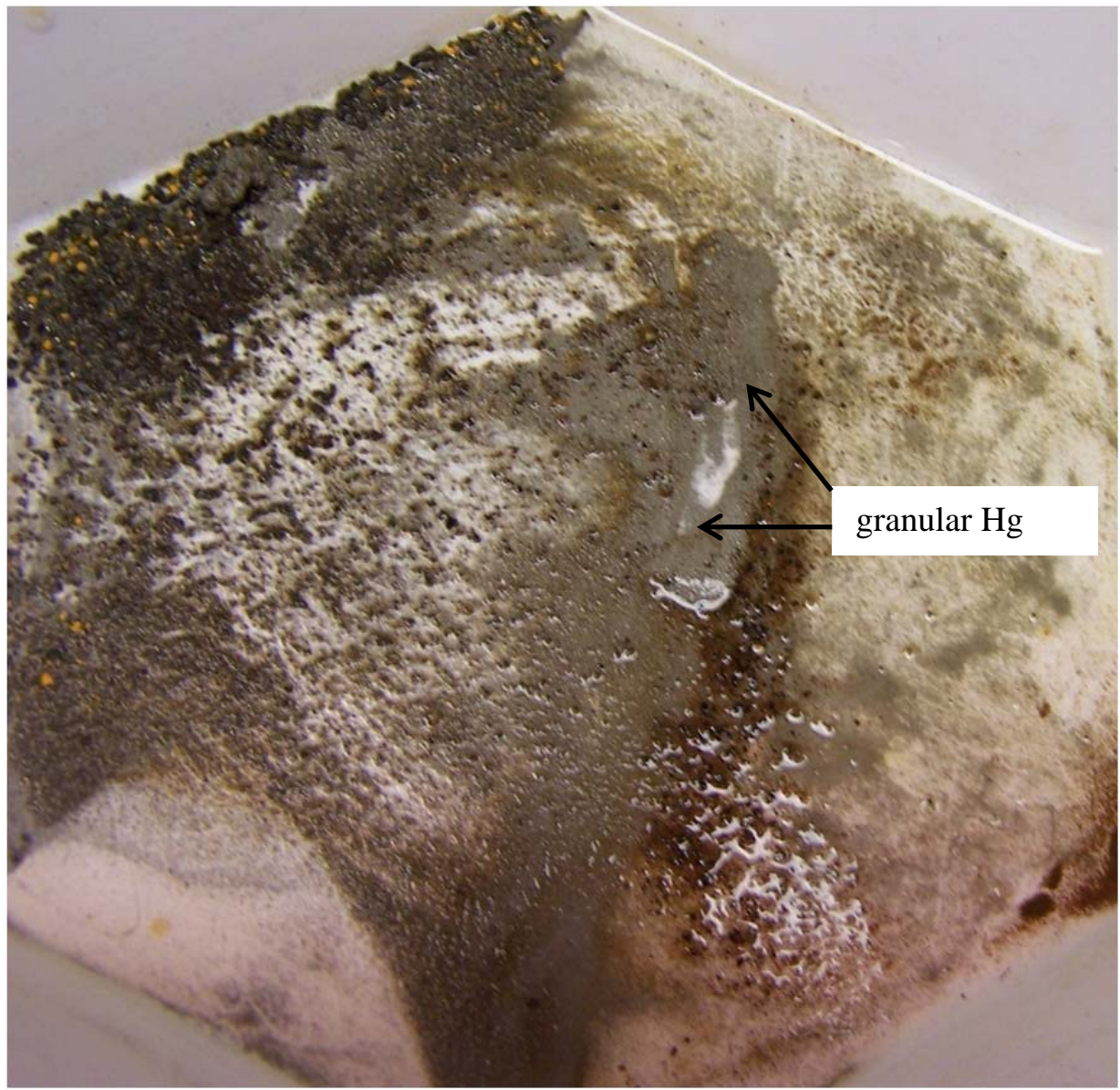

Figure 4-38. Extremely granular mercury from SRAT bottom from run HG6

The HG2 run where the mercury was added as HgO dissolved in nitric acid left the most unusual residue. This residue is shown in Figure 4-39. The outlined cylinder shows the approximate location of the immersion heating rod. The Hg residue on the side wall and bottom of the vessel was stuck very tightly to the glass and required scraping and water flushing to remove. These deposits were a mixture of $\mathrm{Hg}$ and sludge, and once removed, looked no different than the granular residue from other runs. There were no deposits on the heating rod itself. 


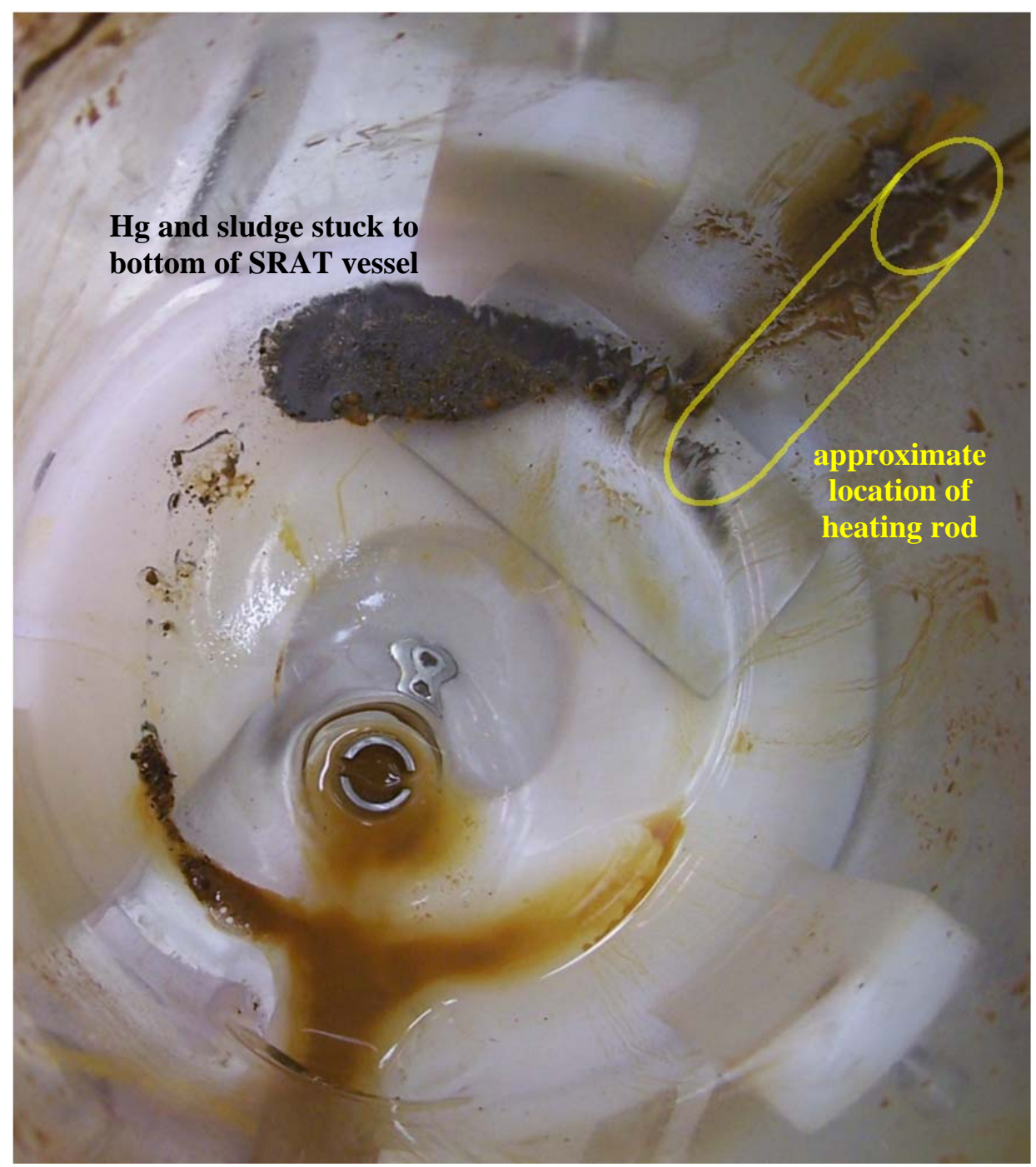

Figure 4-39. Mercury deposits in SRAT from Run HG2

The mercury recovered from several GF SRAT and SB7a SME dried products are shown in Table 4-10. These samples were dissolved in aqua regia and analyzed by ICP-ES. Significant amounts of several metals were found in these samples as amalgams. All of the samples contained one or more of the elements $\mathrm{Ag}, \mathrm{Cu}, \mathrm{Pd}, \mathrm{Rh}$, and $\mathrm{Ru}$. The SB7a-4 mercury bead contained about $93 \%$ of the total Ag added and $82 \%$ of the Pd added, but no detectable $\mathrm{Cu}$. All of the mercury containing copper had a copper color. Only the SB6-22 sample contained a detectable amount of Ru. The amounts of all the metals varied widely between the samples. The SB7a-6 and GF18 mercury phases were very viscous and could be formed into shapes as shown in the table. The mercury from the SB7a-4 and GF 20 runs acted similarly to pure elemental mercury.

These highly viscous mercury deposits would be much harder to remove with the DWPF mercury pump than would just elemental mercury. 
Table 4-10. Metals found in mercury recovered from SRAT and SME

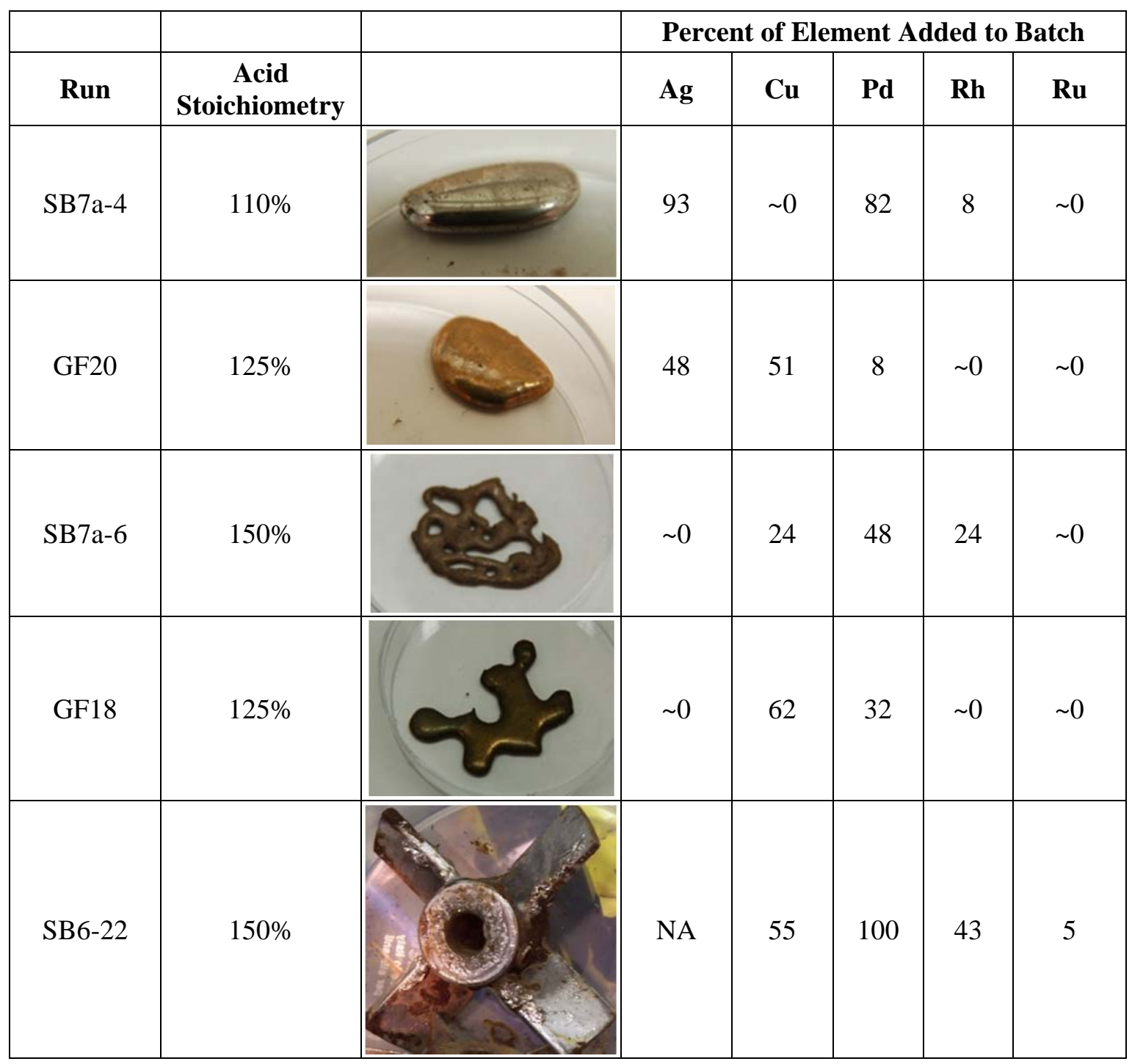

\subsection{Process Modeling of Mercury Reactions in the Offgas and Condensate (by Max Gorensek)}

A dynamic model of the DWPF SRAT offgas system that would allow the user to simulate volatile mercury transport was begun. The plan was to develop the model in Aspen Custom Modeler (ACM) or Aspen Plus Dynamics (APD), using thermodynamic properties for Hg species specifically developed for this purpose by OLI Systems, which would necessitate using the Aspen-OLI properties interface.

The initial effort focused on establishing the correct Mixed Solvent Electrolyte model-based chemistry or model definition. The model chemistry should include all species of interest, but no more than that because computational overhead increases with the number of species and equilibrium reactions considered. Mercury and nitrogen species and their redox reactions were selected, but the nitrogen redox species were restricted to zero and several positive oxidation states. It was also found that oxygen could 
not be included in any system without instantaneously oxidizing elemental mercury, so a work-around was planned where $\mathrm{N}_{2}$ would substitute for $\mathrm{O}_{2}$ in general, with adding $\mathrm{O}_{2}$ as needed where $\mathrm{Hg}$ oxidation is known to occur. The final chemistry settled on contains 43 species, with 5 of them being Hg-containing solids that could form in the SRAT offgas handling system: $\mathrm{Hg}^{0}, \mathrm{Hg}_{2} \mathrm{Cl}_{2}, \mathrm{HgCl}_{2}, \mathrm{HgO}$, and $\mathrm{Hg}_{2}\left(\mathrm{NO}_{3}\right)_{2} \cdot 2 \mathrm{H}_{2} \mathrm{O}$. This chemistry model was generated using the Aspen-OLI interface and used the resulting Aspen Plus model file to build Aspen Plus v7.2 and v7.3 steady-state models that duplicated the equilibrium results obtained with OLIAnalyzer 3.2 and ESP 8.3.

The next step was to build a dynamic model of the SRAT offgas handling system, starting with Aspen Plus, which allows a steady-state flowsheet to be assembled very easily. The intent was to prepare a steady-state model and export it to APD, which is layered on ACM. Once a steady-state version of the off-gas handling system was created, it would be very easy to convert it to a dynamic model and perform a variety of simulations and analyses. Unfortunately, the APD versions of the unit operation models in Aspen Plus use property call subroutines that are incompatible with Aspen-OLI when more than one solid species can precipitate. Several attempts were made to export Aspen Plus flowsheets into APD with the same result (convergence errors due to property model failures). Consequently, it was decided to switch to ACM, where it was demonstrated that the flash procedure (vaporization/condensation) is not incompatible with Aspen-OLI. It was possible to simulate three Hg species precipitating simultaneously. The drawback with ACM is that every unit operation model has to be built from scratch. APD would have allowed the use of canned models for standard unit operations like tanks, condensers, and heaters.

This work was suspended at the end of FY11.

\subsection{Conclusions}

Literature references indicate that elemental mercury can react with $\mathrm{NO}_{2}$ gas or $\mathrm{HNO}_{3}$ to form mercurous nitrate hydroxides similar to those found in the DWPF GC filters. This material may also be similar to the crystalline deposits found in the Mercury Transfer Header, SMECT mercury pump, and Mercury Purification Cell. The conditions described to form these compounds are likely to exist within the DWPF CPC system.

Heat transfer and heater fouling problems were found in the SRAT when attempting to concentrate sludge from 23 to $28 \mathrm{wt} \%$ by caustic boiling.

The solubility of HgO in caustic simulant was found to be slightly higher than predicted by the OLI software and literature references. The amount of dissolved mercury reaches a maximum at the end of nitric acid addition and then quickly drops to $<10 \mathrm{mg} / \mathrm{kg}$ slurry during formic acid addition due to reduction of the $\mathrm{HgO}$ to $\mathrm{Hg}$ metal.

The reaction of $\mathrm{HgO}$ with formic acid in the presence of excess oxalate may have formed mercuric oxalate rather than reducing the $\mathrm{HgO}$ to $\mathrm{Hg}^{0}$ metal.

In many simulant runs, a significant amount of $\mathrm{Hg}$ metal was found on the vessel bottom at the end of tests. Overall material balances on mercury had better closure when the Hg segregated from the sludge in the bottom of the vessel was included. Material balance closure improved from $12-71 \%$ to $48-93 \%$ when the segregated $\mathrm{Hg}$ was considered. The amount of $\mathrm{Hg}$ retained in the slurry ranged from $1-40 \%$ while the amount segregated as elemental $\mathrm{Hg}$ on the vessel bottom was 4-77\%.

The highest recovery of mercury in the offgas system (MWWT + condensates) during simulated SRAT HG runs was found in the runs with excess antifoam and high noble metals, which had the highest 
retention of $\mathrm{Hg}$ in the slurry. The highest recovery of $\mathrm{Hg}$ in the offgas system generally correlated with the highest retention of $\mathrm{Hg}$ in the slurry. Low retention in the slurry (high segregation) resulted in low recovery in the offgas system. High agitation rates appear to result in lower retention of mercury in the slurry.

Both recovery of mercury in the offgas system and removal (segregation + recovery) from the slurry correlate with slurry consistency. Higher consistency results in better retention of $\mathrm{Hg}$ in the slurry (less segregation) and better recovery in the offgas system, but the relationships of recovery and retention with consistency are sludge dependent. Some correlation with slurry yield stress and acid stoichiometry was also found.

Better retention of mercury in the slurry resulted in better recovery in the offgas system because the mercury in the slurry was stripped more easily than the segregated mercury at the bottom of the vessel. Although better retention gave better recovery, the time to reach a particular slurry mercury content (wt\%) was longer than when the retention was poorer because the segregation was faster. The segregation of mercury was generally a faster process than stripping.

The stripping factors of mercury at the start of boiling were found to be less than $1000 \mathrm{lb}$ water evaporated per lb Hg evaporated compared to the assumed design basis value of 750 . However, within two hours, this value increased to at least 2000. For runs with higher mercury recovery in the offgas system, the stripping factor remained around 2000, but runs with low recovery had stripping factors of 4000 to 40,000 . DWPF data shows similar trends with the stripping factor value increasing during boiling. These high values correspond to high segregation and low retention of mercury in the sludge. The stripping factor of a pure $\mathrm{Hg}$ metal bead in water was found to be about 10,000 lb/lb.

The concentration of dissolved mercury in the SRAT condenser condensate was up to $2800 \mathrm{mg} / \mathrm{L}$ and 10 $36 \%$ of the total $\mathrm{Hg}$ evaporated in a SRAT cycle was refluxed back to the SRAT during formic acid addition and boiling. Mercury is dissolved as a result of nitric acid formation from absorption of $\mathrm{NO}_{\mathrm{x}}$. The actual solubility of dissolved mercury in the acidic condensate is about 100 times higher than the actual concentrations measured. Mercury metal present in the MWWT from previous batches could be dissolved by this acidic condensate.

The test of the effect of higher SRAT condenser temperature on recovery of mercury in the MWWT and offgas system was inconclusive. The recovery at higher temperature was lower than several low temperature runs, but about the same as other runs. Factors other than temperature appear to affect the mercury recovery.

The presence of chloride in simulants at greater than approximately $700 \mathrm{mg} / \mathrm{kg}$ slurry results in mercurous chloride $\mathrm{Hg}_{2} \mathrm{Cl}_{2}$ in addition to elemental mercury in the MWWT. The $\mathrm{Hg}_{2} \mathrm{Cl}_{2}$ is black, coats the elemental $\mathrm{Hg}$, and does not coalesce. However, historical data for sludge batches show that the chloride content of actual waste is lower than $700 \mathrm{mg} / \mathrm{kg}$. The addition of iodide to the HG run simulant at about $85 \mathrm{mg} / \mathrm{kg}$ slurry resulted in mostly mercurous iodide in the MWWT in several runs, but not in others. The mercurous iodide was a blackish solid that did not coalesce. Iodide, other than ${ }^{129} \mathrm{I}$, in the actual waste has not been analyzed in any sludge batches.

Use of excess antifoam hindered the coalescence of elemental $\mathrm{Hg}$ and resulted in finely divided beads on the SRAT condenser tubes. Nominal antifoam amounts gave significantly less finely divided $\mathrm{Hg}$ and did not result in as many condenser deposits, except for runs where mercurous iodide was formed. The mercury collected in the MWWT with use of excess antifoam was also found to turn into a green 
gelatinous material near the end of the SRAT run. Accumulation of Isopar ${ }^{\mathrm{TM}} \mathrm{L}$ on the offgas lines was also found to hinder the settling and coalescence of elemental mercury.

None of these results show why there has been no measurable recovery of mercury in the DWPT MWWT in recent sludge batches. Several factors affecting this recovery have been found in this work, but how to apply this information to DWPF operation is not apparent. Some characteristics of the DWPF process such as equipment cleanliness and deposits, physical configuration of equipment, flow velocities, etc. could not be studied in the laboratory.

Mercury deposits segregated on the bottom of the SRAT vessel ranged from very large beads to finely divided granular beads. In several runs, unreacted $\mathrm{HgO}$ was also found. Mercury deposits were found to be amalgamated with $\mathrm{Ag}, \mathrm{Cu}, \mathrm{Pd}$, and Rh. Very little $\mathrm{Ru}$ was found with the $\mathrm{Hg}$. In some samples, greater than $50 \%$ of the total amount of one of the metals $\mathrm{Ag}, \mathrm{Cu}$, or Pd added in the batch was found in the amalgam. Some of these deposits were extremely viscous and would be difficult to pump with the DWPF mercury pump.

\subsection{Recommendations}

\subsection{Improved Retention and Stripping of Mercury}

Conditions that favor retention of mercury in the slurry should be targeted if improved recovery in the MWWT (or offgas system) is desired. The most significant factor appears to be slurry consistency and yield stress, with 'thicker' slurries giving higher recovery. However, because stripping is a slower process than segregation, the processing time to reach a particular $\mathrm{Hg}$ concentration endpoint will be higher that if the main mode of $\mathrm{Hg}$ removal from the slurry is segregation.

\subsection{Improved Removal of Mercury in the SRAT Condenser and MWWT}

Operation of the SRAT condenser at a lower temperature may improve mercury removal in the SRAT condenser, but the experimental data for this conclusion were not definitive.

Cleaning of offgas system components (SRAT condenser, condensate lines) may improve mercury removal in the offgas system. Organic deposits from antifoam have been found to hinder the coalescence of the elemental mercury condensed.

Further laboratory-scale experimental work to specifically study why DWPF has seen very little recovery of mercury in the MWWT is probably not warranted. The lab-scale experiments have not shown the consistently poor recovery of mercury in the MWWT. Recovery of elemental mercury metal in the dewater or scrubber (SMECT) has not occurred as it has in DWPF.

Conditions in the DWPF CPC offgas system (that cannot be reproduced in the lab-scale tests) that could affect air flow velocities or liquid holdups should be studied. Specifically, the effect of the blockage of the Mercury Transfer Header vent from the SMECT on air and condensate flows should be examined to see if it can affect the condensate flows.

SRAT air inleakage may have a significant effect on the condensation of mercury in the SRAT condenser. The air inleakage should be measured or calculated from process data to ensure that it is not significantly higher than assumed. (The effect of air inleakage was not studied in the laboratory.)

Samples of crystalline compounds in the SMECT bottom, Mercury Purification Cell, and any other locations should be analyzed to determine if these are mercury compounds. Changes in operating conditions or methods to alleviate the formation of these compounds might then be devised. 


\section{3. $\quad$ Removal of Mercury from the SRAT Bottom in DWPF}

DWPF should consider alternate methods for removal of mercury from the bottom of the SRAT. The highly viscous mercury amalgams found in the lab-scale studies may not be pumpable using the DWPF mercury pump.

\subsection{Improvements to Simulant Studies}

Simulant demonstrations should minimize chloride and iodide concentrations in the sludge because these can have a significant effect on the chemistry of mercury in the offgas system. Historical data indicates that actual waste chloride concentrations are much lower than most simulants that have been used. The presence of total iodide above $2 \mathrm{mg} / \mathrm{kg}$ slurry is uncertain and should be measured in actual waste.

Improved methods for adding $\mathrm{HgO}$ as a trim chemical should be investigated to reduce the agglomeration of the $\mathrm{HgO}$ reagent prior to addition to the SRAT vessel.

\subsection{Effect of Oxalate on Mercury Reduction}

The attempted reduction of $\mathrm{HgO}$ by formic acid in the presence of excess oxalate may have produced mercuric oxalate rather than elemental mercury. Further study of the effect of oxalate may be warranted since the DWPF feed may contain more oxalate in the future from waste tank cleaning.

\subsection{Acknowledgements}

The authors would like to acknowledge the assistance of the Process Science Analytical Lab personnel for their support with sample analysis, including numerous difficult mercury analyses. The assistance of the Analytical Development section with XRF, XRD, and iodine analyses is also acknowledged. The E\&CPT Research Programs technical analysts, both at Aiken County Technology Laboratory, and those loaned from the main SRNL campus, were instrumental in setting up the test equipment and conducting the process simulations which required round-the-clock coverage. The batch reaction tests were conducted by summer intern Eric Lambert. The authors also acknowledge the technical assistance of M. E. Stone in setting up the new SRAT equipment, in reviewing the simulation R\&D directions, and in reviewing this report. Also acknowledged is Max Gorensek for his work on Aspen modeling of offgas reactions. 


\subsection{References}

1. B.R. Wingard, "Path Forward to Address the Mercury Balance at the DWPF and Determine How to Recover, Transfer, and Purify Mercury in the CPC," SRR-WSE2010-00077, 2010.

2. D.C. Koopman and D.R. Best, "Sludge Batch 6 Phase II Flowsheet Simulations," SRNLSTI-2010-00041 Rev. 0, 2010.

3. $\quad$ D.C. Koopman, "Sludge Batch 6/Tank 40 Simulant Chemical Process Cell Simulations," SRNL-STI-2010-00212 Rev. 0, 2010.

4. D.C. Koopman and D.R. Best, "Sludge Batch 6/Tank 51 Simulant Chemical Process Cell Simulations," SRNL-STI-2010-00173 Rev. 0, 2010.

5. A.I. Fernandez and D.C. Koopman, "Sludge Batch 7 Qualification and Flowsheeet Chemical Process Cell Simulation," SRNL-STI-2011-00006 Rev. 1, 2011.

6. B.R. Pickenheim, M.E. Stone, and J.D. Newell, "Glycolic - Formic Acid Flowsheet Development," SRNL-STI-2010-00523 Rev. 0, 2010.

7. "Task Technical Request: Modeling and Experimental Work to Identify Behavior of Mercury During CPC Processing," HLW-DWPF-TTR-2011-0007 Rev. 0, 2011.

8. J.R. Zamecnik, "Task Technical and Quality Assurance Plan for Modeling and Experimental Work to Identify Behavior of Mercury During DWPF Processing," SRNLRP-2011-00266 Rev. 0, 2011.

9. J.R. Zamecnik and A.S. Choi, "Modeling the Impact of Elevated Mercury in Defense Waste Processing Facility Melter Feed on the Melter Off-Gas System - Preliminary Report," SRNL-STI-2009-00149, Rev. 1, 2009.

10. J.R. Zamecnik and A.S. Choi, "Impact of Eliminating Mercury Removal Pretreatment on the Performance of a High-Level Radioactive Waste Melter Offgas System " Environmental Engineering Science, 27 [7] 593-611 (2010).

11. N.D. Hutson, J.R. Zamecnik, M.E. Smith, D.H. Miller, and J.A. Ritter, "Integrated DWPF Melter System (IDMS) Campaign Report - Mercury Operation," WSRC-TR-910363, 1991.

12. J.R. Zamecnik, "Behavior of Mercury in the Formic Acid Vent Condenser - Interim Report," WSRC-RP-94-1141, Rev. 0, 1994.

13. J.R. Zamecnik, "Behavior of Mercury in the Formic Acid Vent Condenser - Final Report," WSRC-RP-96-352, Rev. 0, 1996.

14. E.S. Freeman and S. Gordon, "The Reaction between Mercury and Nitrogen Dioxide," J. Am. Chem. Soc., 78 [9] 1813-5 (1956).

15. H. Schneider and R.F. Murray, "The Oxidation of Mercury by Nitric Acid," Phillips Petroleum Co. Atomic Energy Division Report IDO-14423, 1957.

16. C.J. Bannochie and K.J. Imrich, "DWPF GC Filter Assembly Sampling and Analysis," SRNL-STI-2009-00602 Rev. 0, 2009.

17. K.-H. Tan and M.J. Taylor, "Vibrational Spectra of Mercury (I) Nitrate in Aqueous Solution and of the Crystalline Hydrolysis Products," Aust. J. Chem., 31 [12] 2601-8 (1978).

18. D.C. Koopman, "Preparation, Characterization, and Preliminary SRAT/SME Testing of a Simulant for the Hydrogen and Rheology Modifier Programs," SRNL-PSE-2007-00091 Rev. 0, 2007.

19. D.C. Koopman, D.R. Best, and B.R. Pickenheim, "SRAT Chemistry and Acid Consumption During Simulated DWPF Melter Feed Preparation," WSRC-STI-200800131 Rev. 0, 2008.

20. M.E. Stone, "Lab-Scale CPC Equipment Set-Up," SRNL-L3100-2011-00127 Rev. 1, 2011. 
21. "Laboratory Scale Chemical Process Cell Simulations," SRNL Manual L29, Procedure ITS-0094 Rev. 5, 2011.

22. D.C. Koopman, A.I. Fernandez, and B.R. Pickenheim, "Preliminary Evaluations of Two Proposed Stoichiometric Acid Equations," SRNL-L3100-2009-00146 Rev. 0, 2009.

23. C.M. Jantzen and M.E. Stone, "Role of Manganese Reduction/Oxidation (RedOx) on Foaming and Melt Rate in High Level Waste Melters," WSRC-STI-2006-00066 Rev. 0, 2006.

24. D.C. Koopman, "DWPF Simulant CPC Studies for Sb7b," SRNL-STI-2011-00547 Rev. 0, 2011.

25. $\quad$ OLIAnalyzer Software 3.2.6, OLI Systems, Inc., Morris Plains, NJ, 2011.

26. $\quad$ D.A. Janes, "DWPF Mercury Recovery Design Basis," DPST-82-893, 1982.

27. International Critical Tables of Numerical Data, Physics, Chemistry and Technology, Vol. IV, 1st Electronic ed.; p. 362. Edited by E.W. Washburn. Knovel, 2003.

28. K.E. Zeigler and N.E. Bibler, "Characterization of DWPF Melter Off-Gas Quencher and Steam Atomized Scrubber Deposit Samples," WSRC-STI-2007-00262, Rev. 0, 2007.

29. A.I. Fernandez, "SB6-H Simulant Development: Evaluation Memo," SRNL-L31002010-00159 Rev. 0, 2010.

30. D.M. Ferrara, N.E. Bibler, M.S. Hay, B.C. Ha, and M.K. Andrews, "Shielded Cells Batch 1 - Sludge Only Campaign with Tank 51 Sludge and Frit 200," WSRC-TR-95-0481 Rev. 0, 1995.

31. T.L. Fellinger, N.E. Bibler, J.M. Pareizs, A.D. Cozzi, and C.L. Crawford, "Macrobatch 3 Acceptance Evaluation - Data from the Shielded Cells Demonstration of Defense Waste Processing Facility's Feed Preparation Cycles for Macrobatch 3 (Sludge Batch 2)," WSRC-RP-2001-00971 Rev. 0, 2001.

32. C.J. Bannochie, T.L. Fellinger, and J.M. Pareizs, "Tank 40 Final SB3 Chemical Characterization Results," WSRC-TR-2005-00049 Rev. 0, 2005.

33. C.J. Bannochie, "Tank 40 Final Sb4 Chemical Characterization Results," WSRC-STI-2-7-00674 Rev. 0, 2008.

34. C.J. Bannochie and D.R. Click, "Tank 40 Final SB5 Chemical Characterization Results Prior to Np Addition," SRNL-STI-2009-00060 Rev. 0, 2009.

35. C.J. Bannochie, "Tank 40 Final SB6 Chemical Characterization Results," SRNL-STI2010-00441 Rev. 0, 2010.

36. J.M. Pareizs, A.L. Billings, and D.R. Click, "Sludge Washing and Demonstration of the DWPF Flowsheet in the SRNL Shielded Cells for Sludge Batch 7a Qualification," SRNL-STI-2011-00226 Rev. 0, 2011.

37. J.M. Pareizs, A.L. Billings, S.H. Reboul, D.P. Lambert, and D.R. Click, "Sludge Batch 7b Qualification Activities with Srs Tank Farm Sludge," SRNL-STI-2100-00548 Rev. 0, 2011. 


\subsection{Appendices}

10.1. Offgas Compositions

$\mathrm{NO}_{\mathrm{x}}$ concentrations were estimated from oxygen depletion and material balance.

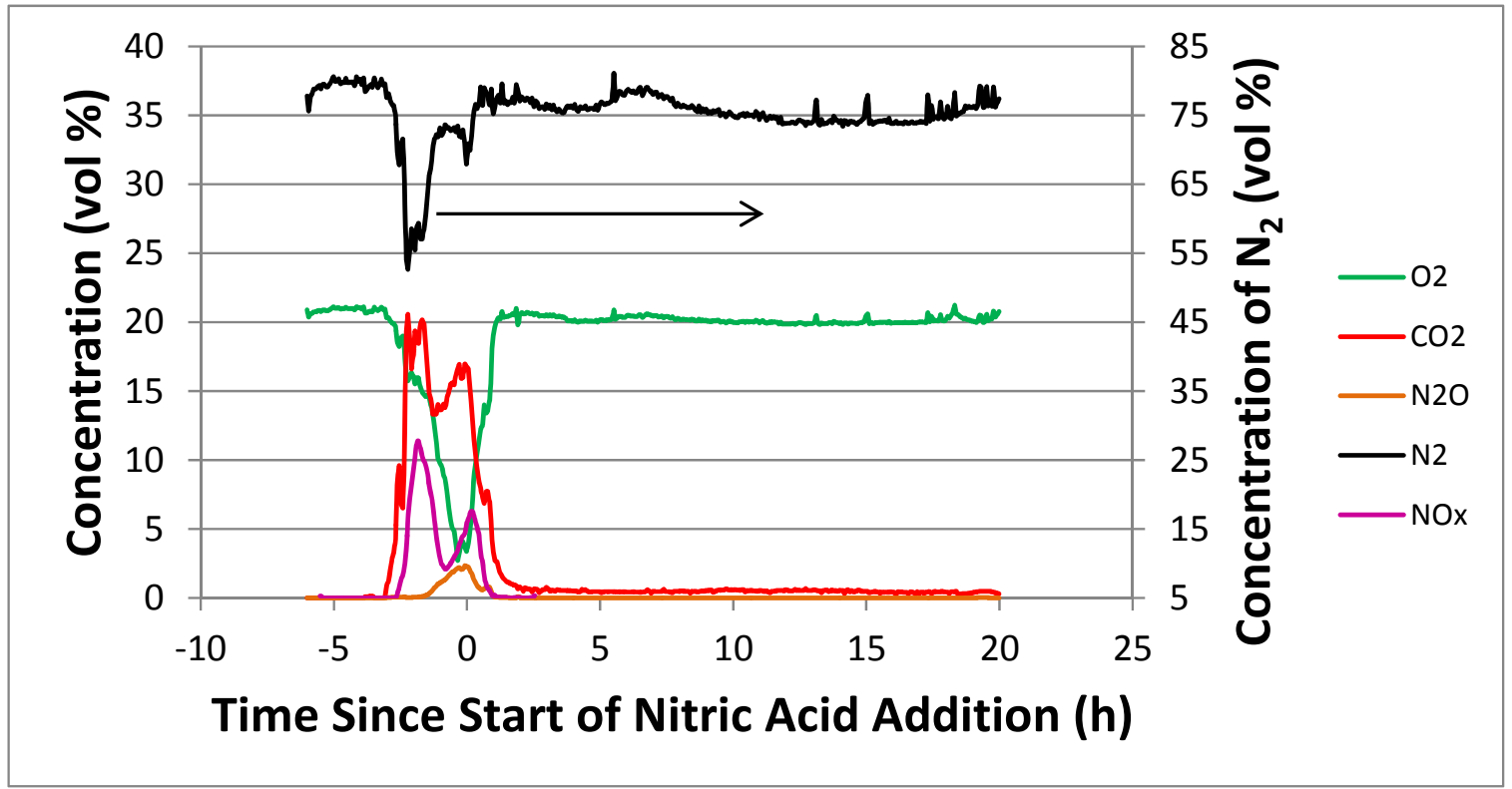

Figure 10-1. HG1 offgas compositions

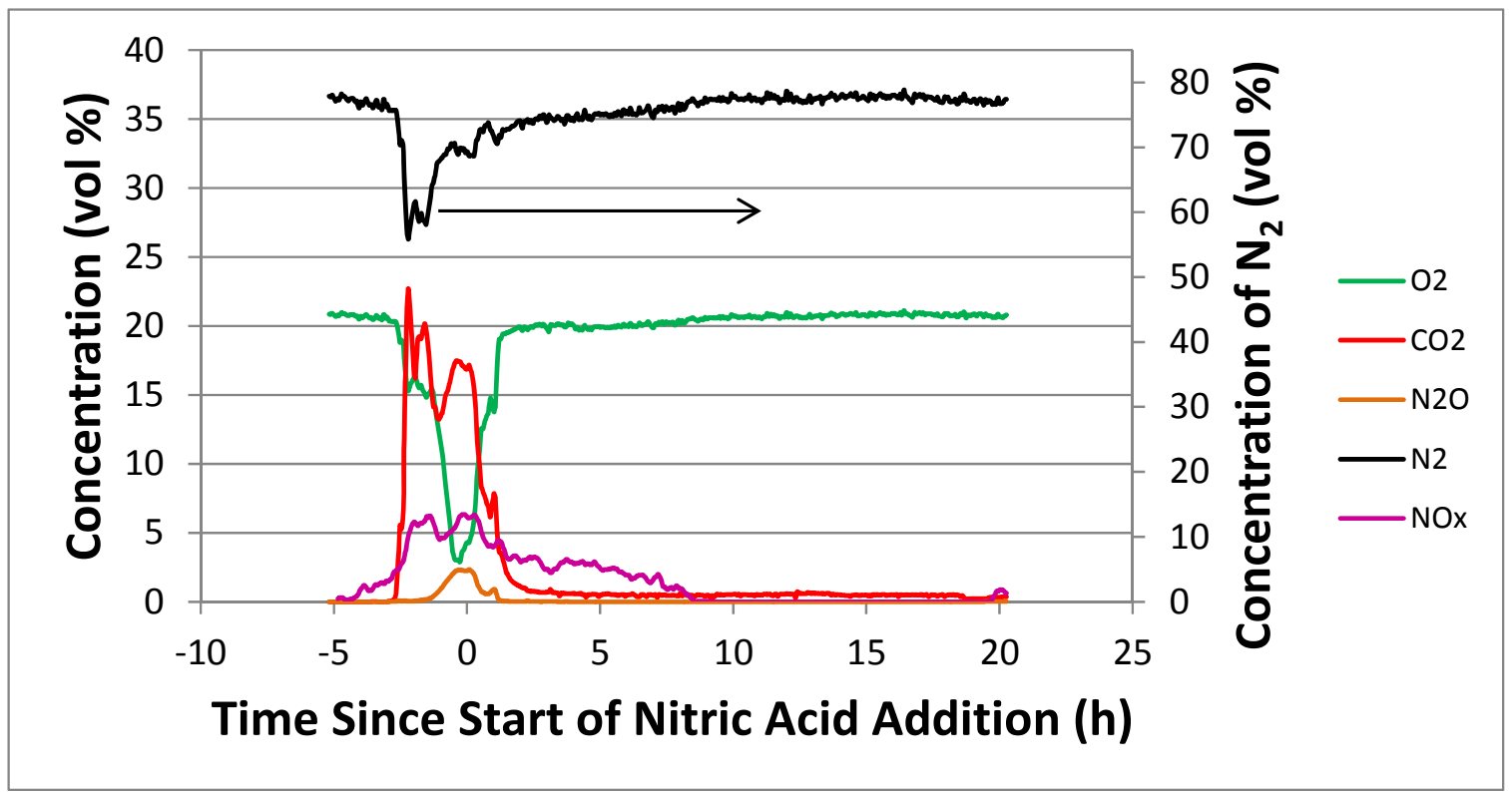

Figure 10-2. HG2 offgas compositions 


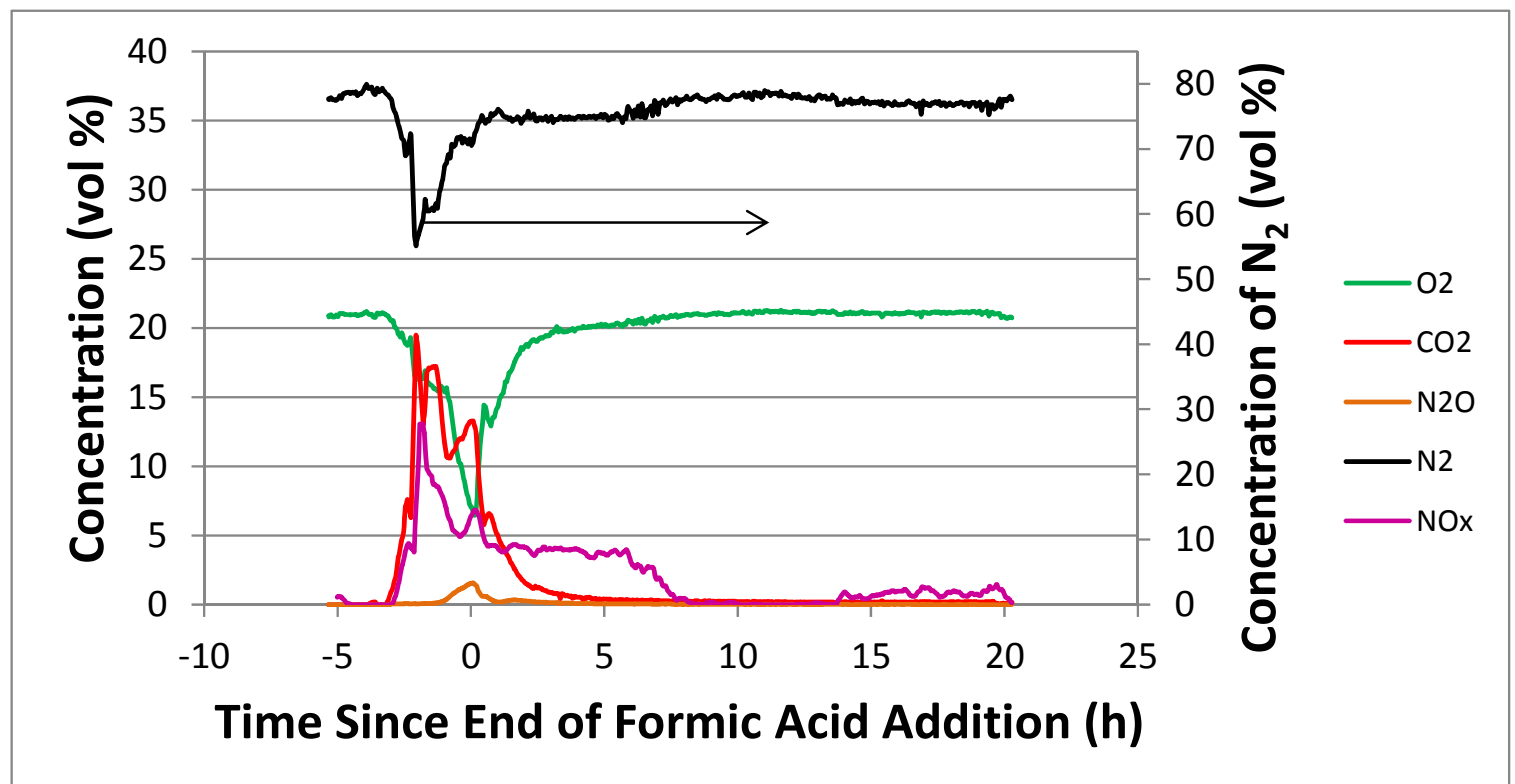

Figure 10-3. HG3 offgas compositions

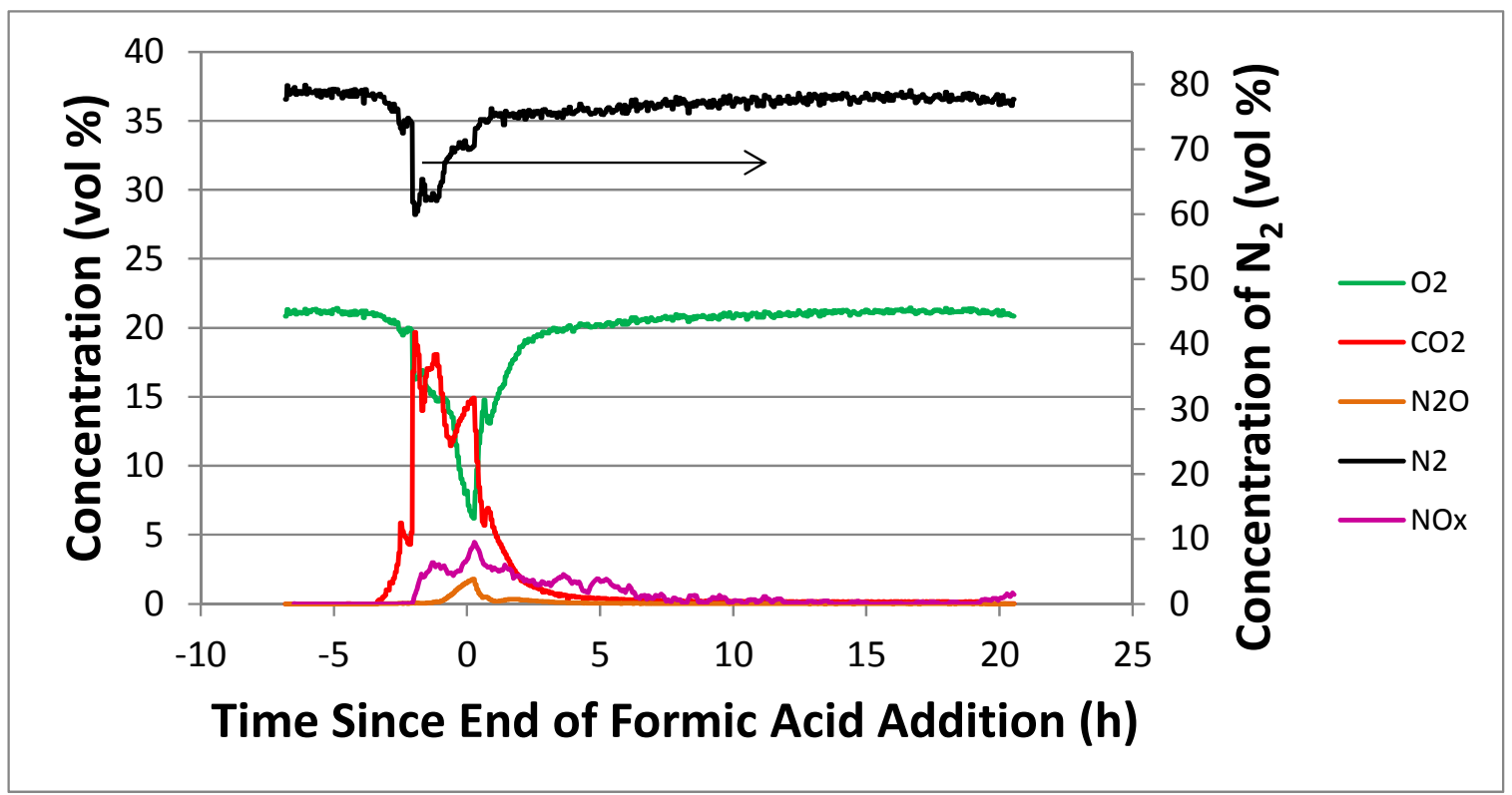

Figure 10-4. HG4 offgas compositions 


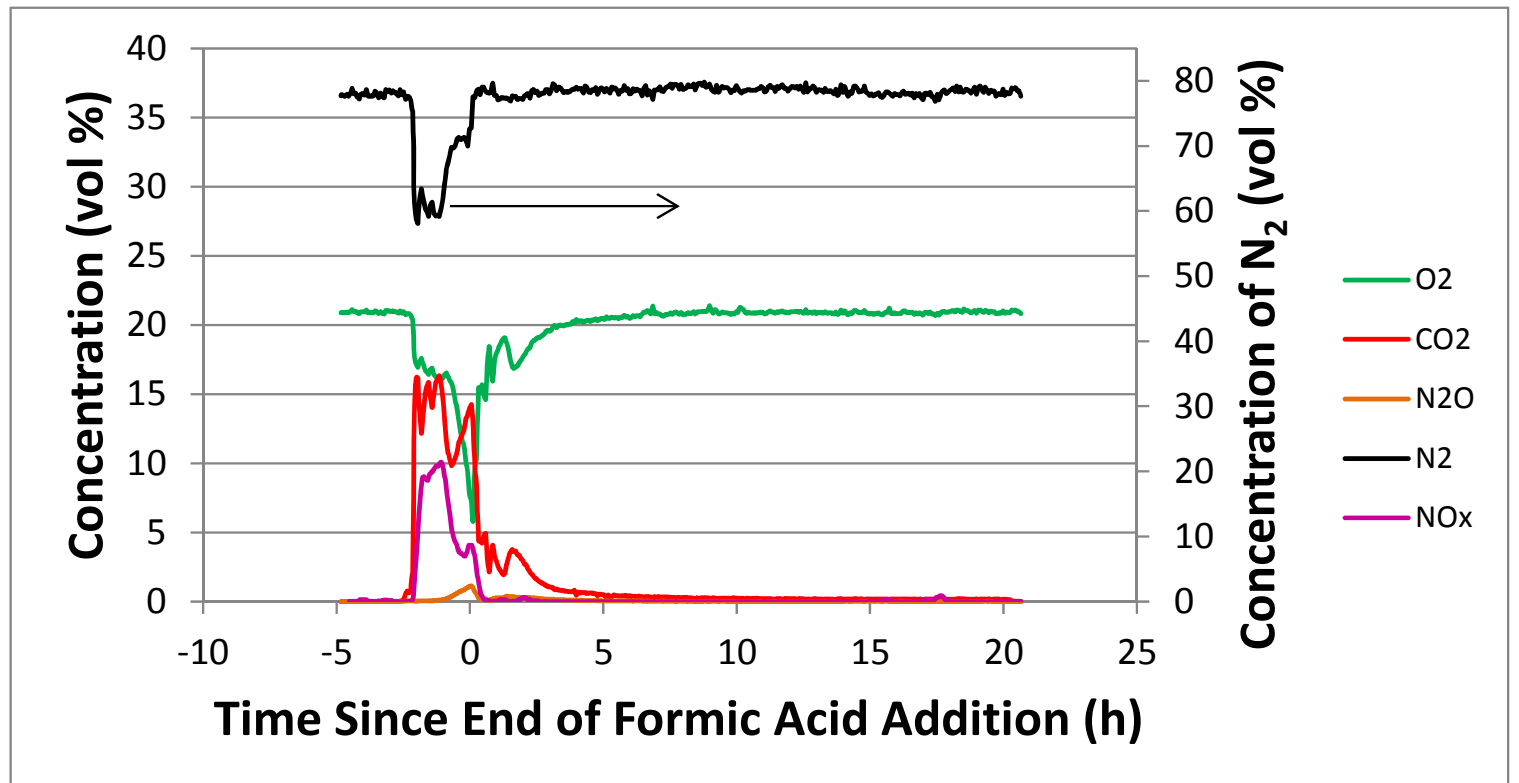

Figure 10-5. HG5 offgas compositions

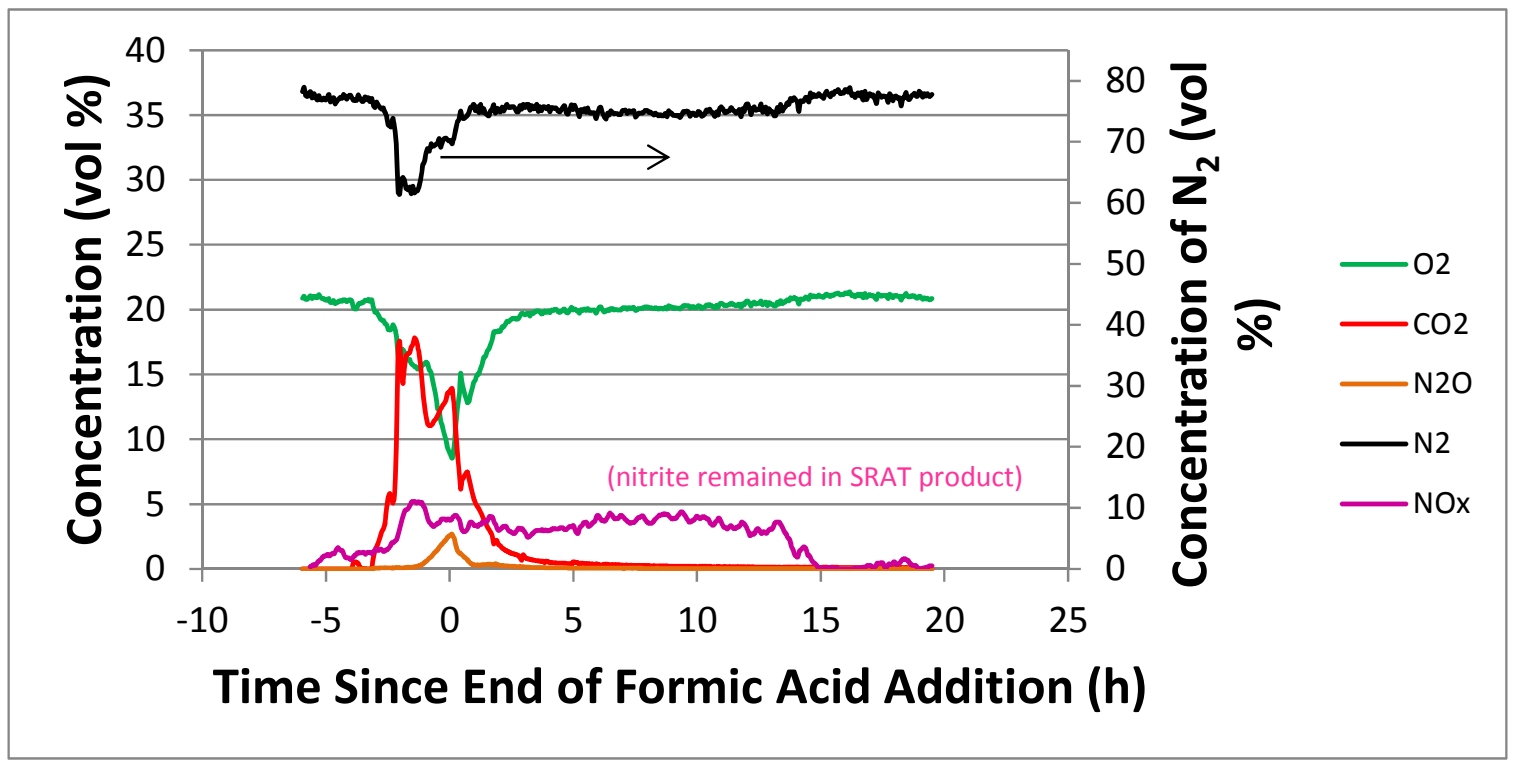

Figure 10-6. HG6 offgas compositions 


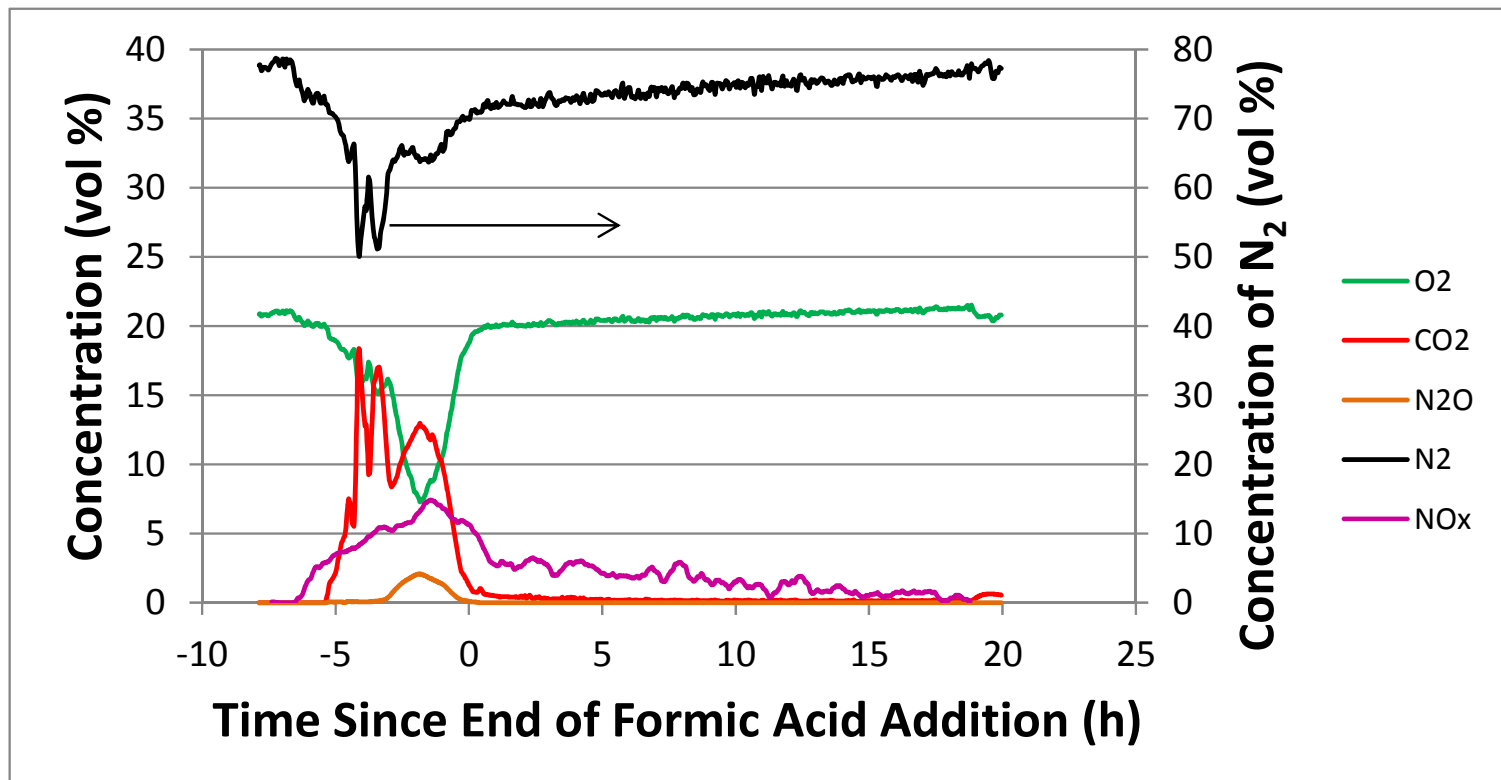

Figure 10-7. HG7 offgas compositions

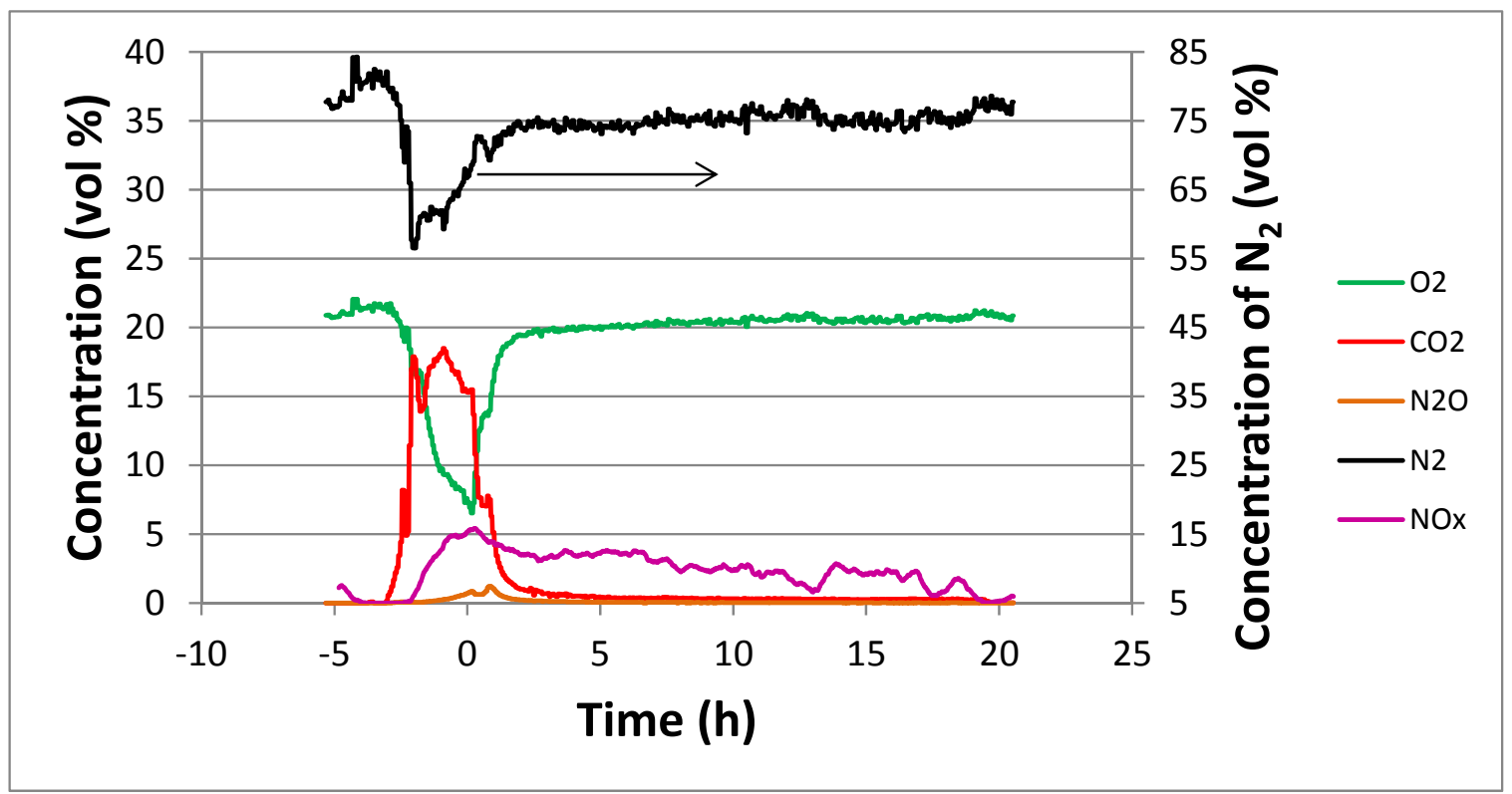

Figure 10-8. HG8 offgas compositions 


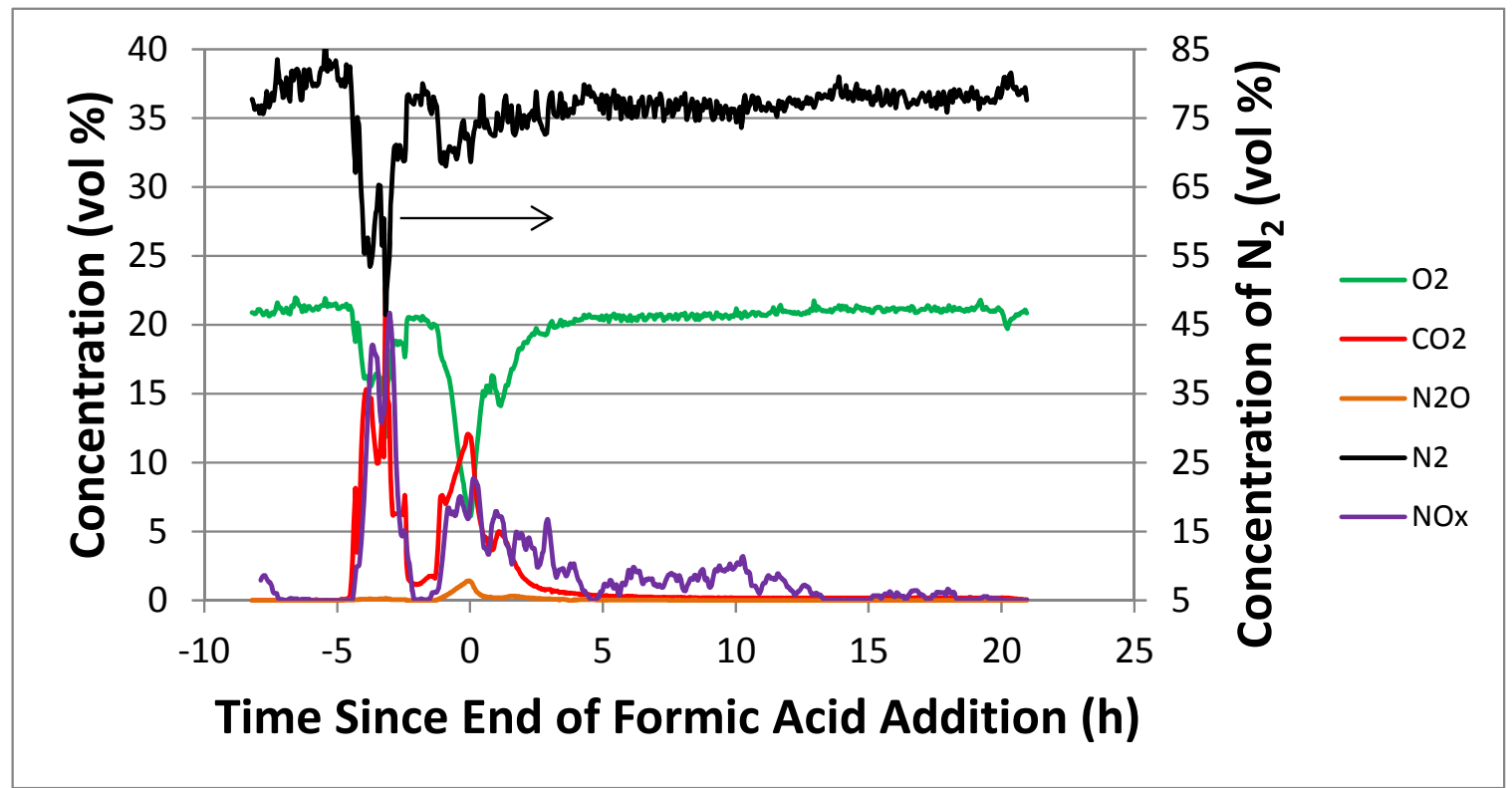

Figure 10-9. HG9 offgas compositions

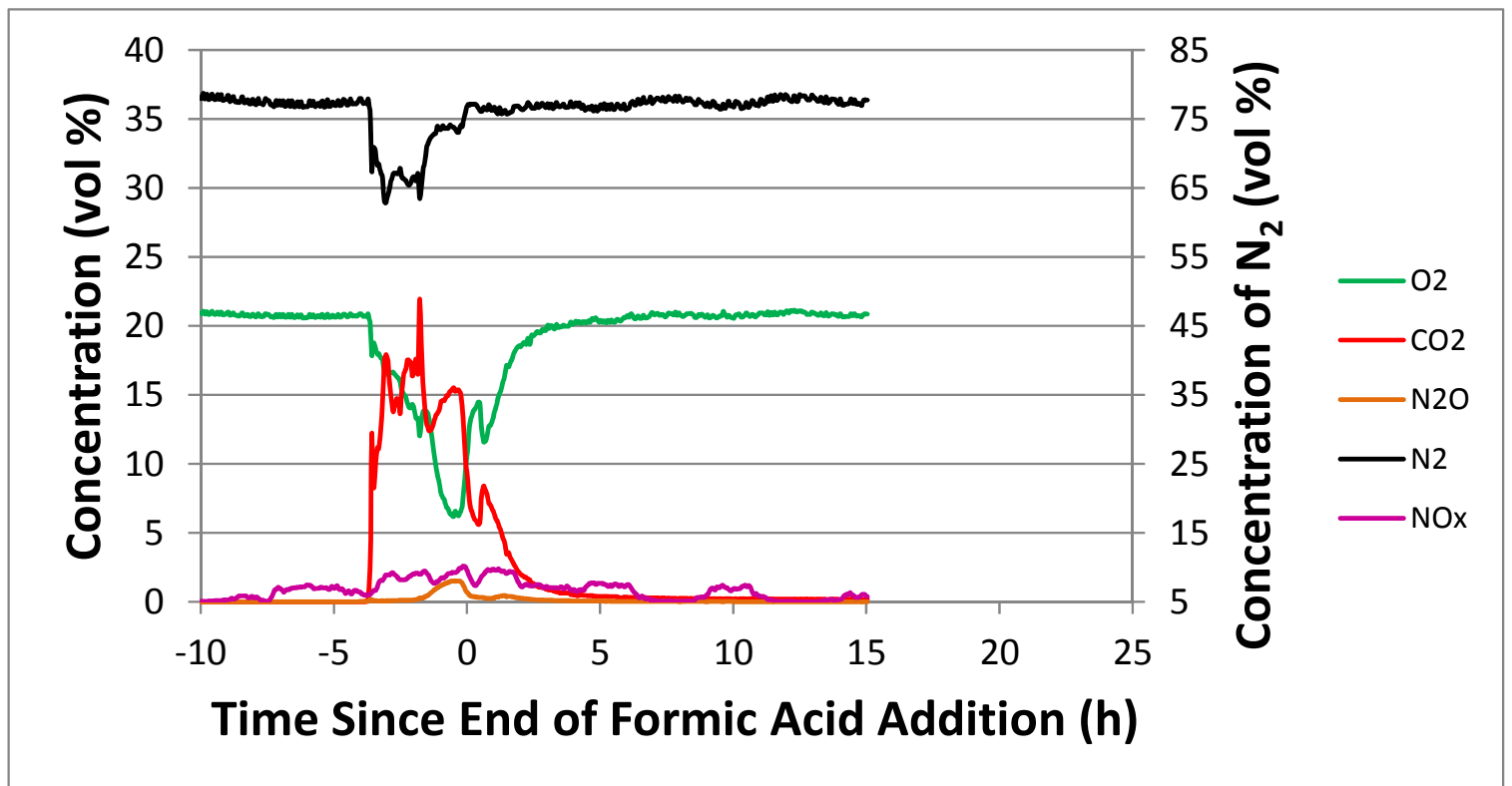

Figure 10-10. HG10 offgas compositions 
10.2. Mercury Chemistry Test Matrix Concentrations

\begin{tabular}{|c|c|c|c|c|c|c|c|c|c|c|c|c|c|}
\hline \multirow[b]{2}{*}{ 总 } & \multicolumn{5}{|c|}{ Matrix Test Levels } & \multicolumn{5}{|c|}{$\begin{array}{l}\text { Calculated Concentrations } \\
\text { (mg/kg slurry) }\end{array}$} & \multirow[b]{2}{*}{ 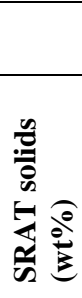 } & \multirow[b]{2}{*}{ 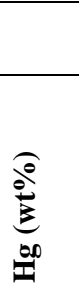 } & \multirow[b]{2}{*}{ 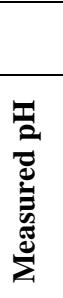 } \\
\hline & 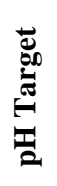 & 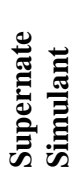 & 荀 & 芦 & : & 䒿 & 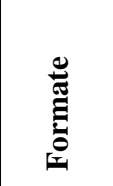 & 营 & 冚 & Z & & & \\
\hline 0 & 13 & 0 & 0 & 0 & 0 & 0 & 0 & 0 & 0 & 2934 & 0 & 0.19 & 12.8 \\
\hline 3 & 13 & 0 & + & 0 & 0 & 0 & 0 & 21681 & 0 & 14491 & 0 & 0.19 & 12.9 \\
\hline 6 & 13 & 0 & 0 & + & 0 & 0 & 0 & 0 & 11027 & 8534 & 0 & 0.19 & 12.8 \\
\hline 7 & 13 & 0 & + & + & 0 & 0 & 0 & 21323 & 10662 & 19490 & 0 & 0.18 & 12.8 \\
\hline 1 & 13 & + & 0 & 0 & 0 & 20100 & 50251 & 0 & 0 & 36011 & 0 & 0.19 & 12.8 \\
\hline 4 & 13 & + & + & 0 & 0 & 19440 & 48600 & 21702 & 0 & 46149 & 0 & 0.17 & 12.7 \\
\hline 8 & 13 & + & 0 & + & 0 & 19775 & 49438 & 0 & 11030 & 40837 & 0 & 0.19 & 12.7 \\
\hline 9 & 13 & + & + & + & 0 & 19132 & 47830 & 21366 & 10688 & 50661 & 0 & 0.18 & 12.8 \\
\hline 2 & 13 & + & 0 & 0 & + & 19981 & 49952 & 0 & 0 & 35797 & 0.40 & 0.37 & 12.8 \\
\hline 5 & 13 & + & + & 0 & + & 19322 & 48306 & 21600 & 0 & 45885 & 0.39 & 0.36 & 12.8 \\
\hline 10 & 13 & + & 0 & + & + & 19659 & 49149 & 0 & 10974 & 40602 & 0.39 & 0.36 & 12.7 \\
\hline 11 & 13 & + & + & + & + & 19060 & 47650 & 21311 & 10614 & 50466 & 0.39 & 0.17 & 12.7 \\
\hline 0 & 10 & 0 & 0 & 0 & 0 & 0 & 0 & 0 & 0 & 0 & 0 & 0.19 & 10.2 \\
\hline 3 & 10 & 0 & + & 0 & 0 & 0 & 0 & 21710 & 0 & 11341 & 0 & 0.17 & 7.8 \\
\hline 6 & 10 & 0 & 0 & + & 0 & 0 & 0 & 0 & 11051 & 5522 & 0 & 0.18 & 7.9 \\
\hline 7 & 10 & 0 & + & + & 0 & 0 & 0 & 21340 & 10685 & 16487 & 0 & 0.17 & 9.7 \\
\hline 1 & 10 & + & 0 & 0 & 0 & 20100 & 50250 & 0 & 0 & 33114 & 0 & 0.37 & 8.2 \\
\hline 4 & 10 & + & + & 0 & 0 & 19409 & 48524 & 21680 & 0 & 43302 & 0 & 0.17 & 8.2 \\
\hline 8 & 10 & + & 0 & + & 0 & 19771 & 49427 & 0 & 11058 & 38098 & 0 & 0.19 & 9.8 \\
\hline 9 & 10 & + & + & + & 0 & 19129 & 47823 & 21367 & 10699 & 48023 & 0 & 0.18 & 9.8 \\
\hline 2 & 10 & + & 0 & 0 & + & 19816 & 49540 & 0 & 0 & 32646 & 0.40 & 0.17 & 10.0 \\
\hline 5 & 10 & + & + & 0 & + & 19083 & 47706 & 21315 & 0 & 42573 & 0.39 & 0.35 & 10.0 \\
\hline 10 & 10 & + & 0 & + & + & 19467 & 48668 & 0 & 10888 & 37513 & 0.39 & 0.36 & 10.0 \\
\hline 11 & 10 & + & + & + & + & 18844 & 47109 & 21048 & 10539 & 47306 & 0.39 & 0.35 & 10.0 \\
\hline 0 & 6 & 0 & 0 & 0 & 0 & 7347 & 0 & 0 & 0 & 2912 & 0 & 0.19 & 3.0 \\
\hline 3 & 6 & 0 & + & 0 & 0 & 8329 & 0 & 21498 & 0 & 14368 & 0 & 0.19 & 7.1 \\
\hline 6 & 6 & 0 & 0 & + & 0 & 7701 & 0 & 0 & 10941 & 8467 & 0 & 0.19 & 8.1 \\
\hline 7 & 6 & 0 & + & + & 0 & 7970 & 0 & 21151 & 10576 & 19332 & 0 & 0.18 & 7.3 \\
\hline 1 & 6 & + & 0 & 0 & 0 & 28785 & 49798 & 0 & 0 & 35687 & 0 & 0.19 & 5.2 \\
\hline 4 & 6 & + & + & 0 & 0 & 27847 & 48176 & 21513 & 0 & 45747 & 0 & 0.17 & 5.4 \\
\hline 8 & 6 & + & 0 & + & 0 & 28089 & 49011 & 0 & 10935 & 40485 & 0 & 0.18 & 6.2 \\
\hline 9 & 6 & + & + & + & 0 & 27183 & 47431 & 21188 & 10599 & 50238 & 0 & 0.18 & 6.4 \\
\hline 2 & 6 & + & 0 & 0 & + & 28615 & 49504 & 0 & 0 & 35476 & 0.40 & 0.37 & NA \\
\hline 5 & 6 & + & + & 0 & + & 27737 & 47885 & 21411 & 0 & 45485 & 0.39 & 0.36 & NA \\
\hline 10 & 6 & + & 0 & + & + & 27926 & 48727 & 0 & 10880 & 40254 & 0.39 & 0.36 & NA \\
\hline 11 & 6 & + & + & + & + & 27082 & 47254 & 21133 & 10526 & 50046 & 0.39 & 0.17 & NA \\
\hline
\end{tabular}


Distribution:

J.E. Occhipinti

D.C. Sherburne

A.V. Staub

J.F. Iaukea

J.W. Ray

E.W. Holtzscheiter

T.L. Fellinger

J.M. Bricker

A.M. Behrouzi

S.L. Marra

C.C. Herman

M.E. Stone

D.C. Koopman

J.D. Newell

S.H. Reboul

J.M. Pareizs

D.P. Lambert

D.R. Best

W.T. Riley

D.K. Peeler 